Universidade de São Paulo

Faculdade de Medicina de Ribeirão Preto

\title{
2017
}

Efeitos agudos de diferentes métodos de alongamento sobre a performance da força máxima, potência e parâmetros neuromuculares em jovens jogadores de futebol
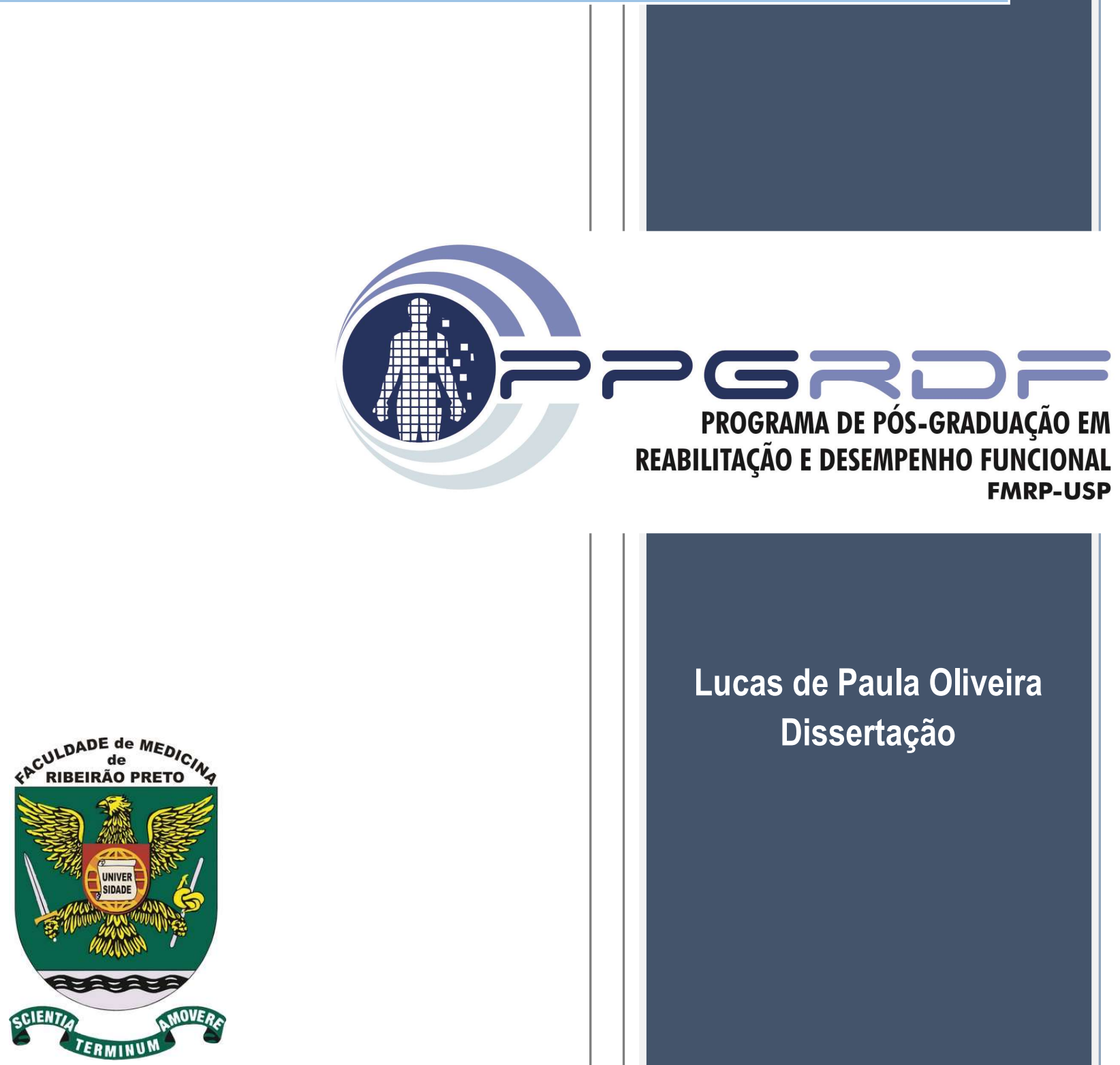

Lucas de Paula Oliveira Dissertação 


\section{LUCAS DE PAULA OLIVEIRA}

Efeitos agudos de diferentes métodos de alongamento sobre a performance da força máxima, potência e parâmetros neuromusculares em jovens jogadores de futebol

Dissertação apresentada a

Faculdade de Medicina de Ribeirão

Preto da Universidade de São Paulo para a obtenção de título de Mestre em Reabilitação e Desempenho Funcional.

Área de concentração: Fisioterapia

Orientador: Prof. Dr. Enrico Fuini Puggina

Ribeirão Preto 
Autorizo a divulgação parcial ou total deste estudo, por qualquer meio convencional ou eletrônico, para fins de estudo e pesquisa, desde que citada à fonte.

Faculdade de Medicina de Ribeirão Preto da Universidade de São Paulo

Oliveira, Lucas de Paula.

Efeitos agudos de diferentes métodos de alongamento sobre a performance da força máxima, potência e parâmetros neuromusculares em jovens jogadores de futebol / Lucas de Paula Oliveira; orientador Enrico Fuini Puggina. - São Paulo, 2017. 103 f.: il.

Dissertação (Mestrado) - Universidade de São Paulo, 2017.

1. Flexibilidade. 2. Testes motores. 2. Esporte coletivo. 3. Eletromiografia. 4. Twitch Interpolation I. Puggina, Enrico Fuini. II. Título: Efeitos agudos de diferentes métodos de alongamento sobre a performance da força máxima, potência e parâmetros neuromusculares em jovens jogadores de futebol. 
OLIVEIRA, Lucas de Paula

Título: Efeitos agudos de diferentes métodos de alongamento sobre a performance da força máxima, potência e parâmetros neuromusculares em jovens jogadores de futebol.

Aprovado em:

Banca examinadora

Dissertação apresentada a

Faculdade de Medicina de

Ribeirão Preto da

Universidade de São Paulo

para a obtenção de título de

Mestre em Reabilitação e

Desempenho Funcional.

\section{Banca examinadora}

Prof. Dr. Instituição

Julgamento Assinatura

Prof. Dr. Instituição

Julgamento Assinatura

Prof. Dr. Instituição

Julgamento Assinatura 
Dedico esta dissertação aos meus pais Carlos Alberto de Oliveira e Ivone Maria de Paula Oliveira (in memorian), meus maiores exemplos. 


\section{AGRADECIMENTOS}

Eu, Lucas de Paula Oliveira, gostaria de direcionar meus agradecimentos:

- Ao meu orientador Prof. Dr. Enrico Fuini Puggina, primeiro pela oportunidade, e também por todo o companheirismo e atenção dispensada em todos os momentos, bons e ruins, que enfrentamos juntos durante a execução desta dissertação. Exemplo de professor, com o qual tive o privilégio de conviver e aprender muitos ensinamentos que levarei para além da área acadêmica;

- Aos meus familiares;

- Em especial ao meu pai Carlos Alberto de Oliveira, minha mãe Ivone Maria de Paula Oliveira (in memorian), minha madrasta Eliana de Fátima Costa Oliveira, meus irmãos Matheus de Paula Oliveira, Thiago de Paula Oliveira e Maria Gabriela Costa Oliveira, minha avó Maria Madalena de Paula (vó Lena), meu avô Miguel Francisco de Paula (vô Miguel), e minha tia Gimene Moreira de Paula Arantes (tia Gi), pelo apoio incondicional desde o início da minha graduação até atualmente na pós-graduação. Sem vocês, sem dúvida, nada do que já realizei em minha vida academica, profissional e pessoal seria possível;

- Aos meus eternos amigos e irmãos Luiz Henrique Palucci Vieira (Nerd), Rodrigo Leal de Queiroz Thomaz de Aquino (Dinei), João Paulo Vieira Manechini, Vitor Luiz de Andrade (Vitão), seria impossível agradecer o suficiente por tudo que vocês me ensinaram e por todos os momentos que vivenciamos juntos ao longo desses dois anos. Vocês são exemplos e fonte de motivação para mim, muito obrigado mesmo;

- Aos meus amigos Rafael Guilherme Fornel (Teló), Luiz Guilherme Cruz Gonçalvez (Foda), Fábio Marzliak Pozzi de Castro, Vitor Marqueti Arpini (Vitão 2), Bruno Luiz de Souza Bedo (Botcha), Alisson Luiz da Rocha (Avatar), Nayan Xavier Ribeiro (in memorian), Carlos Augusto Kalva Filho (Beiço), Ricardo Augusto Barbieri, Guilherme Henrique Munhoz Martins (Batata), Fábio Pamplona Mariano, Eduardo Bergonzoni Junqueira (Du), José Artur Berti Júnior, Rosangela Alice Batistela (Rô), Andréia Abud da Silva Costa (Déia), e Luciana Oliveira dos Santos ( $\mathrm{Lu}$ ) por todo apoio e amizade;

- A todos os membros da comissão técnica e diretoria do Botafogo Futebol Clube de Ribeirão Preto, em especial aos meus amigos Antônio Carlos Tosetti (Tonim Kajuru), 
José Alves Vila Júnior (Vila), Stefano Guimaro Bueno (Tete), Danilo Augusto, Everton Pimenta, Marcelo Nascimento (Xexéu), Luiz Fernando Paião (Paião), Bernardo de Mattos, Antônio Novo Junior, Matheus Henrique Faria e Thiago Kosloski;

- A todos os atletas do Hebei Jing Ying Football Club e ao Ms Xiao Dong Chen, por todos os momentos que passamos juntos, por tudo que me ensinaram sobre sua cultura, e também por me suportarem durante a árdua temporada de preparação;

- A todos meus professores da graduação e pós-graduação, que contribuíram para a minha formação. Em especial aos Profs. Drs. Paulo Roberto Pereira Santiago, Adelino Sanchez Ramos da Silva e Marcelo Papoti, pela amizade, pelos conselhos, por serem pessoas e profissionais exemplares e fonte de admiração e motivação para mim;

- A todos os funcionários da EEFERP. 


\section{RESUMO}

Oliveira, L.P. Efeitos agudos de diferentes métodos de alongamento sobre a performance da força máxima, potência e parâmetros neuromusculares em jovens jogadores de futebol. 2017. 75 f. Dissertação (Mestrado) - Faculdade de Medicina de Ribeirão Preto, Universidade de São Paulo, 2017.

O objetivo da presente dissertação foi comparar os efeitos agudos de diferentes métodos de alongamento sobre a performance em testes motores e parâmetros neuromusculares. Para tanto, foram realizados dois estudos. Participaram do estudo 1, doze jogadores de futebol treinados, sendo submetidos a 5 condições experimentais: alongamento ativo (AT), balístico (BA), passivo (PA), facilitação neuromuscular proprioceptiva (FNP) ou condição controle (CO), em ordem randomizada e com intervalo mínimo de $48 \mathrm{~h}$ entre cada condição. Foram avaliados a altura de salto $(\mathrm{H})$, potência pico (PP) e potência relativa (PR) no squat jump (SJ) e countermovent jump (CMJ), amplitude de movimento (ADM), tempo (s) nos 10-20-30 m durante o sprint e percepção subjetiva de esforço (PSE). Os métodos de alongamento AT e BA não promoveram alterações agudas na performance nos 10, 20 e $30 \mathrm{~m}$, e na H, PP e PR em ambas as técnicas CMJ e SJ. Por outro lado, os métodos PA e FNP promoveram efeitos negativos $(p<0.05)$ na performance na H, PP e PR no CMJ e SJ. Além disso, escores significativamente superiores de PSE foram relatados após as sessões de alongamento PA e FNP em comparação a AT e BA. Foram encontrados aumentos significativos em ADM após todos os métodos de alongamento. Portanto, os métodos AT e BA podem ser utilizados previamente a atividades de salto vertical e sprint, com o objetido de aumento de flexibilidade. Já os métodos PA e FNP devem ser evitados, em função das maiores intensidades alcançadas nestas condições e pela extensa possibilidade de efeitos negativos posteriores na performance do salto vertical. Para o estudo 2, os jogadores de futebol foram submetidos as mesmas condições experimentais $(\mathrm{CO}, \mathrm{AT}, \mathrm{BA}, \mathrm{PA}$ e FNP). Porem, foram avaliados a força máxima por meio do teste de uma repetição máxima (1 RM) para o exercício agachamento completo, e parâmetros neuromusculares através da técnica do twitch interpolation. Foram monitorados as variáveis força pico, taxa de desenvolvimento de força, amplitude da twitch superimposed e twitch potentiated, e percentual de ativação voluntária referentes ao sinal de força, e a root mean square, M-Wave e razão RMS/M-Wave referentes ao sinal eletromigráfico (EMG) (músculos: vasto lateral e reto femoral), durante contrações voluntária isométrica máxima (CVM) de extensão de joelho. Não foram encontradas alterações significativas na performance do teste de $1 \mathrm{RM}$ e CVM após as condições CO, AT, BA, PA e FNP. Além disso, também não foram encontradas alterações significativas nas variáveis relativas ao sinal EMG. Dessa forma, sessões de alongamento semelhantes a do estudo [3 séries x $30 \mathrm{~s}$ de alongamento à 100\% do point of discomfort (POD)], independente do método de alongamento, parecem não promover efeitos negativos posteriores na performance da força máxima e em parâmetros neuromusculares em atletas treinados.

Palavras chave: flexibilidade; testes motores; esporte coletivo; twitch interpoltation; eletromiografia. 


\begin{abstract}
Oliveira, L.P. Acute effects of different stretching methods on maximal strength and power performance, and on neuromuscular parameters in young soccer players. 2017. 75 p. Thesis (Master degree) - Faculty of Medicine at Ribeirão Preto, University of São Paulo, 2017.
\end{abstract}

The aim of this dissertation was to compare the acute effects of different stretching methods on motor tests performance and neuromuscular parameters. For this, two studies were conducted. Participated in the study 1, twelve trained soccer players, being submitted to 5 experimental conditions: active stretching (AC), ballistic (BA), passive (PA), proprioceptive neuromuscular facilitation (PNF) or control condition (CO), in random order and with a minimum interval of $48 \mathrm{~h}$ between each condition. It was evaluated the jump height $(\mathrm{H})$, peak power (PP) and relative power (PR) in squat jump (SJ) and countermovent jump (CMJ), range of motion (ROM), 10-20-30 m sprint time and rating of perception exertion (RPE). The AC and BA stretching methods did not promote acute changes in performance at 10-20-30 m sprint time, and in H, PP and PR in both CMJ and SJ techniques. On the other hand, PA and PNF methods promoted negative effects $(\mathrm{p}<0.05)$ on $\mathrm{H}, \mathrm{PP}$ and PR performance in CMJ and SJ. In addition, significantly higher RPE scores were reported after the PA and PNF stretching sessions compared to AC and BA. Significant increases were found in ROM after all stretching methods. Therefore, AC and BA methods can be used prior to vertical jump and sprint activities, with the aim of increasing flexibility. On the other hand, the PA and PNF methods should be avoided, due to the higher intensities reached in these methods and the extensive possibility of subsequent negative effects on vertical jump performance. For study 2, soccer players underwent the same experimental conditions $(\mathrm{CO}, \mathrm{AC}, \mathrm{BA}$, PA and PNF). However, maximum strength was assessed by a maximal repetition test (1 RM) for the full squat exercise, and neuromuscular parameters using the twitch interpolation technique. The variables peak force, rate of force development, amplitude of superimposed twitch and potentiated twitch, and percentage of voluntary activation referring to the force signal, and root mean square, M-Wave and RMS/M-Wave ratio referring to the Electromyographic (EMG) signal (muscles: vastus lateralis and rectus femoris), during maximal isometric voluntary contractions (MVC) of knee extension. No significant changes were found in the $1 \mathrm{RM}$ and CVM performance after $\mathrm{CO}, \mathrm{AC}$, BA, PA and PNF conditions. In addition, no significant changes were found in the variables related to the EMG signal. Thus, stretching sessions similar to the study [3 series $\times 30 \mathrm{~s}$ of $100 \%$ point of discomfort (POD) stretching], independent of the stretching method, do not seem to promote posterior negative effects on maximum strength performance and on neuromuscular parameters in trained athletes.

Key words: Flexibility; motor test; team sport; twitch interpoltation; electromyography. 


\section{LISTA DE TABELAS}

Tabela 1. Breve revisão sobre os efeitos agudos de diferentes métodos de alongamento sobre a performance da potência de membros inferiores.

Tabela 2. Breve revisão sobre os efeitos agudos de diferentes métodos de alongamento sobre a performance da força máxima de membros inferiores 16

Tabela 3. Caracterização de performance dos participantes do estudo .28

Tabela 4. Efeitos agudos dos métodos de alongamento ativo (AT), balístico (BA), passivo (PA) e facilitação neuromuscular proprioceptiva (FNP) e condição controle (CO) sobre a altura de salto $(\mathrm{H})$, potência pico $(\mathrm{PP})$ e potência relativa $(\mathrm{PR})$ no squat jump (SJ) .30

Tabela 5. Efeitos agudos dos métodos de alongamento ativo (AT), balístico (BA), passivo (PA) e facilitação neuromuscular proprioceptiva (FNP) e condição controle (CO) sobre a altura de salto $(\mathrm{H})$, potência pico $(\mathrm{PP})$, potência relativa $(\mathrm{PR})$ no counter movement jump (CMJ)

Tabela 6. Efeitos agudos dos métodos de alongamento ativo (AT), balístico (BA), passivo (PA) e facilitação neuromuscular proprioceptiva (FNP) e condição controle (CO) sobre a amplitude de movimento (ADM) e percepção subjetiva de esforço (PSE).

Tabela 7. Efeitos agudos dos métodos de alongamento ativo (AT), balístico (BA), passivo (PA) e facilitação neuromuscular proprioceptiva (FNP) e condição controle 
(CO) sobre o tempo obtido nas distâncias de dez metros $(10 \mathrm{~m})$, vinte metros $(20 \mathrm{~m})$, e

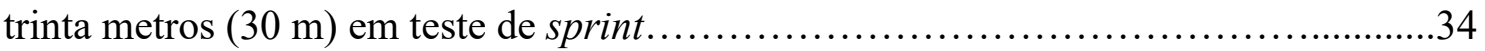

Tabela 8. Efeitos agudos dos métodos de alongamento ativo (AT), balístico (BA), passivo (PA) e facilitação neuromuscular proprioceptiva (FNP) e condição controle (CO) sobre a amplitude de movimento (ADM) e percepção subjetiva de esforço (PSE) para os protocolos 1 e 2 .

Tabela 9. Efeitos agudos dos métodos de alongamento ativo (AT), balístico (BA), passivo (PA) e facilitação neuromuscular proprioceptiva (FNP) e condição controle (CO) sobre a performance no teste de uma repetição máxima (1 RM) no agachamento, e sobre a força pico (Fpico) e taxa de desenvolvimento de força (TDF) na contração voluntária isométrica máxima de extensão de joelho .57

Tabela 10. Efeitos agudos dos métodos de alongamento ativo (AT), balístico (BA), passivo (PA) e facilitação neuromuscular proprioceptiva (FNP) e condição controle (CO) sobre as variáveis twitch superimposed (TS), twitch potentiated (TP) e percentual de ativação voluntária $(\% \mathrm{AV})$ do twitch interpolation .58

Tabela 11. Efeitos agudos dos métodos de alongamento ativo (AT), balístico (BA), passivo (PA) e facilitação neuromuscular proprioceptiva (FNP) e condição controle (CO) sobre a root mean square (RMS), M-Wave e razão do root mean square e MWave (RMS/M-Wave) do sinal eletromiográfico do músculo vasto lateral ... 60

Tabela 12. Efeitos agudos dos métodos de alongamento ativo (AT), balístico (BA), passivo (PA) e facilitação neuromuscular proprioceptiva (FNP) e condição controle 
(CO) sobre a root mean square (RMS), M-Wave e razão do root mean square e M-

Wave (RMS/M-Wave) do sinal eletromiografico do músculo reto femoral................61 


\section{LISTA DE FIGURAS}

Figura 1. Considerações iniciais sobre os estudos necessários para responder o questionamento central. .16

Figura 2. Sequência de exercícios de alongamento empregados durante o protocolo experimental para o método de alongamento ativo (a), ambos os métodos passivo e de facilitação neuromuscular proprioceptiva (b) e balístico (c) .24

Figura 3. a) Desenho experimental do protocolo 1. b) Desenho experimental do protocolo 2. c) Sequência de eventos durante o protocolo experimental 2. Teste de uma repetição máxima (1 RM); Contração voluntária isométrica máxima (CVM); Técnica do twitch interpolation $(\mathrm{TI})$ 46

Figura 4. A) Sinal de força durante a avaliação neuromuscular e determinação da twitch superimposed (TS) e twitch potentiated (TP). B) Sinal de força amplificado e determinação da twitch superimposed (TS). C) Sinal de força amplificado e determinação da twitch potentiated (TP) .65

Figura 5. A) Sinal eletromigráfico muscular durante a avaliação neuromuscular e determinação da M-Wave. B) Sinal eletromiográfico amplificado e determinação da MWave. .66 
POD - point of discomfort;

H - altura de salto;

PP - potência pico;

PR - potência relativa;

SJ - squat jump;

CMJ - counter movement jump;

ADM - amplitude de movimento;

$10 \mathbf{~ m}$ - tempo obtido nos dez metros;

20 m - tempo obtido nos vinte metros;

$30 \mathbf{~ m}$ - tempo obtido nos trinta metros;

PSE - percepção subjetiva de esforço;

CO - condição controle;

AT - condição alongamento ativo;

BA - condição alongamento balístico;

PA - condição alongamento passivo;

FNP - condição alongamento por facilitação neuromuscular proprioceptiva;

CVM - contração voluntária isométrica máxima;

TI - twitch interpolation;

EMG - eletromiografia;

VL - músculo vasto lateral;

$\mathbf{R F}$ - músculo reto femoral;

1 RM - teste de uma repetição máxima;

Fpico - força pico;

TDF - taxa de desenvolvimento de força; 
TS - twitch superimposed;

TP - twitch potentiated;

\%AV - percentual de ativação voluntária;

RMS - root mean square;

M-Wave - amplitude máxima do sinal eletromiográfico atingido após a estimulação elétrica;

RMS/M-Wave - razão da root mean square por M-Wave;

$\Delta$ - delta de alteração;

ES - effect size;

$\mathbf{C Q}$ - chances quantitativas; 


\section{SUMÁRIO}

CAPÍTULO 1. REVISÃO DA LITERATURA.

1.1. Flexibilidade e Alongamento 16

1.2. Tipos de flexibilidade 16

1.3. Proprioceptores e alongamento. 17

1.4. Métodos de treinamento da flexibilidade. 18

1.4.1 Alongamento ativo 18

1.4.2. Alongamento balístico. 18

1.4.3. Alongamento Passivo 19

1.4.4. Alongamento por facilitação neuromuscular proprioceptiva 19

1.5. Alongamento e performance física 21

1.6. Possíveis mecanismos associados a queda de performance física após exercícios de alongamento 26

1.7. Abordagem experimental do problema 28

1.8. Objetivos 29

1.8.1. Objetivo geral 29

1.8.2. Objetivos específicos 29

CAPÍTULO 2. Estudo 1: EFEITOS AGUDOS DOS MÉTODOS DE ALONGAMENTO ATIVO, BALÍSTICO, PASSIVO E DE FACILITAÇÃO NEUROMUSCULAR PROPRIOCEPTIVA SOBRE A PERFORMANCE NO SALTO VERTICAL E SPRINT EM JOVENS JOGADORES DE FUTEBOL 30

2.1. RESUMO 31 


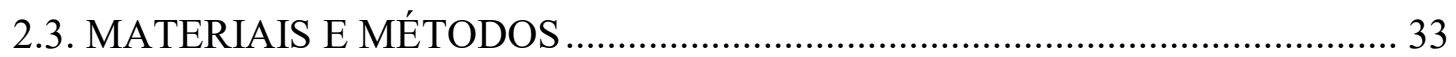

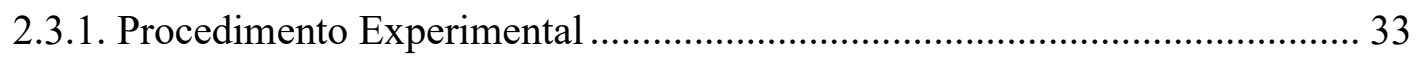

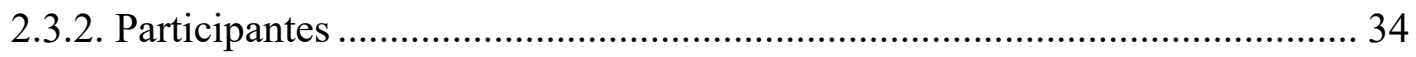

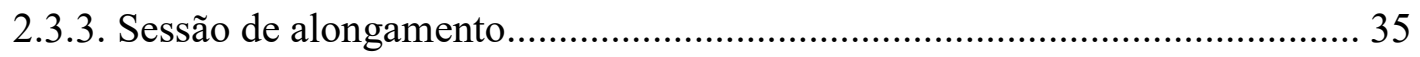

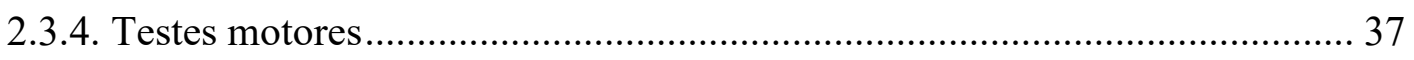

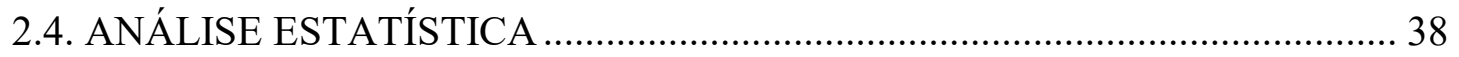

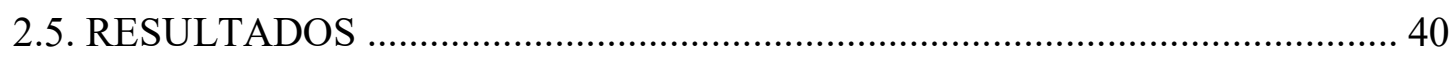

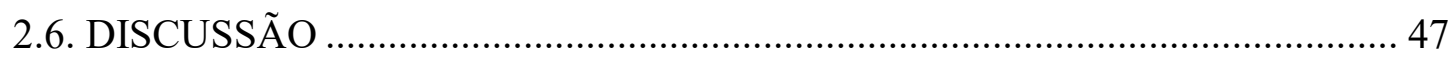

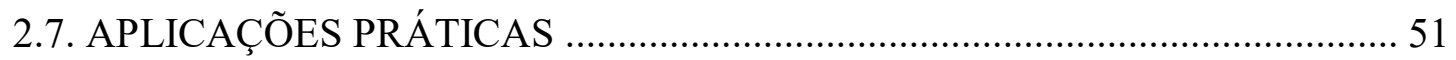

CAPÍTULO 3. Estudo 2: EFEITOS AGUDOS DOS MÉTODOS DE ALONGAMENTO ATIVO, BALÍSTICO, PASSIVO E DE FACILITAÇÃO NEUROMUSCULAR PROPRIOCEPTIVA EM PARÂMETROS

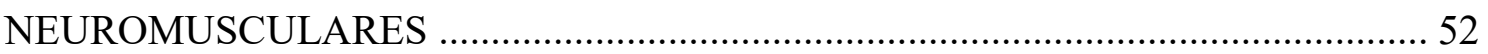

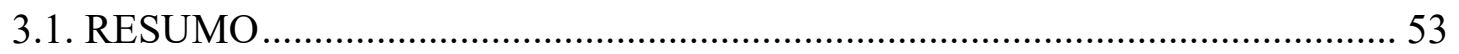

3.2. INTRODUÇÃ

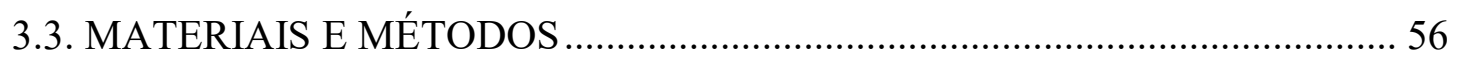

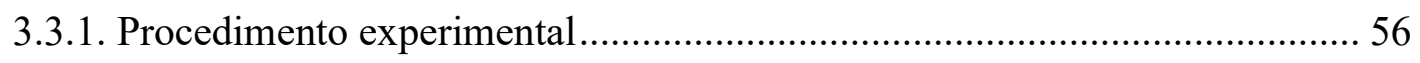

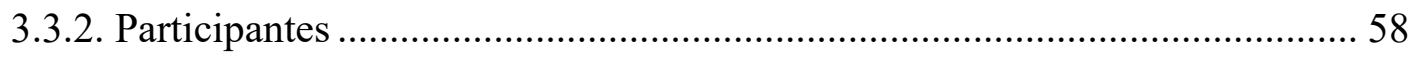

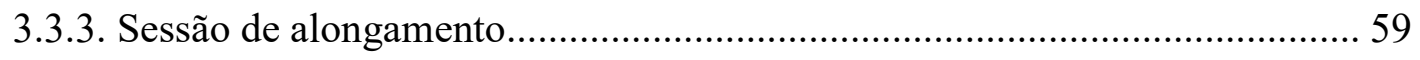

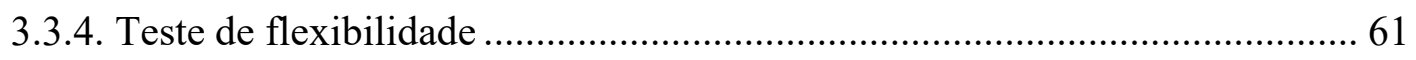

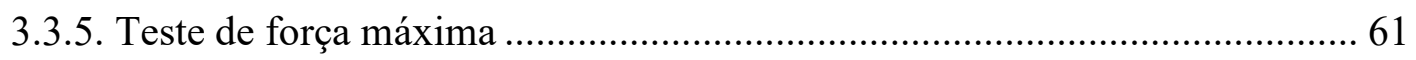




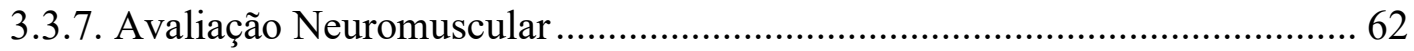

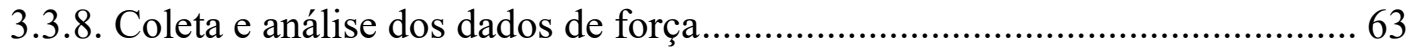

3.3.9. Coleta e análise dos dados de atividade muscular...................................... 64

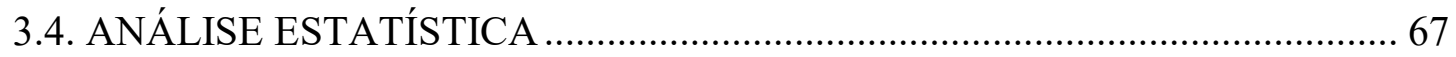

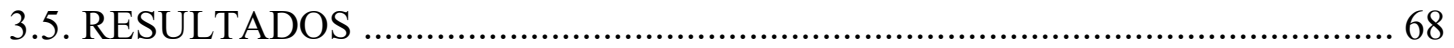

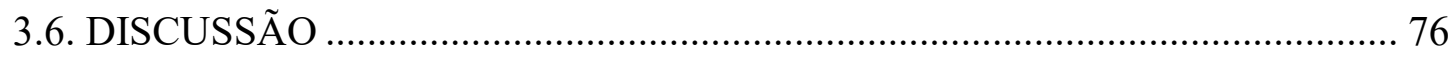

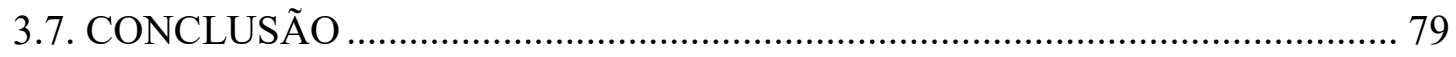

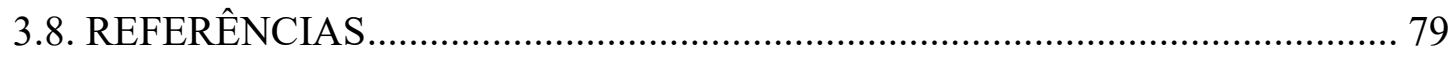

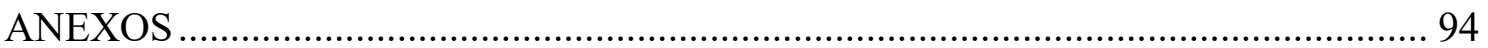


CAPÍTULO 1

REVISÃO DA LITERATURA 


\subsection{Flexibilidade e Alongamento}

Inicialmente é importante distinguir-se os conceitos de flexibilidade e alongamento. A flexibilidade é uma capacidade motora que está associada a amplitude de movimento (ADM) que uma articulação pode realizar (CHARRO et al., 2010). Pode ser denominada também, como a amplitude articular máxima em uma ou mais articulações (ANDERSON; BURKE, 1991). Além disso, a flexibilidade pode ser definida de forma mais objetiva como a ADM disponível em uma ou um grupo de articulações (STONE; KROLL, 1991).

Por outro lado, o alongamento é um exercício utilizado com o objetivo principal de aumentar a ADM (KISNER; COLBY, 2002). Sendo, portanto, exercícios utilizados no treinamento da capacidade motora flexibilidade, com o intuito de melhorar a performance global dos atletas (BLOOMFIELD; WILSON, 2000).

\subsection{Tipos de flexibilidade}

A literatura trata como flexibilidade geral e especial/específica, ativa e passiva. Trata-se de flexibilidade geral, quando o nível de flexibilidade se encontra suficientemente desenvolvido nas principais articulações (i.e., ombro, quadril e coluna vertebral) (WEINECK, 2005). Trata-se como flexibilidade especial/específica, quando a flexibilidade se refere a uma determinada articulação (WEINECK, 2005).

A flexibilidade ativa é designada quando se alcança a maior ADM possível por meio da contração dos músculos agonistas, sem auxílio externo (BARBANTI, 2010; WEINECK, 2005). A flexibilidade passiva é designada quando se alcança a maior ADM possível, sob a ação de forças externas (e.g., parceiro, peso corporal ou aparelhos) 
(BARBANTI, 2010; WEINECK, 2005). Ainda dentro da flexibilidade ativa e passiva, é possível se diferenciar entre estática e dinâmica, em função da existência ou não de movimento articular e também da manutenção ou não posição final de alongamento.

\subsection{Proprioceptores e alongamento}

As respostas musculares do alongamento estão associadas aos mecanismos neurofisiológicos de ativação de dois receptores, os fusos neuromusculares e os orgãos tendinosos de Golgi (OTG). Os fusos neuromusculares estão localizados no interior das fibras musculares intrafusais, com orientação paralela às fibras extrafusais, fornecendo informações mecanossensoriais acerca de modificações no comprimento muscular (MCARDLE; KACTH; KACTH, 2011). Durante um alongamento muito intenso ou rápido, neurônios sensoriais estimulam neurônios motores da medula espinhal, que por sua vez promovem uma resposta de contração das fibras musculares extrafusais alongadas (MCARDLE; KACTH; KACTH, 2011; BARBANTI, 2010). Esta resposta é denominada como reflexo de estiramento ou reflexo de alongamento (BARBANTI, 2010; BEACHLE; EARLE, 2008).

Os OTG estão localizados próximo a junção do tendão com o músculo, fornecendo informações sobre modificações na tensão muscular (MCARDLE; KACTH; KACTH, 2011). Estes receptores apresentam maior sensibilidade a alterações de tensões ativas que tensões passivas (BARBANTI, 2010). Ao contrário do fuso neuromuscular, os OTG quando estimulados pela tensão ativa promovem uma resposta de relaxamento muscular. Esta resposta é denominada como inibição autógena (BEACHLE; EARLE, 2008). Além disso, o aumento de tensão promovido pela contração ativa de determinado músculo agonista, estimulam os OTG e desencadeiam uma resposta de relaxamento do 
músculo antagonista. Esta resposta é denominada como inibição recíproca (BEACHLE; EARLE, 2008).

\subsection{Métodos de treinamento da flexibilidade}

\subsubsection{Alongamento ativo}

O alongamento ativo estático envolve esforço muscular ativo com manutenção da posição final. Tendo por característica ser realizado de maneira lenta e constante com manutenção da posição final por cerca de 30 s (BEACHLE; EARLE, 2008). Por ser realizado de maneira lenta e controlada, o alongamento estático produz pouco reflexo de estiramento do músculo alongado, tendo um menor potencial lesivo em comparação ao alongamento balístico (BARBANTI, 2010; BEACHLE; EARLE, 2008; WEINECK, 2005). Além disso, este método é de baixa complexidade e fácil aprendizagem, tendo demonstrado ser eficiente na melhora da ADM (BARBANTI, 2010; BEACHLE; EARLE, 2008).

\subsubsection{Alongamento balístico}

O alongamento balístico também envolve esforço muscular ativo, porem, é realizado com movimentos de balanceamento ou insistências em que a posição final não é mantida (BARBANTI, 2010; BEACHLE; EARLE, 2008; WEINECK, 2005). Este método é frequentemente utilizado durante o aquecimento em sessões de treinamento, no entanto, alguns autores apontam que este método pode ser potencialmente lesivo em função de desencadear alto reflexo de estiramento durante os movimentos "bruscos" de insistência característico deste método (BEACHLE; EARLE, 2008; WEINECK, 2005). 
Para Barbanti (2010), esta preocução é valida especialmente para pessoas sedentárias ou pouco treinadas, no entanto, no caso de pessoas treinadas e esportistas o autor ressalta que seja pouco provável, uma vez que o alongamento balístico é muito mais controlado e menos exigente do que os próprios movimentos realizados durante a prática do esporte.

\subsubsection{Alongamento Passivo}

Para o alongamento passivo não há esforço muscular voluntário, sendo que o movimento é executado por um agente externo, seja um parceiro, um equipamento ou mesmo o peso corporal pela ação da gravidade (ALTER, 2010). O treinamento empregando o método passivo representa uma maneira efetiva na melhora da ADM (BEACHLE; EARLE, 2008). No entanto é necessário um conhecimento prévio do parceiro/isntrutor sobre a técnica de execução, além de boa comunicação entre os envolvidos, já que o alongamento "abrupto" ou muito intenso pode representar considerável risco de lesões (BARBANTI, 2010; WEINECK, 2007).

\subsubsection{Alongamento por facilitação neuromuscular proprioceptiva}

O alongamento pelo método de facilitação neuromuscular proprioceptiva (FNP) também é executado por um auxílio de um parceiro, e envolve movimentos passivos e ações musculares ativas concêntrica e isométricas (BEACHLE; EARLE, 2008). Da mesmo forma que para o método passivo, este método também requer conhecimento prévio para a execução e boa comunição entre os envolvidos. O alongamento por FNP é realizado por três fases, sendo que na primeira é realizado um alongamento passivo por 
cerca de 10 s (BEACHLE; EARLE, 2008). A segunda e a terceira fases diferem em função das três técnicas de execução do FNP, (1) técnica de "sustentar-relaxar, (2) técnica de "contrair-relaxar" e (3) técnica de "sustentar-relaxar com contração agonista".

A técnica de "sustentar-relaxar", conforme mencionado, inicia com um alongamento passivo mantido em determinado ponto de desconforto. Em seguida, o parceiro aplica uma força no segmento alongado, enquanto o participante faz força no sentido contrário de forma a resistir ao movimento, ocorrendo uma ação muscular isométrica mantida por cerca de $6 \mathrm{~s}$. Após, o atleta relaxa o grupamento muscular e um alongamento passivo é executado e mantido por mais cerca de $30 \mathrm{~s}$. Esta técnica permite que um alongamento de grande magnitude seja alcançado, em função do mecanismo anteriormente citado da inibição autógena (BEACHLE; EARLE, 2008).

A técnica de "contrair-relaxar" também inicia com um alongamento passivo do grupamento muscular alvo. Em seguida, o participante realiza força no sentido contrário ao do parceiro, ocorrendo no caso desta técnica uma ação muscular concêntrica mediante a ADM completa. Após, há o relaxamento do grupamento muscular e um alongamento passivo adicional é realizado e mantido por mais cerca de $30 \mathrm{~s}$. Com esta técnica, o aumento em ADM final é facilitado também pela mecanismo da inibição autógena (BEACHLE; EARLE, 2008).

A técnica do "sustentar-relaxar com contração agonista", possui as duas primeiras fases idênticas às da técnica "sustentar-relaxar". No entanto, durante a terceira fase o participante realiza uma ação muscular concêntrica do agonista junto ao alongamento passivo realizado pelo parceiro, contribuindo para a força no sentido do alongamento. Para esta técnica, o aumento em ADM dever ser permitido, em um 
primeiro momento, pela inibição autógena e, posteriormente, pela inibição recíproca (BEACHLE; EARLE, 2008).

\subsection{Alongamento e performance física}

Os exercícios de alongamento são tradicionalmente realizados durante o aquecimento antes de sessões de treinamento ou competições esportivas. Muitos treinadores acreditam que esse tipo de prática reduz a incidência de lesões, acelera a recuperação, e aumenta a performance dos atletas (OZMEN et al., 2016).

Estudos prévios demonstram que os exercícios de alongamento de fato podem interferir na performance física e que seus efeitos parecem depender do método de alongamento empregado (BARROSO et al., 2012; BRADLEY; OLSEN; PORTAS, 2007; ALEMDAROGLU; KOKLU; KOZ, 2016; MANOEL et al., 2008; LITTLE; WILLIAMS, 2006; AVLONITI et al., 2014; DALLAS et al., 2014; JAGGERS et al., 2008). A Tabela 1 e 2 apresentam breves revisões sobre os efeitos agudos dos diferentes métodos de alongamento sobre a performance física em atividades dependentes de potência e força máxima de membros inferiores, respectivamente.

Tem sido demonstrado que os métodos passivo (PA) e de facilitação neuromuscular proprioceptiva (FNP) podem reduzir a capacidade de produção da força máxima e a performance no sprint e salto vertical (BARROSO et al., 2012; BRADLEY; OLSEN; PORTAS, 2007; ALEMDAROGLU; KOKLU; KOZ, 2016). Por outro lado, a literatura tem mostrado melhora de forma aguda da potência avaliada em dinamômetro isocinético (MANOEL et al., 2008), performance em testes de sprints e agilidade (LITTLE; WILLIAMS, 2006; AVLONITI et al., 2014), e incrementos ou inalteração na 
altura de salto vertical (DALLAS et al., 2014; JAGGERS et al., 2008), após a realização de protocolos balístico (BA) e ativo (AT).

Apesar da literatura apontar para uma resposta diferenciada entre os métodos, há muitos resultados controversos relacionados aos efeitos dos diferentes métodos de alongamento em parâmetros de performance física (AVLONITI et al., 2014; MANOEL et al., 2008; BARROSO et al., 2012; BRADLEY; OLSEN; PORTAS, 2007). O fato de haver diferenças no design experimental entre estes estudos faz com que estas contradições possam estar associadas não exclusivamente às diferenças entre os métodos de alongamento empregados, mas também a outras variáveis como o tipo de teste (e.g., sprints, salto vertical, isocinético), volume de alongamento (e.g., curta, média ou longa duração), intensidade de alongamento [e.g., $\geq$ ou $\leq$ point of discomfort (POD)], grupamento muscular avaliado (e.g., músculos tríceps sural ou quadríceps femoral), população amostral (e.g., atletas ou não-atletas) e nível de treinamento (e.g., iniciantes, moderadamente ou altamente treinados) dos participantes (BEHM; CHAOUACHI, 2011; BEHM; BLAZEVICH; KAY; MCHUGH, 2015).

Portanto, apesar do aumento do número de pesquisas dedicadas a investigar os efeitos do alongamento sobre diversos parâmetros da performance física, percebe-se ainda a falta de estudos que apresentem um design experimental do tipo cross-over com medidas repetidas no qual os mesmos participantes sejam submetidos aos diferentes métodos de alongamento com padronização em relação aos tipos de testes aplicados, volume de alongamento e grupamento muscular avaliado, permitindo a confrontação direta entre os resultados. 
Tabela 1. Breve revisão sobre os efeitos agudos de diferentes métodos de alongamento sobre a performance da potência de membros inferiores.

\begin{tabular}{|c|c|c|c|c|}
\hline Referências & Participantes & $\begin{array}{l}\text { Volume de } \\
\text { alongamento por } \\
\text { músculo } \\
\end{array}$ & $\begin{array}{l}\text { Intensidade de } \\
\text { alongamento }\end{array}$ & Efeito e Percentual de alteração \\
\hline $\begin{array}{l}\text { Alemdaroglu, } \\
\text { Koklu e Koz } \\
(2016)\end{array}$ & $\begin{array}{l}\text { Praticantes de Taekwondo } \quad(n=12 ; \\
\text { idade }=15,00 \pm 0,50 \text { anos })\end{array}$ & 4 séries $\times 30 \mathrm{~s}$ & $<$ POD & $\begin{array}{l}\text { BA, PA e FNP: redução nos } 10 \text { e } 20 \text { m (percentual } \\
\text { de alteração NR) }\end{array}$ \\
\hline $\begin{array}{l}\text { Avloniti et al. } \\
(2014)\end{array}$ & $\begin{array}{l}\text { Atletas de moderada } \quad(n=25 ; \\
\text { idade }=20,60 \pm 1,20 \text { anos }) \text { e alta }(n=25 ; \\
\text { idade }=20,40 \pm 1,50 \text { anos }) \text { performance }\end{array}$ & $\begin{array}{l}1 \text { série } \mathrm{x} 10,15,20 \text {, } \\
\quad 30,40 \text { ou } 60 \mathrm{~s}\end{array}$ & POD & $\begin{array}{l}\text { AT: Moderada performance - redução nos } 10 \mathrm{~m} \\
(4,20 \%) \text {, e nos } 20 \mathrm{~m}(4,10 \%) \text {, após alongamentos de } \\
15 \text { e } 20 \mathrm{~s} \text {, respectivamente; Alta performance - } \\
\text { inalteração }\end{array}$ \\
\hline Dallas et al. (2014) & $\begin{array}{l}\text { Atletas de ginástica artística } \quad(n=18 ; \\
\text { idade }=21,83 \pm 1,76)\end{array}$ & 1 série $x 15 \mathrm{~s}$ & $<\mathrm{POD}$ & AT e FNP: inalteração na $\mathrm{H}_{\mathrm{CMJ}}$ e $\mathrm{H}_{\mathrm{SJ}}$ \\
\hline $\begin{array}{l}\text { Alikhajeh et al. } \\
(2012)\end{array}$ & $\begin{array}{l}\text { Jogadores de futebol amadores }(\mathrm{n}=120 \text {; } \\
\text { idade }=17,50 \pm 0,58 \text { anos) }\end{array}$ & 1 série $\times 20 \mathrm{~s}$ & $<$ POD & $\begin{array}{l}\text { AT e PA: redução nos } 20 \mathrm{~m} \text {; BA: aumento nos } 20 \mathrm{~m} \\
\text { (percentual de alteração NR) }\end{array}$ \\
\hline $\begin{array}{l}\text { Carvalho et al. } \\
(2012)\end{array}$ & $\begin{array}{l}\text { Jogadores de tênis } \quad(n=16 ; \\
\text { idade }=14,50 \pm 2,80 \text { anos })\end{array}$ & 3 séries $\times 15 \mathrm{~s}$ & $<$ POD & $\begin{array}{l}\text { BA: inalteração na } \mathrm{H}_{\mathrm{SJ}} \text { e } \mathrm{H}_{\mathrm{CMJ}} \text {; } \mathrm{AT} \text { e PA: redução na } \\
\mathrm{H}_{\mathrm{SJ}} \text { (percentual de alteração } \mathrm{NR} \text { ) e inalteração na } \\
\mathrm{H}_{\mathrm{CMJ}}\end{array}$ \\
\hline Place et al. (2012) & $\begin{array}{l}\text { Homens fisicamente ativos } \quad(n=20 ; \\
\text { idade }=27,70 \pm 7,30 \text { anos })\end{array}$ & 4 séries $\times 15 \mathrm{~s}$ & $<$ POD & FNP: inalteração na $\mathrm{H}_{\mathrm{CMJ}}$ \\
\hline $\begin{array}{l}\text { Vasconcellos et al. } \\
(2012)\end{array}$ & $\begin{array}{l}\text { Jogadores de futebol } \quad(n=45 ; \\
\text { idade }=14,00 \pm 0,66 \text { anos })\end{array}$ & 4 séries $\times 16 \mathrm{~s}$ & $>$ POD & PA: redução na $\mathrm{H}_{\mathrm{CMJ}}(34,10 \%)$ \\
\hline Gelen (2010) & $\begin{array}{l}\text { Jogadores profissionais de futebol } \\
(\mathrm{n}=26 \text {; idade }=23,30 \pm 3,20 \text { anos })\end{array}$ & $\begin{array}{l}2 \text { séries } \times 20 \mathrm{~s}\left(1^{\circ}\right. \\
\text { série }) \text { e } 30 \mathrm{~s}\left(2^{\circ}\right. \\
\text { série })\end{array}$ & $<$ POD & AT: redução nos 30 m $(8,50 \%)$ \\
\hline $\begin{array}{l}\text { Chaouachi et al. } \\
(2009)\end{array}$ & $\begin{array}{l}\text { Estudantes universitários treinados } \\
(\mathrm{n}=22 ; \text { idade }=20,60 \pm 1,20 \text { anos })\end{array}$ & 2 séries $\times 30 \mathrm{~s}$ & $<$ POD & AT e BA: inalteração nos 10 e $30 \mathrm{~m}$ e na $\mathrm{H}_{\mathrm{CMJ}}$ \\
\hline $\begin{array}{l}\text { Bradley, Olsen e } \\
\text { Portas (2007) }\end{array}$ & $\begin{array}{l}\text { Estudantes universitários } \quad(n=18 ; \\
\text { idade }=24,30 \pm 3,20 \text { anos })\end{array}$ & 4 séries $\times 30 \mathrm{~s}$ & $<\mathrm{POD}$ & $\begin{array}{l}\text { BA: inalteração; PA: redução na } \mathrm{H}_{\mathrm{CMJ}} \text { e } \mathrm{H}_{\mathrm{SJ}} \\
(4,00 \%) \text {; FNP: redução na } \mathrm{H}_{\mathrm{CMJ}} \text { e } \mathrm{H}_{\mathrm{SJ}}(5,10 \%)\end{array}$ \\
\hline $\begin{array}{l}\text { Stewart et al. } \\
(2007)\end{array}$ & $\begin{array}{l}\text { Atletas de rugby de elite } \quad(n=14 ; \\
\text { categoria sub19) }\end{array}$ & 3 séries $\times 45 \mathrm{~s}$ & POD & AT: inalteração nos $40 \mathrm{~m}$ \\
\hline $\begin{array}{l}\text { Little e Wiliams } \\
(2006)\end{array}$ & $\begin{array}{l}\text { Jogadores profissionais de futebol } \\
(\mathrm{n}=18 ; \text { idade=NR })\end{array}$ & 1 série $\times 30 \mathrm{~s}$ & POD & $\begin{array}{l}\text { AT: aumento nos } 20 \text { m; BA: aumento nos } 10 \text { e } 20 \text { m } \\
\text { (percentual de alteração NR); AT e BA: inalteração } \\
\text { na } H_{\text {CMJ }}\end{array}$ \\
\hline
\end{tabular}




\begin{tabular}{|c|c|c|c|c|}
\hline $\begin{array}{l}\text { Fletcher e Jones } \\
\text { (2004) }\end{array}$ & $\begin{array}{l}\text { Jogadores amadores de Rugby }(n=97 \text {; } \\
\text { idade }=23,00 \pm 8,40 \text { anos) }\end{array}$ & 1 série $\mathrm{x} 20 \mathrm{~s}$ & $<$ POD & $\begin{array}{l}\text { BA: aumento nos } 20 \mathrm{~m} \text {; AT e PA: re } \\
\text { (percentual de alteracão NR) }\end{array}$ \\
\hline
\end{tabular}
(2004) idade $=23,00 \pm 8,40$ anos $)$ (percentual de alteração NR)

Alongamento ativo (AT), balístico (BA), passivo (PA) e por facilitação neuromuscular proprioceptiva (FNP); point of discomfort (POD); não relatado (NR); altura de salto no squat jump $\left(\mathrm{H}_{\mathrm{SJ}}\right)$ e counter movement jump $\left(\mathrm{H}_{\mathrm{CMJ}}\right)$; sprint de quarenta metros $(40 \mathrm{~m})$, trinta metros $(30 \mathrm{~m})$, vinte metros $(20 \mathrm{~m})$ e dez metros $(10 \mathrm{~m})$.

Tabela 2. Breve revisão sobre os efeitos agudos de diferentes métodos de alongamento sobre a performance da força máxima de membros inferiores.

\begin{tabular}{|c|c|c|c|c|}
\hline Referência & Participantes & $\begin{array}{l}\text { Volume de } \\
\text { alongamento por } \\
\text { músculo }\end{array}$ & $\begin{array}{l}\text { Intensidade de } \\
\text { alongamento }\end{array}$ & Efeito e Percentual de alteração \\
\hline $\begin{array}{l}\text { Miller et al. } \\
(2016)\end{array}$ & $\begin{array}{l}\text { Homens saudáveis }(\mathrm{n}=14 ; \text { idade }=22,00 \pm 3,00 \\
\text { anos) }\end{array}$ & 8 séries $\times 30 \mathrm{~s}$ & POD & PA: redução na CVM $(8,60 \%)$ \\
\hline $\begin{array}{l}\text { Stafilidis e Tilp } \\
(2015)\end{array}$ & $\begin{array}{ll}\begin{array}{l}\text { Estudantes } \\
\text { idade }=25,50 \pm 3,10 \text { anos })\end{array} & (\mathrm{n}=11 ;\end{array}$ & $\begin{array}{c}1 \text { série } x 15 \mathrm{~s} \text { ou } 60 \\
\mathrm{~s}\end{array}$ & POD & AT: inalteração na CVM \\
\hline $\begin{array}{l}\text { Trajano et al. } \\
(2014)\end{array}$ & $\begin{array}{l}\text { Homens saudáveis }(\mathrm{n}=18 \text {; idade }=26,80 \pm 4,50 \\
\text { anos) }\end{array}$ & $\begin{array}{l}1 \text { série } x 5 \text { min ou } 5 \\
\text { séries } \times 1 \text { min }\end{array}$ & $<$ POD & $\begin{array}{l}\text { PA: redução na Fpico em ambas as condições, } \\
\text { alongamento contínuo e intermitente }(14,30 \% \text { e } \\
23,80 \% \text {, respectivamente) }\end{array}$ \\
\hline $\begin{array}{l}\text { Miyahara et al. } \\
(2013)\end{array}$ & $\begin{array}{ll}\begin{array}{l}\text { Estudantes } \\
\text { idade }=20,00 \pm 1,00 \text { anos })\end{array} & (\mathrm{n}=13 \text {; }\end{array}$ & $\begin{array}{c}5 \text { séries x } 45 \mathrm{~s}(\mathrm{PA}) \\
\text { ou } 61 \mathrm{~s}(\mathrm{FNP})\end{array}$ & $>$ POD & $\begin{array}{l}\text { PA e FNP: redução na CVM }(6,90 \% \text { e } 7,10 \% \text {, } \\
\text { respectivamente) }\end{array}$ \\
\hline $\begin{array}{lll}\text { Reis et al. } \\
(2013)\end{array}$ & $\begin{array}{l}\text { Indivíduos } \quad \text { sedentários }(\mathrm{n}=16 ; \\
\text { idade }=21,30 \pm 1,80 \text { anos }) \text { e jogadores de futsal } \\
(\mathrm{n}=17 ; \text { idade }=25,70 \pm 4,80 \text { anos })\end{array}$ & 2 séries $\times 30 \mathrm{~s}$ & POD & $\begin{array}{l}\text { PA: inalteração em ambos os grupos, sedentário e } \\
\text { jogadores de futsal }\end{array}$ \\
\hline $\begin{array}{lll}\text { Serra } & \text { et } & \text { al. } \\
(2013) & & \end{array}$ & $\begin{array}{l}\text { Indivíduos não treinados }(\mathrm{n}=9 ; \\
\text { idade }=27,00 \pm 4,00 \text { anos }) \text { e treinados em força } \\
(\mathrm{n}=11 ; \text { idade }=26,00 \pm 6,00 \text { anos })\end{array}$ & 3 séries $\times 30 \mathrm{~s}$ & NR & $\begin{array}{l}\text { PA: redução em ambos os grupos, não treinado e } \\
\text { treinado em força, no } 1 \text { RM ( } \sim 8,00 \% \text { e } 5,00 \% \text {, } \\
\text { respectivamente) no leg press }\end{array}$ \\
\hline $\begin{array}{l}\text { Trajano et al. } \\
(2013)\end{array}$ & $\begin{array}{l}\text { Homens saudáveis ( } \mathrm{n}=13 \text {; idade }=26,50 \pm 5,00 \\
\text { anos) }\end{array}$ & 1 série $\times 5$ min & $<\mathrm{POD}$ & PA: redução na Fpico $(15,70 \%)$ \\
\hline $\begin{array}{l}\text { Barroso et al. } \\
(2012)\end{array}$ & $\begin{array}{l}\text { Estudantes universitários treinados }(\mathrm{n}=20 \\
\text { idade }=20,40 \pm 4,50 \text { anos })\end{array}$ & 3 séries $\times 30 \mathrm{~s}$ & NR & $\begin{array}{l}\text { AT e BA: inalteração; FNP: redução no } 1 \text { RM } \\
(5,50 \%) \text { no leg press }\end{array}$ \\
\hline $\begin{array}{l}\text { Oliveira et al. } \\
(2012)\end{array}$ & $\begin{array}{ll}\text { Estudantes } \quad \text { universitários } & (\mathrm{n}=15 ; \\
\text { idade }=21,30 \pm 2,40 \text { anos })\end{array}$ & 20 séries $\times 30 \mathrm{~s}$ & $<$ POD & $\begin{array}{l}\text { AT: redução na CVM (percentual de alteração } \\
\text { NR) }\end{array}$ \\
\hline $\begin{array}{l}\text { Pablo et al. } \\
(2010)\end{array}$ & $\begin{array}{l}\text { Homens saudáveis }(\mathrm{n}=16 ; \mathrm{idade}=21,10 \pm 1,70 \\
\text { anos) }\end{array}$ & 9 séries $\times 135 \mathrm{~s}$ & POD & PA: redução na Fpico $(9,00 \%)$ \\
\hline
\end{tabular}




\begin{tabular}{|c|c|c|c|c|}
\hline $\begin{array}{l}\text { Bacurau et al. } \\
\text { (2009) }\end{array}$ & $\begin{array}{l}\text { Estudantes fisicamente ativos } \quad(n=14 ; \\
\text { idade }=23,10 \pm 3,60 \text { anos })\end{array}$ & 9 séries $\times 30 \mathrm{~s}$ & NR & $\begin{array}{l}\text { AT: redução no } 1 \text { RM }(13,4 \%) \text { no leg press; BA: } \\
\text { inalteração }\end{array}$ \\
\hline $\begin{array}{l}\text { Herda et al. } \\
(2009)\end{array}$ & $\begin{array}{l}\text { Homens saudáveis }(\mathrm{n}=15 ; \text { idade }=24,00 \pm 4,00 \\
\text { anos) }\end{array}$ & 9 séries $\times 135 \mathrm{~s}$ & POD & PA: redução na Fpico $(10,00 \%)$ \\
\hline $\begin{array}{l}\text { Siatras et al. } \\
(2008)\end{array}$ & $\begin{array}{l}\text { Estudantes universitários }(\mathrm{n}=50 ; \text { idade }=19-23 \\
\text { anos) }\end{array}$ & $\begin{array}{l}1 \text { série } \times 10,20,30 \\
\text { ou } 60 \mathrm{~s}\end{array}$ & POD & $\begin{array}{l}\text { AT: redução nos grupos } 30 \text { e } 60 \mathrm{~s}(8,50 \% \text { e } \\
16,00 \% \text {, respectivamente })\end{array}$ \\
\hline $\begin{array}{l}\text { Bride } \quad \text { e } \\
\text { Nimphius } \\
(2007)\end{array}$ & $\begin{array}{l}\text { Estudantes } \quad \text { universitários } \quad(n=8 ; \\
\text { idade }=21,40 \pm 0,70 \text { anos })\end{array}$ & 3 séries $\times 33 \mathrm{~s}$ & NR & $\begin{array}{l}\text { PA: redução na CVM no exercício de extensão de } \\
\text { joelho (percentual de alteração NR), e inalteração } \\
\text { na CVM no exercício de agachamento }\end{array}$ \\
\hline $\begin{array}{l}\text { Ogura et al. } \\
(2007)\end{array}$ & $\begin{array}{l}\text { Homens saudáveis }(\mathrm{n}=10 ; \text { idade }=20,00 \pm 0,00 \\
\text { anos) }\end{array}$ & $\begin{array}{c}2 \text { séries } \times 30 \mathrm{~s} \text { ou } 60 \\
\mathrm{~s}\end{array}$ & $<\mathrm{POD}$ & $\begin{array}{l}\text { AT: redução após a série de } 60 \mathrm{~s} \text { (percentual de } \\
\text { alteração NR), e inalteração após a série de } 30 \mathrm{~s}\end{array}$ \\
\hline $\begin{array}{l}\text { Power et al. } \\
(2004)\end{array}$ & $\begin{array}{l}\text { Estudantes universitários }(\mathrm{n}=20 \text {; idade }=\text { entre } \\
20-44 \text { anos })\end{array}$ & 6 séries $\mathrm{x} 45 \mathrm{~s}$ & POD & AT: redução na CVM $(9,50 \%)$ \\
\hline $\begin{array}{l}\text { Behm, Button e } \\
\text { Butt (2001) }\end{array}$ & $\begin{array}{l}\text { Estudantes universitários }(\mathrm{n}=12 ; \text { idade }=20-43 \\
\text { anos) }\end{array}$ & 20 séries x $45 \mathrm{~s}$ & NR & AT+PA: redução na CVM $(12,20 \%)$ \\
\hline
\end{tabular}

Alongamento ativo (AT), balístico (BA), passivo (PA) e por facilitação neuromuscular proprioceptiva (FNP); não relatado (NR); point of discomfort (POD); teste de uma repetição máxima (1 RM); contração voluntária isométrica máxima (CVM); força pico (Fpico). 


\subsection{Possíveis mecanismos associados à queda de performance física após exercícios de alongamento}

Apesar do mecanismo preciso responsável pela diminuição da força após exercícios de alongamento ainda ser desconhecido, efeito denominado como "stretching-induced force deficit" (RYAN et al., 2008a), alguns pesquisadores tem sugerido que sua causa possa estar associada a fatores neurais, mecânicos ou mesmo uma combinação entre fatores neurais e mecânicos (FOWLES; SALE; MACDOUGALL, 2000; CRAMER et al., 2005; CRAMER et al., 2007; COSTA et al., 2010).

Um dos fatores associados a este fenômeno, é a diminuição do grau de rigidez tecidual ou stiffness (fator mecânico) da unidade músculo-tendão, que está associada à rigidez da musculatura esquelética, tecido conjuntivo, cápsula articular, tendões e ligamentos (RYAN et al., 2008b). Sabendo que uma das funções dos tendões é de transferir a força produzida pela musculatura esquelética para os ossos e articulações, uma unidade músculo-tendão menos rígida ou mais maleável, pode afetar negativamente a transmissão da força causando queda de performance física.

Além disso, uma diminuição no grau de rigidez ou stiffness da unidade músculotendão pode promover alterações na relação tensão-comprimento do sarcômero (WILSON et al., 1994). O sarcômero possui um comprimento ótimo para a produção de força, que fica entre 2,00-2,25 $\mu \mathrm{m}$ (MCARDLE; KATCH; KATCH, 2011). Em comprimentos acima ou abaixo desse valor a força ativa produzida pelo sarcômero diminui, devido a menor possibilidade de formação das pontes cruzadas. Segundo Wilson et al. (1994) uma diminuição na rigidez da unidade músculo-tendão levaria a uma resposta transitória de encurtamento na ausência de sobrecarga, o que colocaria os 
elementos contráteis do sarcômero em uma posição menos favorável para a produção de força.

Outro mecanismo mencionado na literatura é a diminuição na capacidade de recrutamento de unidades motoras (fator neural) (FOWLES; SALE; MACDOUGALL, 2000; CRAEMER et al., 2005; CRAEMER et al., 2007). Estas reduções na capacidade de ativação muscular podem ocorrer em função do mecanismo de inibição recíproca promovido pelos OTG. Este mecanismo é desencadeado como forma de proteção a potenciais danos às estruturas da unidade músculo-tendão causados por tensões excessivas. Além disso, Craemer et al. (2005) em seu estudo encontraram reduções significativas da capacidade de produção de força e amplitude do sinal eletromiográfico em ambas as pernas, alongada e não alongada. Dessa forma, os autores sugeriram que as reduções de força induzida pelos exercícios de alongamento possam, em parte, serem atribuídas a um mecanismo inibitório central, oque ainda não foi identificado. 


\subsection{Abordagem experimental do problema}

A presente dissertação teve como objetivo comparar os efeitos agudos de diferentes métodos de alongamento sobre a performance em testes motores e parâmetros neuromusculares em jovens jogadores de futebol treinados. Para tanto, foram realizados dois estudos originais para alcançar este objetivo (Fig. 1).

\section{PERGUNTA CENTRAL:}

Quais os efeitos agudos promovidos pelos métodos de alongamento ativo, balístico, passivo e facilitação neuromuscular proprioceptiva sobre a performance em testes motores e em parâmetros neuromusculares em atletas treinados?

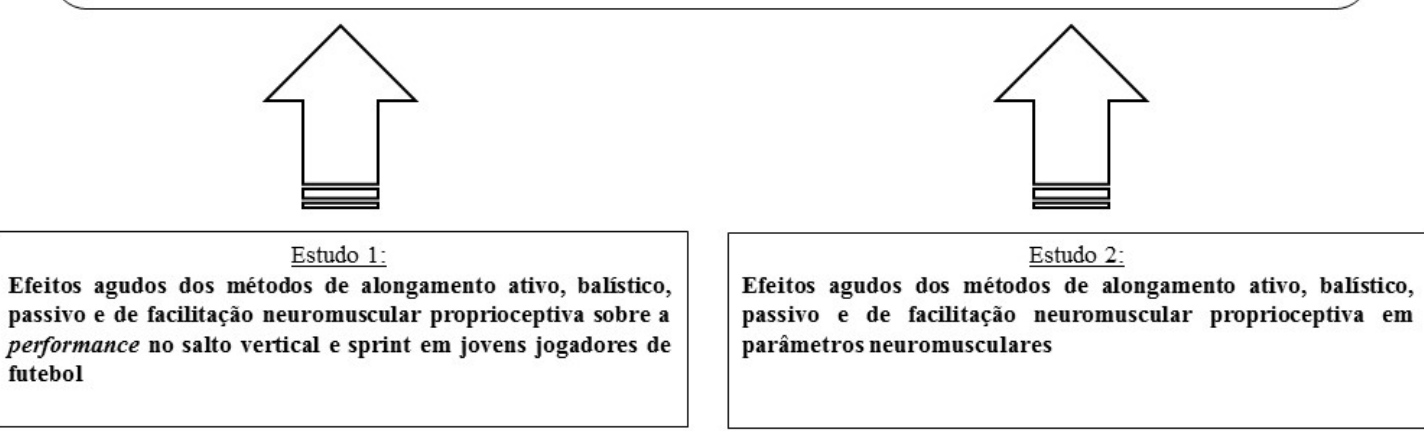

Figura 1. Considerações iniciais sobre os estudos necessários para responder o questionamento central. 


\subsection{Objetivos}

\subsubsection{Objetivo geral}

Comparar os efeitos agudos de diferentes métodos de alongamento sobre a performance em testes motores e parâmetros neuromusculares em jovens jogadores de futebol.

\subsubsection{Objetivos específicos}

- Comparar os efeitos agudos dos métodos de alongamento ativo, balístico, passivo e facilitação neuromuscular proprioceptiva, sobre a performance em teste de salto vertical, sentar e alcançar e sprint de 10-20-30 m (estudo 1);

- Comparar os efeitos agudos dos métodos de alongamento ativo, balístico, passivo e facilitação neuromuscular proprioceptiva sobre parâmetros associados à força e eletromiografia muscular em teste de uma repetição máxima no exercício agachamento e contração voluntária isométrica máxima na extensão de joelho (estudo 2). 
CAPÍTULO 2

Estudo 1: EFEITOS AGUDOS DOS MÉTODOS DE ALONGamento ATIVo, BALÍSTiCo, PASSivo E DE FACILITAÇÃO NEUROMUSCULAR PROPRIOCEPTIVA SOBRE A PERFORMANCE NO SALTO VERTICAL E SPRINT EM JOVENS JOGADORES DE FUTEBOL 


\subsection{RESUMO}

O objetivo do presente estudo foi comparar os efeitos agudos dos métodos de alongamento ativo (AT), balístico (BA), passivo (PA), facilitação neuromuscular proprioceptiva (FNP) sobre a performance no salto vertical, sentar e alcançar e sprint em jovens jogadores de futebol. Doze jogadores de futebol treinados $(17,67 \pm 0,87$ anos $)$ participaram do estudo. Foram avaliados a altura de salto $(\mathrm{H})$, potência pico (PP) e potência relativa (PR) no squat jump (SJ) e countermovent jump (CMJ), amplitude de movimento (ADM), percepção subjetiva de esforço (PSE), e o tempo (s) nos 10-20-30 $\mathrm{m}$ durante o sprint. Foram encontradas diferenças significativas $(\mathrm{p}<0.05)$ na $\mathrm{H}$ nas comparações PA $(39,73 \pm 4,15 \mathrm{~cm})$ e condição controle $(\mathrm{CO})(41,98 \pm 4,50 \mathrm{~cm})$ para o SJ. Para o CMJ, foram encontradas diferenças na $\mathrm{H}$ entre $\mathrm{PA}(42,07 \pm 4,68 \mathrm{~cm})$ e $\mathrm{CO}$ $(44,30 \pm 4,40 \mathrm{~cm})$, e FNP $(41,58 \pm 3,92 \mathrm{~cm}) \mathrm{com} \mathrm{CO}(44,30 \pm 4,40 \mathrm{~cm})$ e BA $(43,65 \pm 4,16$ cm), e na PP entre FNP $(3383,44 \pm 304,28$ W) e CO $(3563,74 \pm 297,65 \mathrm{~W})$, AT $(3560,44 \pm 274,57 \mathrm{~W})$ e BA $(3509,27 \pm 286,27 \mathrm{~W})$, assim como na PR entre FNP $\left(51,20 \pm 3,03 \mathrm{~W} \cdot \mathrm{kg}^{-1}\right)$ e BA $\left(52,85 \pm 3,32 \mathrm{~W} \cdot \mathrm{kg}^{-1}\right)$. Foram encontrados aumentos significativos na ADM nas condições AT $(4,19 \pm 2,25 \%)$, BA $(4,73 \pm 3,44 \%)$, PA $(5,67 \pm 4,76 \%)$ e $\operatorname{FNP}(6,51 \pm 4,05 \%)$, em comparação ao $\operatorname{CO}(0,85 \pm 1,32)$. Em relação a PSE, escores superiores foram relatados nas condições PA $(8,50 \pm 1,31$ u.a) e FNP $(8,83 \pm 0,94$ u.a.) em comparação a $\operatorname{AT}(5,42 \pm 1,68$ u.a.) e BA $(6,17 \pm 1,85$ u.a.). Não foram encontradas diferenças significativas no sprint de 10-20-30m. Portanto, os métodos AT e BA podem ser utilizados previamente a atividades de salto vertical e sprint, com o objetido de aumento de flexibilidade. Já os métodos PA e FNP devem ser evitados, em função das maiores intensidades alcançadas nestas condições e pela extensa possibilidade de efeitos negativos posteriores na performance do salto vertical.

Palavras chave: Esporte coletivo; Flexibilidade; Performance física; Testes motores. 


\subsection{INTRODUÇÃO}

Os exercícios de alongamento são tradicionalmente realizados durante o aquecimento antes de sessões de treinamento ou competições esportivas. Muitos treinadores acreditam que esse tipo de prática reduz a incidência de lesões, acelera a recuperação, e aumenta a performance dos atletas (OZMEN et al., 2016).

Estudos prévios demonstram que os exercícios de alongamento de fato podem interferir na performance física e que seus efeitos parecem depender do método de alongamento empregado (BARROSO et al., 2012; BRADLEY; OLSEN; PORTAS, 2007; ALEMDAROGLU; KOKLU; KOZ, 2016; MANOEL et al., 2008; LITTLE; WILLIAMS, 2006; AVLONITI et al., 2014; DALLAS et al., 2014; JAGGERS et al., 2008). Tem sido demonstrado que os métodos passivo (PA) e de facilitação neuromuscular proprioceptiva (FNP) podem reduzir a capacidade de produção da força máxima e a performance no sprint e salto vertical (BARROSO et al., 2012; BRADLEY; OLSEN; PORTAS, 2007; ALEMDAROGLU; KOKLU; KOZ, 2016). Por outro lado, a literatura tem mostrado melhora de forma aguda da potência avaliada em dinamômetro isocinético (MANOEL et al., 2008), performance em testes de sprints e agilidade (LITTLE; WILLIAMS, 2006; AVLONITI et al., 2014), e incrementos ou inalteração na altura de salto vertical (DALLAS et al., 2014; JAGGERS et al., 2008), após a realização de protocolos balístico (BA) e ativo (AT).

Apesar da literatura apontar para uma resposta diferenciada entre os métodos, há muitos resultados controversos relacionados aos efeitos dos diferentes métodos de alongamento em parâmetros de performance física (AVLONITI et al., 2014; MANOEL et al., 2008; BARROSO et. al, 2012; BRADLEY; OLSEN; PORTAS, 2007). O fato de haver diferenças no design experimental entre estes estudos faz com que estas contradições possam estar associadas não exclusivamente às diferenças entre os 
métodos de alongamento empregados, mas também a outras variáveis como o tipo de teste (e.g., sprints, salto vertical, isocinético), volume de alongamento (e.g., curta, média ou longa duração), intensidade de alongamento [e.g., $\geq$ ou $\leq$ point of discomfort (POD)], grupamento muscular avaliado (e.g., músculos tríceps sural ou quadríceps femoral), população amostral (e.g., atletas ou não-atletas) e nível de treinamento (e.g., iniciantes, moderadamente ou altamente treinados) dos participantes (BEHM; CHAOUACHI, 2011; BEHM; BLAZEVICH; KAY; MCHUGH, 2015). Portanto, apesar do aumento do número de pesquisas dedicadas a investigar os efeitos do alongamento sobre diversos parâmetros da performance física, percebe-se ainda a falta de estudos que apresentem um design experimental do tipo cross-over com medidas repetidas no qual os mesmos participantes sejam submetidos aos diferentes métodos de alongamento com padronização em relação aos tipos de testes aplicados, volume de alongamento e grupamento muscular avaliado, permitindo a confrontação direta entre os resultados.

Partindo deste pressuposto, o objetivo do presente estudo foi comparar os efeitos agudos dos métodos de alongamento AT, BA, PA e FNP, sobre a performance em teste de salto vertical, sentar e alcançar e sprint de 10-20-30 m em jovens jogadores de futebol treinados. As hipóteses formuladas para a presente investigação foram de que os métodos PA e FNP possam ser capazes de reduzir, enquanto que os métodos AT e BA promovam aumento ou nenhuma alteração da performance nos testes motores avaliados.

\subsection{MATERIAIS E MÉTODOS}

\subsubsection{Procedimento Experimental}

Antes do início do estudo foram realizadas duas a três sessões de familiarização dos participantes aos testes e exercícios de alongamento propostos no protocolo 
experimental, na tentativa de evitar possíveis interferências nos resultados em função de aprendizagem e coordenação dos movimentos.

A fim de comparar o comportamento da potência antecedida ou não por exercícios de alongamento, os participantes foram avaliados em cinco dias separados, sendo todos no mesmo período do dia. As temperaturas diárias médias foram: dia $1,32^{\circ}$ $\mathrm{C}$; dia $2,33{ }^{\circ} \mathrm{C}$; dia $3,30{ }^{\circ} \mathrm{C}$; dia $4,32{ }^{\circ} \mathrm{C}$; dia $5,30{ }^{\circ} \mathrm{C}$ (recordatório climático do Instituto de Pesquisas Meteorológicas, IPMet, Brasil). No dia da avaliação, cada participante realizava um aquecimento geral composto de 5 min de corrida, em esteira ergométrica a uma velocidade de $9 \mathrm{~km} . \mathrm{h}^{-1}$, seguido de teste inicial de flexibilidade. Logo após, cada participante passou por uma das cinco condições experimentais do estudo (alongamento AT, PA, BA, FNP ou condição controle [CO]), de forma randomizada e com intervalo mínimo de 48 h entre eles. Nas condições envolvendo alongamento, foi realizada uma sessão de alongamento com 15 min de duração total, enquanto que na condição $\mathrm{CO}$ os participantes permaneceram o mesmo tempo em repouso. Finalmente, foi realizado um novo teste de flexibilidade, seguido dos testes motores de salto vertical e sprint de 10-20-30 m.

\subsubsection{Participantes}

Participaram do estudo 12 jogadores de futebol treinados (média \pm DP: idade $17,67 \pm 0,87$ anos; estatura 1,76 $\pm 0,06 \mathrm{~m}$; massa corporal $67,38 \pm 4,82 \mathrm{~kg}$; \%gordura $6,80 \pm 2,43 \% ; \mathrm{VO}_{2}$ máx 49,76 $\left.\pm 2,12 \mathrm{~mL} \cdot \mathrm{kg}^{-1} \cdot \mathrm{min}^{-1}\right)$, pertencentes à categoria de base de uma equipe que disputa a terceira divisão da liga nacional chinesa. O estudo foi conduzido na pré-temporada, momento em que os atletas realizavam treinamento sistematizado com uma frequência de oito sessões semanais ( 100 min por sessão), incluindo um jogo amistoso. Foram utilizados como critérios de inclusão não possuir 
lesões musculoesqueléticas ou problemas de saúde que limitassem a prática de exercícios físicos. O presente estudo foi aprovado por um Comitê de Ética em Pesquisa institucional ( $\mathrm{n}^{\mathrm{o}}$ 1.050.789), sendo conduzido de acordo com os princípios estabelecidos pela Declaração de Helsinki.

\subsubsection{Sessão de alongamento}

As sessões de alongamento foram compostas com base em quatro exercícios (i.e., "toque das pontas dos pés na posição sentada, alongamento do quadríceps em decúbito lateral, flexão de joelho em decúbito dorsal, alongamento com step "; [maiores detalhes em BAECHLE e EARLE, 2008]), alternando-se os métodos de alongamento empregados (Fig. 2). Os exercícios de alongamento foram voltados para a musculatura primária na execução dos movimentos de salto vertical e sprint (i.e., quadríceps femoral, isquiotibiais, glúteo máximo, e tríceps sural).

Para todos os métodos de alongamento utilizados no estudo, foram realizadas três séries seguindo o protocolo proposto por Barroso et al. (2012). Durante a realização do método AT, cada série de exercícios foi composta por $30 \mathrm{~s}$ de manutenção na posição alongada, seguido por $30 \mathrm{~s}$ de intervalo. No método PA, o mesmo protocolo foi empregado, porém realizando-se aumentos progressivos na amplitude de alongamento, com base na percepção subjetiva relatada, auxiliada por um pesquisador experiente. Para o método BA os participantes realizaram movimentos oscilatórios de alongamento, em uma cadência de 1:1 s por ciclo, durante $1 \mathrm{~min}$, sendo a frequência controlada por um metrônomo. Por fim, durante o método de FNP, foi empregada a técnica de "sustentar-relaxar", a qual consistiu em $5 \mathrm{~s}$ de alongamento passivo, seguido de $5 \mathrm{~s}$ de contração isométrica submáxima ( 65\% do máximo; SHEARD \& PAINE, 2010) do músculo alongado, relaxamento do grupo muscular, e mais $20 \mathrm{~s}$ de alongamento 
passivo. A intensidade do alongamento foi pré-fixada no ponto máximo de desconforto (100\% do POD), ou seja, nível 100 em uma escala de 0 - 150 u.a. de percepção de esforço, desenvolvida e validada especificamente para exercícios de alongamento (maiores detalhes em FREITAS et al., 2015; APÊNDICE 1). O volume total de alongamento foi equalizado entre as condições, sendo realizado três séries de $30 \mathrm{~s}$ de alongamento com $30 \mathrm{~s}$ de intervalo, e um exercício para cada grupamento muscular (quadríceps femoral, isquiotibiais, glúteo máximo, e tríceps sural). Imediatamente após cada sessão de alongamento a escala CR-10, adaptada por Foster et al. (2001), foi apresentada a cada atleta para verificação da percepção subjetiva de esforço (PSE).

(a)
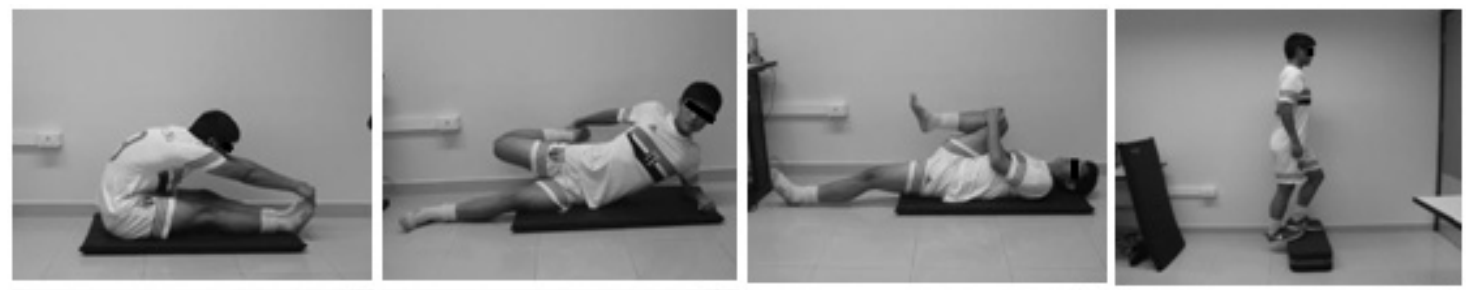

(b)
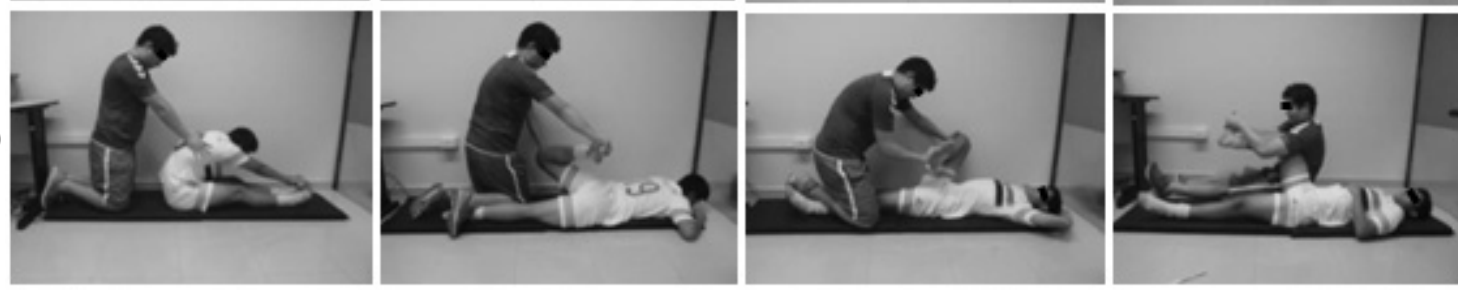

(c)
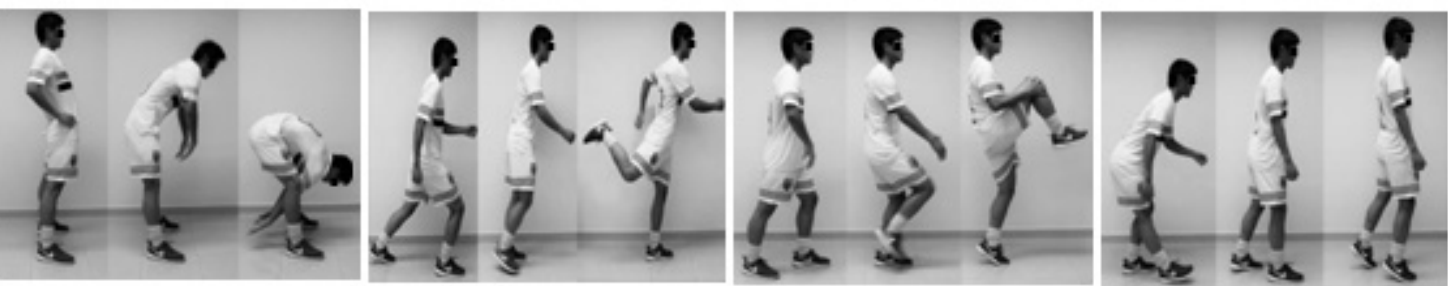

Figura 2. Sequência de exercícios de alongamento empregados durante o protocolo experimental para o método de alongamento ativo (a), ambos os métodos passivo e de facilitação neuromuscular proprioceptiva (b) e balístico (c). 


\subsubsection{Testes motores}

\subsubsection{Salto vertical, sentar e alcançar e sprint de 10-20-30 m}

Para o teste de salto vertical os participantes realizaram duas técnicas de execução, squat jump (SJ) e counter movement jump (CMJ). Para a técnica SJ os participantes partiram de uma posição estática de meio-agachamento, em aproximadamente $90^{\circ}$ de flexão de joelho e com as mãos posicionadas na cintura, e realizaram um salto vertical para a maior altura possível. Já para a técnica CMJ os participantes realizaram um movimento prévio de flexão e extensão, com uma transição rápida entre as fases de flexão e extensão, seguido de salto vertical para a maior altura possível. Em ambas as técnicas não foi permitida a flexão dos joelhos durante a fase aérea. O teste foi conduzido no equipamento Ergo Jump (Cefise ${ }^{\circledR}$, Nova Odessa Brasil), sendo mensurado as variáveis altura de salto $(\mathrm{H})$, potência pico absoluta (PP) e potência relativa a massa corporal (PR), a partir do tempo de vôo e aceleração da gravidade (BOSCO et al., 1995; SAYERS et al., 1999): $\mathbf{H}=\left(\right.$ tempo de $\mathbf{v o o}^{2} \times$ aceleração da gravidade $\left.\times \mathbf{8}^{-1}\right) ; \mathrm{PP}_{\mathrm{SJ}}=\left[60.7 \times\left(\mathrm{H}_{\mathrm{SJ}}\right)+45.3 \times(\right.$ massa corporal $)-$ 2055]; $P P_{\mathrm{CMJ}}=\left[51.9 \times\left(\mathrm{H}_{\mathrm{CMJ}}\right)+48.9 \times(\right.$ massa corporal $\left.)-2007\right] ; \mathrm{PR}=(\mathrm{PP} \div$ massa corporal). Além disso, foi calculado o índice de capacidade elástica (IE) (ARTEAGA et al., 2000): IE $(\%)=\left[\left(\mathbf{H}_{\mathbf{C M J}}-\mathbf{H}_{\text {SJ }}\right) \times \mathbf{1 0 0} \div \mathbf{H}_{\text {SJ }}\right]$.

Para avaliar a amplitude de movimento (ADM), foi utilizado o teste de sentar e alcançar, proposto originalmente por Wells e Dillon (1952), seguindo a padronização canadense do Canadian Standardized Test of Fitness (1986). Os participantes permanceram sentados, joelhos extendidos e com a planta dos pés apoiada no caixote de avaliação. Para a execução os participantes realizaram três movimentos preparatórios, 
deslocando-se no quarto movimento as mãos sobrepostas ao longo da régua, levando o tronco à frente até o ponto máximo de alcance possível e mantendo a posição por $2 \mathrm{~s}$.

Previamente ao teste de sprint, os participantes realizaram um aquecimento específico composto por três sprints de $30 \mathrm{~m}$ com intensidade submáxima, sendo progressivamente aumentada a intensidade e dado um intervalo de recuperação completo (2-3 min) entre as repetições. O teste foi conduzido a partir de uma posição inicial ereta e os tempos gastos para percorrer as distâncias de 10-20-30 m, foram determinados a partir do sistema de fotocélulas Fspeed (FEsistemas ${ }^{\circledR}$, Sorocaba Brasil). O procedimento foi realizado em campo de futebol com grama artificial, e todos os jogadores utilizavam materiais esportivos tradicionais de treinamentos e competições (uniforme do clube e chuteiras) durante a execução.

Para todos os procedimentos descritos foram realizadas três tentativas, sendo considerado para fins estatísticos apenas a melhor medida. O intervalo de recuperação foi de 1 min entre as tentativas e 5 min entre as técnicas $\mathrm{SJ}$ e $\mathrm{CMJ}$, para o teste de salto vertical (SMIRNIOTOU et al., 2008), e de 2-3 min entre as tentativas para o teste de sprint de $30 \mathrm{~m}$ (LITTLE; WILLIANS, 2005). Foi fornecido feedback a todos os participantes após cada tentativa, sobre a técnica de execução e performance, além de encorajamento verbal durante a execução.

\subsection{ANÁLISE ESTATÍSTICA}

Inicialmente foi testada e confirmada a normalidade dos dados pelo teste de Shapiro Wilk, e posteriormente realizadas análises descritivas (média \pm DP, valores mínimo e máximo). A fim de comparar os resultados dos testes motores aplicados no estudo nos momentos (pré vs pós) foi empregado teste-t student para amostras pareadas, 
e nas condições experimentais (alongamento AT, PA, BA, FNP ou CO) foi empregado ANOVA para medidas repetidas seguido pelo post hoc de Bonferroni. A magnitude do efeito (ES) foi calculada pelo Cohen's " $d$ " (COHEN, 1998): trivial $<0.1 ; 0.1 \geq$ small $\leq$ $0.20 ; 0.20 \geq$ moderate $\leq 0.50 ; 0.50 \geq$ large $\leq 0.80 ;$ very large $>0.80)$. A chance quantitativa (CQ) de efeito de aumento/positivo ou redução/negativo na performance foi interpretado qualitativamente como: almost certainly not $<1 \%$; very unlikely $1-5 \%$; unlikely 5-25\%; possible 25-75\%; likely 75-95\%; very likely 95-99\%; almost certain $>99 \%$. Se a chance de ocorrer aumento/positivo ou redução/negativo na performance forem ambas $>5 \%$ a diferença verdadeira foi interpretada como unclear (HOPKINS et al., 2009). Todos os procedimentos estatísticos foram realizados no software IBM® SPSS ${ }^{\circledR}$ Statistics, versão 20.0 (IBM Corporation ${ }^{\circledR}$ ), sendo adotado como critério de significância $\mathrm{p}<0.05$. 


\subsection{RESULTADOS}

A Tabela 3 apresenta os dados descritivos referentes a performance dos participantes do estudo em todos os testes motores aplicados.

Tabela 3. Caracterização de performance dos participantes do estudo.

\begin{tabular}{lcc}
\hline & Média \pm DP & Mínimo-Máximo \\
\hline $\mathrm{H}_{\mathrm{SJ}}(\mathrm{cm})$ & $41,98 \pm 4,50$ & $36,40-49,00$ \\
$\mathrm{PP}_{\mathrm{SJ}}(\mathrm{W})$ & $3534,94 \pm 317,15$ & $3076,69-4081,24$ \\
$\mathrm{PR}_{\mathrm{SJ}}\left(\mathrm{W} . \mathrm{kg}^{-1}\right)$ & $52,47 \pm 4,39$ & $47,23-58,47$ \\
$\mathrm{H}_{\mathrm{CMJ}}(\mathrm{cm})$ & $44,30 \pm 4,40$ & $37,20-52,80$ \\
$\mathrm{PP}_{\mathrm{CMJ}}(\mathrm{W})$ & $3563,74 \pm 297,65$ & $3185,34-4146,54$ \\
$\mathrm{PR}_{\mathrm{CMJ}}\left(\mathrm{W} . \mathrm{kg}^{-1}\right)$ & $52,88 \pm 3,65$ & $47,91-59,41$ \\
$\mathrm{ADM}(\mathrm{cm})$ & $41,42 \pm 4,64$ & $31,50-49,00$ \\
$10 \mathrm{~m}(\mathrm{~s})$ & $1,80 \pm 0,08$ & $1,68-1,96$ \\
$20 \mathrm{~m}(\mathrm{~s})$ & $3,10 \pm 0,10$ & $2,94-3,26$ \\
$30 \mathrm{~m}(\mathrm{~s})$ & $4,23 \pm 0,09$ & $4,17-4,44$ \\
\hline $\mathrm{Altura}$ &
\end{tabular}

Altura de salto (H); potência pico (PP); potência relativa (PR); squat jump (SJ); counter movement jump (CMJ); amplitude de movimento (ADM); tempo obtido nos dez metros $(10 \mathrm{~m})$, vinte metros $(20 \mathrm{~m})$ e trinta metros (30 m).

Nota: Foram considerados somente os dados da condição experimental controle (CO) para a elaboração da tabela. 
As Tabelas 4 e 5 apresentam as comparações da performance no salto vertical nas diferentes condições experimentais. Para o salto vertical com a utilização do SJ, foram encontradas médias significantemente menores de $\mathrm{H}$ na condição PA em comparação a $\mathrm{CO}(\mathrm{p}=0,02)$, sendo também encontradas reduções no delta de alteração da $\mathrm{H}$ na condição PA em comparação a BA $(p=0,04)$. Da mesma forma, foram encontradas reduções no delta de alteração da PP na condição PA em comparação a AT $(\mathrm{p}=0,04)($ Tab. 4). No salto vertical com a utilização do CMJ, também foram encontradas médias significantemente menores de $\mathrm{H}$ na condição PA em comparação a $\mathrm{CO}(\mathrm{p}=0,008)$. Adicionalmente, foram encontradas médias significantemente menores de H na condição FNP em comparação as condições CO $(p=0,01)$ e BA $(p=0,01)$, e ainda para esta condição foram obtidas menores médias de PP em comparação as condições $\mathrm{CO}(\mathrm{p}=0,03)$, AT $(\mathrm{p}=0,01)$ e BA $(\mathrm{p}=0,02)$. Além disso, foram encontradas médias significantemente menores de PR na condição FNP em comparação a BA (p = 0,01), e também reduções no delta de alteração da PR na condição FNP em comparação com BA ( $p=0,01)$ (Tab. 5). Não foram encontradas diferenças significativas no IE nas condições AT (Média \pm DP: 5,15 $\pm 4,75 \% ; \Delta=-0,53 \pm 5,51 \%$; ES =0,12; QC = $19 / 40 / 41), \mathrm{BA}(3,75 \pm 2,22 \% ; \Delta=-1,93 \pm 4,67 \% ; \mathrm{ES}=0,57 ; \mathrm{CQ}=3 / 20 / 77), \mathrm{PA}(5,88$ $\pm 4,00 \% ; \Delta=0,19 \pm 3,80 \%$; ES $=0,05 ; \mathrm{CQ}=26 / 57 / 17)$ e FNP $(2,16 \pm 4,81 \% ; \Delta=-$ $3,52 \pm 4,46 \% ; \mathrm{ES}=0,77 ; \mathrm{CQ}=0 / 3 / 97)$, em comparação a condição $\mathrm{CO}(5,68 \pm 4,24 \%)$ (não descritos na forma de tabela ou gráfico). 
Tabela 4. Efeitos agudos dos métodos de alongamento ativo (AT), balístico (BA), passivo (PA) e facilitação neuromuscular proprioceptiva (FNP) e condição controle $(\mathrm{CO})$ sobre a altura de salto $(\mathrm{H})$, potência pico $(\mathrm{PP})$ e potência relativa $(\mathrm{PR})$ no squat jump (SJ).

\begin{tabular}{|c|c|c|c|c|c|c|}
\hline & & $\mathrm{CO}$ & AT & $\mathbf{B A}$ & PA & FNP \\
\hline \multicolumn{7}{|l|}{ Teste } \\
\hline \multirow[t]{6}{*}{$\mathrm{H}_{\mathrm{sj}}(\mathrm{cm})$} & Média \pm DP & $41,98 \pm 4,50$ & $41,77 \pm 4,38$ & $42,06 \pm 3,72$ & $39,73 \pm 4,15^{\mathrm{a}}$ & $40,78 \pm 4,23$ \\
\hline & $\Delta(\%)$ & - & $-0,37 \pm 5,02$ & $0,48 \pm 4,96$ & $-5,21 \pm 4,30^{\mathrm{c}}$ & $-2,73 \pm 4,35$ \\
\hline & ES & - & 0,05 & 0,02 & 0,52 & 0,27 \\
\hline & & & trivial & trivial & large & moderate \\
\hline & CQ (\%) & - & $4 / 85 / 11$ & $8 / 86 / 5$ & $0 / 2 / 98$ & $0 / 33 / 67$ \\
\hline & & & unclear & unclear & very likely - & possibly - \\
\hline \multirow[t]{6}{*}{$\mathrm{PP}_{\mathrm{sj}}(\mathrm{W})$} & Média \pm DP & $3534,94 \pm 317,15$ & $3525,53 \pm 275,82$ & $3509,45 \pm 299,16$ & $3360,58 \pm 315,89$ & $3414,75 \pm 300,80$ \\
\hline & $\Delta(\%)$ & - & $0,04 \pm 6,98$ & $-0,58 \pm 4,61$ & $-4,80 \pm 5,47^{\mathrm{b}}$ & $-3,30 \pm 4,05$ \\
\hline & ES & - & 0,03 & 0,08 & 0,55 & 0,38 \\
\hline & & & trivial & trivial & large & moderate \\
\hline & CQ (\%) & - & $14 / 65 / 21$ & $4 / 76 / 20$ & $0 / 4 / 96$ & $0 / 12 / 88$ \\
\hline & & & unclear & unclear & very likely - & likely - \\
\hline \multirow[t]{6}{*}{$\mathrm{PR}_{\mathrm{sj}}\left(\mathrm{W} \cdot \mathrm{kg}^{-1}\right)$} & Média \pm DP & $52,48 \pm 4,40$ & $52,58 \pm 4,07$ & $52,85 \pm 3,53$ & $50,74 \pm 3,75$ & $51,73 \pm 3,94$ \\
\hline & $\Delta(\%)$ & - & $0,33 \pm 4,35$ & $0,88 \pm 3,34$ & $-3,18 \pm 3,51$ & $-1,33 \pm 2,90$ \\
\hline & $\mathrm{ES}$ & - & 0,02 & 0,09 & 0,42 & 0,17 \\
\hline & & & trivial & trivial & moderate & small \\
\hline & CQ $(\%)$ & - & $11 / 83 / 6$ & $14 / 84 / 1$ & 0/10/90 & $0 / 67 / 33$ \\
\hline & & & unclear & likely trivial & likely - & possibly - \\
\hline
\end{tabular}

"a" diferença significativa na comparação com a condição $\mathrm{CO}(\mathrm{p}<0.05)$; "b" diferença significativa na comparação com a condição AT ( $\mathrm{p}<0.05)$; "c" diferença significativa na comparação com a condição BA $(\mathrm{p}<0.05)$.

Nota: Os valores de effect size (ES) e chances quantitativas (CQ) foram obtidos a partir da média e desvio padrão da $\mathrm{H}, \mathrm{PP}$ e $\mathrm{PR}$ em cada condição envolvendo alongamento (AT, BA, PA e FNP) em comparação à condição CO, sendo representado no caso do CQ como o percentual de chance de efeito positivo/trivial/negativo, respectivamente. 
Tabela 5. Efeitos agudos dos métodos de alongamento ativo (AT), balístico (BA), passivo (PA) e facilitação neuromuscular proprioceptiva (FNP) e condição controle $(\mathrm{CO})$ sobre a altura de salto $(\mathrm{H})$, potência pico $(\mathrm{PP})$, potência relativa $(\mathrm{PR})$ no counter movement jump (CMJ).

\begin{tabular}{|c|c|c|c|c|c|c|}
\hline & & $\mathrm{CO}$ & AT & BA & PA & FNP \\
\hline Teste & & & & & & \\
\hline \multirow{6}{*}{$\mathrm{H}_{\mathrm{CMJ}}(\mathrm{cm})$} & Média \pm DP & $44,30 \pm 4,40$ & $43,93 \pm 5,13$ & $43,65 \pm 4,16$ & $42,07 \pm 4,68^{\mathrm{a}}$ & $41,58 \pm 3,92^{\mathrm{a}, \mathrm{c}}$ \\
\hline & $\Delta(\%)$ & - & $-0,89 \pm 4,83$ & $-1,26 \pm 5,75$ & $-5,05 \pm 3,80$ & $-5,98 \pm 4,76^{\mathrm{c}}$ \\
\hline & ES & - & 0,08 & 0,15 & 0,49 & 0,65 \\
\hline & & & trivial & small & moderate & large \\
\hline & CQ $(\%)$ & - & $2 / 80 / 17$ & $2 / 63 / 34$ & 0/1/99 & 0/1/99 \\
\hline & & & likely trivial & possibly - & very likely - & very likely - \\
\hline \multirow[t]{6}{*}{$\mathrm{PP}_{\mathrm{CMJ}}(\mathrm{W})$} & Média \pm DP & $3563,74 \pm 297,65$ & $3560,44 \pm 274,57$ & $3509,27 \pm 286,27$ & $3418,74 \pm 325,21$ & $3383,44 \pm 304,28^{\mathrm{a}, \mathrm{b}, \mathrm{c}}$ \\
\hline & $\Delta(\%)$ & - & $0,14 \pm 6,32$ & $-1,44 \pm 3,95$ & $-4,02 \pm 5,12$ & $-5,00 \pm 4,63^{\mathrm{b}, \mathrm{c}}$ \\
\hline & ES & - & 0,01 & 0,18 & 0,46 & 0,59 \\
\hline & & & trivial & small & moderate & large \\
\hline & CQ (\%) & - & $15 / 67 / 18$ & $1 / 58 / 41$ & 0/7/92 & $0 / 2 / 98$ \\
\hline & & & unclear & unclear & likely - & very likely - \\
\hline \multirow[t]{6}{*}{$\mathrm{PR}_{\mathrm{CMJ}}\left(\mathrm{W} \cdot \mathrm{kg}^{-1}\right)$} & Média \pm DP & $52,88 \pm 3,65$ & $53,10 \pm 3,91$ & $52,85 \pm 3,32$ & $51,60 \pm 3,57$ & $51,20 \pm 3,03^{\mathrm{c}}$ \\
\hline & $\Delta(\%)$ & - & $0,48 \pm 4,74$ & $0,04 \pm 3,28$ & $-2,35 \pm 3,90$ & $-3,07 \pm 3,43^{c}$ \\
\hline & ES & - & 0,05 & 0,008 & 0,35 & 0,50 \\
\hline & & & trivial & trivial & moderate & moderate \\
\hline & CQ (\%) & - & $21 / 70 / 8$ & $7 / 86 / 8$ & $0 / 20 / 80$ & $0 / 6 / 94$ \\
\hline & & & unclear & unclear & likely - & likely - \\
\hline
\end{tabular}

"a" diferença significativa na comparação com a condição $\mathrm{CO}(\mathrm{p}<0.05)$; "b" diferença significativa na comparação com a condição AT ( $\mathrm{p}<0.05)$; "c" diferença significativa na comparação com a condição BA $(\mathrm{p}<0.05)$.

Nota: Os valores de effect size (ES) e chances quantitativas (CQ) foram obtidos a partir da média e desvio padrão da $\mathrm{H}, \mathrm{PP}$ e PR em cada condição envolvendo alongamento (AT, BA, PA e FNP) em comparação à condição CO, sendo representado no caso do CQ como o percentual de chance de efeito positivo/trivial/negativo, respectivamente. 
A Tabela 6 apresenta as comparações da ADM entre os momentos pré e pós condições experimentais, e a PSE relatada nas condições envolvendo alongamento. Foram encontradas médias significantemente maiores de ADM nas condições alongamento AT $(p=0,00)$, BA $(p=0,00), \operatorname{PA}(p=0,001)$ e FNP $(p=0,00)$, no momento pós em comparação ao pré. Da mesma forma, foram encontrados aumentos no delta de alteração da ADM nas condições AT $(p=0,002), \operatorname{BA}(p=0,01), \operatorname{PA}(p=0,02)$ e FNP ( $p=0,006)$, quando comparado a condição CO (Tab. 6). Para a PSE, escores significantemente maiores foram relatados após as sessões de alongamento PA quando comparado ao AT $(\mathrm{p}=0,01)$ e BA $(\mathrm{p}=0,01)$, e também após FNP em comparação ao $\operatorname{AT}(p=0,002)$ e BA $(p=0,003)($ Tab. 6).

A Tabela 5 apresenta as comparações do tempo obtido no sprint de 10-20-30 m para as diferentes condições experimentais. Não foram encontradas diferenças significativas nos tempos obtidos nas distâncias de 10-20-30 m, entre as condições experimentais e condição controle (Tab. 7). 
Tabela 6. Efeitos agudos dos métodos de alongamento ativo (AT), balístico (BA), passivo (PA) e facilitação neuromuscular proprioceptiva (FNP) e condição controle (CO) sobre a amplitude de movimento (ADM) e percepção subjetiva de esforço (PSE).

\begin{tabular}{|c|c|c|c|c|c|c|}
\hline & & $\mathrm{CO}$ & AT & $\mathbf{B A}$ & PA & FNP \\
\hline \multicolumn{7}{|l|}{ Teste } \\
\hline \multirow[t]{7}{*}{$\mathrm{ADM}(\mathrm{cm})$} & Média \pm DP (pré) & $41,42 \pm 4,64$ & $40,58 \pm 5,93$ & $40,71 \pm 5,49$ & $40,29 \pm 5,65$ & $39,75 \pm 6,01$ \\
\hline & Média \pm DP (pós) & $41,75 \pm 4,55$ & $42,29 \pm 6,29 *$ & $42,54 \pm 5,11 *$ & $42,50 \pm 5,59 *$ & $42,21 \pm 5,59^{*}$ \\
\hline & $\Delta(\%)$ & $0,85 \pm 1,32$ & $4,19 \pm 2,25^{\mathrm{a}}$ & $4,73 \pm 3,44^{\mathrm{a}}$ & $5,67 \pm 4,76^{\mathrm{a}}$ & $6,51 \pm 4,05^{\mathrm{a}}$ \\
\hline & $\mathrm{ES}$ & 0,07 & 0,28 & 0,34 & 0,39 & 0,42 \\
\hline & & trivial & moderate & moderate & moderate & moderate \\
\hline & CQ (\%) & $0 / 100 / 0$ & $94 / 6 / 0$ & $96 / 4 / 0$ & $97 / 3 / 0$ & $100 / 0 / 0$ \\
\hline & & almost certain trivial & likely + & very likely + & very likely + & almost certain + \\
\hline PSE (u.a.) & Média \pm DP & - & $5,42 \pm 1,68$ & $6,17 \pm 1,85$ & $8,50 \pm 1,31^{\mathrm{b}, \mathrm{c}}$ & $8,83 \pm 0,94^{b, c}$ \\
\hline
\end{tabular}

“*” diferença significativa na comparação com o momento pré sessão de alongamento ( $<0.05)$; "a" diferença significativa na comparação com a condição CO $(\mathrm{p}<0.05)$. "b" diferença significativa na comparação com a condição AT $(\mathrm{p}<0.05)$; "c" diferença significativa na comparação com a condição BA $(\mathrm{p}<0.05)$.

Nota: Os valores de effect size (ES), delta de alteração $(\Delta)$ e de chances quantitativas (CQ) foram obtidos a partir da média e desvio padrão da ADM na comparação entre os momentos pré e pós sessão de alongamento. Os valores de CQ representam o percentual de chance de efeito positivo/trivial/negativo, respectivamente. 
Tabela 7. Efeitos agudos dos métodos de alongamento ativo (AT), balístico (BA), passivo (PA) e facilitação neuromuscular proprioceptiva (FNP) e condição controle (CO) sobre o tempo obtido nas distâncias de dez metros $(10 \mathrm{~m})$, vinte metros $(20 \mathrm{~m})$, e trinta metros $(30 \mathrm{~m})$ em teste de sprint.

\begin{tabular}{|c|c|c|c|c|c|c|}
\hline & & $\mathrm{CO}$ & AT & $\mathbf{B A}$ & PA & FNP \\
\hline \multicolumn{7}{|l|}{ Teste } \\
\hline \multirow[t]{6}{*}{$10 \mathrm{~m}(\mathrm{~s})$} & Média \pm DP & $1,80 \pm 0,08$ & $1,81 \pm 0,07$ & $1,82 \pm 0,08$ & $1,81 \pm 0,09$ & $1,84 \pm 0,07$ \\
\hline & $\Delta(\%)$ & - & $0,24 \pm 5,31$ & $0,90 \pm 5,32$ & $0,36 \pm 5,73$ & $2,27 \pm 6,27$ \\
\hline & ES & - & 0,13 & 0,25 & 0,11 & 0,53 \\
\hline & & & small & moderate & small & large \\
\hline & CQ & - & $29 / 47 / 25$ & $45 / 42 / 13$ & $33 / 42 / 24$ & $73 / 22 / 6$ \\
\hline & & & unclear & unclear & unclear & unclear \\
\hline \multirow[t]{6}{*}{$20 \mathrm{~m}(\mathrm{~s})$} & Média \pm DP & $3,10 \pm 0,10$ & $3,11 \pm 0,10$ & $3,14 \pm 0,11$ & $3,12 \pm 0,13$ & $3,16 \pm 0,16$ \\
\hline & $\Delta(\%)$ & - & $0,17 \pm 2,61$ & $1,08 \pm 2,90$ & $0,48 \pm 4,11$ & $1,95 \pm 5,09$ \\
\hline & ES & - & 0,10 & 0,38 & 0,17 & 0,44 \\
\hline & & & small & moderate & small & moderate \\
\hline & CQ (\%) & - & $23 / 64 / 14$ & $65 / 32 / 5$ & $41 / 42 / 18$ & $79 / 17 / 5$ \\
\hline & & & unclear & unclear & unclear & unclear \\
\hline \multirow[t]{6}{*}{$30 \mathrm{~m}(\mathrm{~s})$} & Média \pm DP & $4,23 \pm 0,09$ & $4,31 \pm 0,12$ & $4,35 \pm 0,14$ & $4,32 \pm 0,17$ & $4,42 \pm 0,26$ \\
\hline & $\Delta(\%)$ & - & $-0,17 \pm 2,05$ & $0,71 \pm 2,53$ & $0,13 \pm 3,10$ & $2,24 \pm 5,16$ \\
\hline & ES & - & 0,75 & 1,02 & 0,66 & 0,97 \\
\hline & & & large & very large & large & very large \\
\hline & CQ (\%) & - & $29 / 47 / 25$ & $45 / 42 / 13$ & $33 / 42 / 24$ & $73 / 22 / 6$ \\
\hline & & & unclear & unclear & unclear & unclear \\
\hline
\end{tabular}

Nota: Os valores de effect size (ES) e chances quantitativas (CQ) foram obtidos a partir da média e desvio padrão dos tempos obtidos nos 10, 20 e $30 \mathrm{~m}$ em cada condição envolvendo alongamento (AT, BA, PA e FNP) em comparação à condição $\mathrm{CO}$, sendo representado no caso do $\mathrm{CQ}$ como o percentual de chance de efeito positivo/trivial/negativo, respectivamente. 


\subsection{DISCUSSÃO}

O objetivo do presente estudo foi comparar os efeitos agudos dos métodos de alongamento AT, PA, BA e FNP, sobre a performance nos testes motores de salto vertical, sentar e alcançar e sprint de 10-20-30 m em jovens jogadores de futebol treinados. Como principais resultados, relata-se reduções da performance nos testes de salto vertical após as sessões de alongamento PA e FNP, possivelmente em função das maiores intensidades alcançadas nestes métodos. Além disso, foram encontrados aumentos em flexibilidade após todas as condições envolvendo alongamento.

Bradley, Olsen e Portas (2007) ao comparar diferentes métodos de alongamento (BA, PA e FNP), encontraram reduções significativas na performance durante o CMJ e SJ após as sessões de alongamento PA e FNP. De forma semelhante, Kirmizigil, Ozcaldiran e Colakoglu (2014) compararam os efeitos da combinação de diferentes métodos de alongamento (BA, FNP + BA e FNP + PA) sobre a performance no CMJ, encontrando reduções significativas após a sessão de alongamento combinando os métodos FNP + PA. Ambos os resultados corroboram com os achados do presente estudo e indicam extensa possibilidade de efeitos negativos na peformance do salto vertical, após as sessões de alongamento envolvendo os métodos PA e FNP, seja de forma isolada ou combinada.

Estas reduções da performance física estão associadas a fatores neurais, mecânicos ou uma combinação entre ambos (FOWLES; SALE; MACDOUGALL, 2000; RYAN et al., 2008b; CRAEMER et al., 2007). Um dos mecanismos responsáveis responsáveis por estas reduções refere-se a diminuição da capacidade de recrutamento de unidades motoras, devido a alta atividade reflexa promovida pelo alongamento (FOWLES; SALE; MACDOUGALL, 2000). Além disso, estas reduções da 
performance física podem ser atribuídas a redução do stiffness da unidade músculotendão (RYAN et al., 2008b), a alterações na relação tensão-comprimento (CRAEMER et al., 2007), ou mesmo a um mecanismo inibitório central (CRAEMER et al., 2005).

Em nosso estudo, escores significativamente superiores de PSE foram relatadas após as sessões de alongamento envolvendo os métodos PA (8,50 u.a) e FNP (8,83 u.a.) em comparação aos métodos AT (5,42 u.a.) e BA (6,17 u.a.), sugerindo uma maior intensidade nestas condições. Young, Elias e Power (2006) compararam os efeitos da manipulação das variáveis volume e intensidade de alongamento e encontraram reduções significativas na performance do Drop Jump nos maiores volumes de alongamento (4-8 séries x 30 s a 100\% do POD), em comparação com menor volume (2 séries x 30 s a 100\% do POD). Por outro lado, quando o volume foi mantido e a intensidade reduzida (4 séries x 30 s a 90\% do POD), não foram encontradas alterações significativas (YOUNG; ELIAS; POWER, 2006). Logo, o fato do volume entre os diferentes métodos de alongamento estarem equalizados ( 3 séries x 30 s de alongamento), leva a crer que as reduções na performance física encontradas em nosso estudo podem ter sido intermediadas pelas altas intensidades de alongamento alcançadas nos métodos PA e FNP.

Adicionalmente, foram encontrados aumentos significativos na ADM em todas as condições envolvendo alongamento. $\mathrm{O}$ que sugere que todos os métodos de alongamento empregados podem ser utilizados para aumentar o nível de flexibilidade de forma aguda. Entretanto, na comparação do delta de alteração da $\mathrm{ADM}$ entre as condições experimentais (AT, BA, PA e FNP) não foram verificadas diferenças significantes. Resultados conflitantes tem sido encontrados na literatura sobre qual dos métodos de alongamento promovem maiores ganhos de forma aguda em ADM (O'HORA et al., 2011; BARROSO et al., 2012; MADDIGAN et al., 2012; PERRIER; 
PAVOL; HOFFMAN, 2011; BACURAU et al., 2009). Enquanto alguns estudos demonstram maiores ganhos após a utilização do método FNP, quando comparado ao AT (O’HORA et al., 2011; BARROSO et al., 2012), outros demonstram ganhos similares (BEEDLE; MANN, 2007; MADDIGAN et al., 2012). Da mesma forma, para o método BA tem sido demonstrados ganhos similares ao AT (BARROSO et al., 2012; PERRIER; PAVOL; HOFFMAN, 2011), enquanto que outros demonstraram uma menor eficiência (BACURAU et al., 2009). Portanto, mais estudos são necessários para avaliar quais métodos são mais efecientes para aumentar os níveis de flexibilidade de forma aguda.

Conforme demonstrado, os métodos de alongamento AT, BA, PA e FNP permitem que diferentes níveis de intensidade sejam alcançadas, oque influencia nos mecanismos responsáveis pelo aumento da ADM. Apesar dos mecanismos precisos ainda não estarem muito bem estabelecidos na literatura, os estudos apontam que os aumentos em ADM após as sessões de alongamento PA e FNP estão associados ao aumento da tolerância ao alongamento (MAGNUSSON et al., 1996a; MITCHELL et al., 2009), redução do stiffness da unidade músculo-tendão (MORSE et al., 2001; MAGNUSSON et al., 1996b), e para o FNP também tem sido apontado a inibição autógena (HINDLE et al., 2012). Enquanto que os aumentos em ADM após as sessões de alongamento AT e BA parecem estar associados ao aumento da tolerância ao alongamento (MAGNUSSON et al., 1996a) e a redução do stiffness da unidade músculo-tendão (MORSE et al., 2001; HERDA et al., 2013).

Para o teste de sprint não foram encontradas alterações significativas na perfomance nos 10-20-30 $\mathrm{m}$ após os diferentes métodos de alongamento. Em contradição, Alemdaroglu, Koklu e Koz (2016) encontraram reduções na performance no sprint de $10 \mathrm{~m}$ e $20 \mathrm{~m}$ após sessões de alongamento empregando os métodos PA e 
FNP, e inalteração após o método BA. Adicionalmente, Gelen (2010) encontrou redução significativa após o método $\mathrm{AT}$, aumento após o $\mathrm{BA}$ e inalteração após a combinação de AT + BA, na performance do sprint de $30 \mathrm{~m}$, drible e velocidade do chute no futebol. Por outro lado, Avloniti et al. (2014) recentemente demonstraram que o estado de treinamento e volume de alongamento podem influenciar as repostas do alongamento na performance física. Os autores apontaram que atletas com nível de performance moderado $(10 \mathrm{~m}>1,82 \mathrm{~s}$ e $20 \mathrm{~m}>3,01 \mathrm{~s})$ parecem se beneficiar de alongamentos de curta duração $(<30 \mathrm{~s})$, enquanto atletas com alto nível de performance $(10 \mathrm{~m}<1,82 \mathrm{~s}$ e $20 \mathrm{~m}<3,01 \mathrm{~s})$ são menos responsivos (AVLONITI et al., 2014). Na confrontação entre os dados descritivos de performance encontrados no presente estudo com os a da literatura científica, é possível verificar que os tempos médios obtidos nos $10 \mathrm{~m}(1,80 \mathrm{~s}), 20 \mathrm{~m}(3,10 \mathrm{~s})$ e $30 \mathrm{~m}(4,23 \mathrm{~s})$, assim como a H no CMJ (44,30 cm), estão muito próximos dos valores de referência de alta performance supracitado (AVLONITI et al., 2014), de jovens jogadores de futebol de elite (NEEDHAM; MORSE; DEGENS, 2009) e até mesmo melhores que profissionais da terceira divisão da Turquia (GELEN, 2010). Portanto, uma hipótese explicativa é que o estado de treinamento (alto nível de treinamento) dos atletas que participaram do estudo e o volume de alongamento (3 séries x $30 \mathrm{~s}$ ), tenham interferido nos resultados evitando possíveis efeitos positivos ou negativos na performance no sprint e salto vertical após os métodos AT e BA.

Adicionalmente, o fato de ter sido encontradas alterações da performance no salto vertical nas condições PA e FNP e o mesmo não se replicar na performance do sprint, leva a crer que outras variáveis podem ter interferido nos resultados. Alemdaroglu, Koklu, Koz (2016) demonstraram que o efeito negativo causado pelos exercícios de alongamento na força muscular é apenas transitório, voltando aos níveis normais após cerca de 15-20 min. Além disso, Taylor et al. (2009) demonstraram que 
quando o alongamento é feito de forma combinada com aquecimento específico da modalidade esportiva o efeito de redução na performance física é revertido. Logo, é possivel que o intervalo entre o término da sessão de alongamento e a realização do teste de sprint $(\sim 15 \mathrm{~min})$ tenha sido o suficiente para que o efeito negativo transitório do alongamento na performance física tenha se dissipado, ou mesmo, que a inclusão do aquecimento específico tenha revertido este efeito.

Como limitação, o presente estudo não incluiu instrumentos de medidas que pudessem identificar de forma direta os mecanismos neurofisiológicos mencionados como possíveis responsáveis pela redução da performance física após os diferentes métodos de alongamento. Portanto, estudos futuros devem incluir avaliações que permitam comparar a influência de fatores mecânicos, neurais ou da associação entre ambos na performance após os métodos de alongamento AT, BA, PA e FNP.

\subsection{APLICAÇÕES PRÁTICAS}

Com base nos resultados encontrados em nosso estudo, os métodos AT e BA não promovem efeitos negativos na performance do salto vertical e sprint. Já os métodos PA e FNP, devem ser vistos com cautela, especialmente pelas maiores intensidades alcançadas nestes métodos e pela extensa possibilidade de efeitos negativos posteriores na performance em atividades que envolvam salto vertical. Dessa forma, preparadores físicos no futebol podem incluir sessões de alongamento AT e BA semelhantes às do presente estudo (3 séries x $30 \mathrm{~s}$ de alongamento à $100 \%$ do POD), em suas rotinas de aquecimento durante sessões de treinamento, permitindo aumentar os níveis de flexibilidade de seus jogadores sem promover efeitos negativos posteriores na performance em atividades de salto vertical e sprint. 
CAPÍTULO 3

Estudo 2: EFEITOS AGUDOS DOS MÉTODOS DE ALONGAMENTo ATIVO, BALÍstico, PASSivo E DE FACILITAÇÃO NEUROMUSCULAR PROPRIOCEPTIVA EM PARÂMETROS NEUROMUSCULARES 


\subsection{RESUMO}

O objetivo do presente estudo foi comparar os efeitos agudos dos métodos de alongamento ativo (AT), balístico (BA), passivo (PA) e facilitação neuromuscular proprioceptiva (FNP) sobre a performance em testes de força máxima e em parâmetros neuromusculares em jovens jogadores de futebol. Participaram do estudo 12 jogadores de futebol treinados (média \pm DP: idade 17,67 $\pm 0,87$ anos; estatura 1,76 $\pm 0,06 \mathrm{~m}$; massa corporal $67,38 \pm 4,82 \mathrm{~kg} ; 1 \mathrm{RM}$ relativo $2,33 \pm 0,24$ u.a.), sendo submetidos a dois protocolos experimentais 1 e 2 . Durante o protocolo 1 , foi avaliada a carga máxima utilizando-se do teste de uma repetição máxima (1 RM) para o exercício agachamento completo. Durante o protocolo 2, foi realizada uma avaliação neuromuscular por meio da técnica do twitch interpolation, sendo monitoradas as variáveis força pico, taxa de desenvolvimento de força, amplitude da twitch superimposed e twitch potentiated, e percentual de ativação voluntária referentes so sinal de força, e root mean square, MWave e razão RMS/M-Wave do sinal eletromigráfico (EMG) dos músculos vasto lateral e reto femoral, durante contrações voluntária isométrica máxima (CVM) de extensão de joelho. Não foram encontradas alterações significativas na performance do teste de 1 RM e CVM. Além disso, também não foram encontradas alterações significativas nas variáveis relativas ao sinal EMG. Dessa forma, sessões de alongamento semelhantes a do estudo [3 séries x $30 \mathrm{~s}$ de alongamento à $100 \%$ do point of discomfort (POD)], independente do método de alongamento empregado, parecem não promover efeitos negativos posteriores na performance da força máxima e em parâmetros neuromusculares em atletas treinados.

Palavras chave: Twitch interpolation; flexibilidade; força máxima; futebol. 


\subsection{INTRODUÇÃO}

Apesar do mecanismo preciso responsável pela diminuição da força após exercícios de alongamento ainda não estar bem estabelecido, efeito denominado como "stretching-induced force deficit" (RYAN et al., 2008a), alguns pesquisadores tem sugerido que sua causa possa estar associada a fatores neurais, musculares ou mesmo a uma combinação entre ambos (FOWLES; SALE; MACDOUGALL, 2000; CRAMER et al., 2005; CRAMER et al., 2007; COSTA et al., 2010).

A literatura científica têm demonstrado que uma sessão aguda de alongamento é capaz de reduzir a capacidade de produção de força máxima e a ativação muscular (FOWLES; SALE; MACDOUGALL, 2000; CRAEMER et al., 2005; CRAEMER et al., 2007). Fowles, Sale e Macdougall (2000) analisaram participantes ativos recreacionistas submetidos a uma avaliação neuromuscular através da técnica do twitch interpolation. Os autores demonstraram que podem ocorrer reduções de $25 \%$ na contração voluntária isométrica máxima (CVM) e de 15\% na amplitude do sinal eletromiográfico (EMG), após uma sessão de 30 min de alongamento passivo para flexores plantares. A partir do método proposto por Duchateau (1995), os autores concluíram que aproximadamente $60 \%$ da redução da força pode ter sido mediadas por fatores neurais (FOWLES; SALE; MACDOUGALL, 2000).

Craemer et al. (2005), analisaram o efeito do alongamento passivo sobre o pico de torque e EMG de músculos extensores de joelho. O design experimental incluía ainda, que um dos membros fosse submetido ao alongamento enquanto o outro era utilizado como controle. Interessantemente, os autores encontraram reduções significativas da força concêntrica e EMG em ambas as pernas, alongada e não alongada. Diante disso, os autores sugeriram que as reduções de força induzida pelos 
exercícios de alongamento possam, em parte, serem atribuídas a um mecanismo inibitório central, o que ainda não foi identificado (CRAEMER et al., 2005).

Por outro lado, alguns estudos têm indicado que fatores mecânicos também possam explicar a redução da força ao alongamento. Fowles, Sale e Macdougall (2000) relataram em seu estudo que grande parte da redução de força possa ser atribuída a alterações nas propriedades mecânicas da unidade músculo-tendão, e não somente a fatores neurais. Os autores sugerem que os exercícios de alongamentos possam diminuir o grau de rigidez ou stiffness dos tecidos conectivos, que auxiliam na transferência da força do tecido muscular ao ósseo (RYAN et al., 2008b; FOWLES; SALE; MACDOUGALL, 2000).

Além disso, Craemer et al. (2007) relataram que uma sessão aguda de alongamentos para extensores de joelho é capaz de "achatar" a curva do torque em função do ângulo, avaliado em aparelho isocinético. Os autores hipotetizaram que o alongamento pode ser capaz de diminuir o pico de torque, mas ao mesmo tempo, permitir que elevados torques possam ser produzidos nos extremos da amplitude de movimento. Dessa forma, os autores sugerem que o alongamento possa afetar a relação tensão-comprimento do sarcômero (CRAMER et al., 2007).

No entanto, apesar das diversas especulações percebe-se que a maioria dos estudos disponíveis na literatura científica se restringem ao método de alongamento passivo (FOWLES; SALE; MACDOUGALL, 2000; COSTA et al., 2010; TRAJANO et al., 2013; TRAJANO et al., 2014), enquanto para a extensão do nosso conhecimento nenhum estudo foi realizado incluindo os diversos métodos de alongamento [i.e., Ativo (AT), Passivo (PA), Balístico (BA) e facilitação neuromuscular proprioceptiva (FNP)], assim como os possíveis mecanismos neurofisiológicos associados à alterações da performance da força máxima. Além disso, nestes estudos supracitados o tempo de 
manutenção da posição alongada (e.g., 30-300 s), assim como o tempo total da sessão de alongamento (e.g., 20-33 min), se baseiam em protocolos experimentais realizados com modelo animal, tendo aplicação limitada para os exercícios de alongamento realizados no contexto da performance atlética (FOWLES; SALE; MACDOUGALL, 2000). Adicionalmente, a maioria dos estudos incluem avaliações em aparelhos como dinamômetro isocinético, cadeira extensora e leg press (FOWLES; SALE; MACDOUGALL, 2000; CRAEMER et al., 2005; CRAEMER et al., 2007; BACURAU et al., 2009; BARROSO et al., 2012; TRAJANO et al., 2013; TRAJANO et al., 2014), enquanto a maioria dos atletas utilizam exercícios de peso livre como o agachamento durante sessões de treinamento.

Partindo deste pressuposto, o objetivo do presente estudo foi comparar os efeitos agudos dos métodos de alongamento AT, BA, PA e FNP sobre parâmetros associados a força e EMG em testes de uma repetição máxima (1 RM) no exercício agachamento e CVM de extensão de joelho.

\subsection{MATERIAIS E MÉTODOS}

\subsubsection{Procedimento experimental}

A fim de se comparar o comportamento da força máxima frente aos diferentes métodos de alongamento, e inferir sobre possíveis fatores que atuam interferindo na performance física (e.g., fatores neurais, musculares, ou ambos), foram realizados dois protocolos experimentais. Os participantes foram avaliados em dez dias separados, cinco dias para cada protocolo, e as avaliações ocorreram sempre no mesmo período do dia (8:00-11:00 a.m.). As temperaturas médias diárias foram: Protocolo 1 - dia 1, $29^{\circ}$ $\mathrm{C}$; dia $2,29^{\circ} \mathrm{C}$; dia $3,30{ }^{\circ} \mathrm{C}$; dia $4,30{ }^{\circ} \mathrm{C}$; dia $5,31{ }^{\circ} \mathrm{C}$; Protocolo 2 - dia $1,32^{\circ} \mathrm{C}$; dia 2 , 
$33{ }^{\circ} \mathrm{C}$; dia $3,30{ }^{\circ} \mathrm{C}$; dia $4,32{ }^{\circ} \mathrm{C}$; dia $5,30{ }^{\circ} \mathrm{C}$ (recordatório climático do Instituto de Pesquisas Meteorológicas, IPMet, Brasil).

Durante o protocolo 1, os participantes inciaram com um aquecimento geral composto por $5 \mathrm{~min}$ de corrida em esteira ergométrica, a uma velocidade correspondente a $9 \mathrm{~km} \cdot \mathrm{h}^{-1}$, seguido por uma medida inicial de flexibilidade. Em seguida, cada participante passou por uma das cinco condições do estudo (condição experimental alongamento AT, PA, BA ou FNP, ou condição controle [CO]), em ordem randomizada e com intervalo mínimo de 48 h entre cada condição. Nas condições envolvendo alongamento, foi realizada uma sessão de alongamento com 15 min de duração total, enquanto que na condição $\mathrm{CO}$ os participantes permaneceram o mesmo tempo em repouso. Por fim, foi realizada uma medida final de flexibilidade, seguido pelo teste de uma repetição máxima (1 RM) no exercício agachamento completo (Fig. 3a).

Durante o protocolo 2, a mesma sequência de eventos foi adotada, aquecimento geral, avaliações de flexibilidade e condições experimentais. No entanto, foi realizado uma avaliação neuromuscular em dois momentos, antes e após condições experimentais (Fig. 3b). Todas as sessões de avaliação neuromuscular foram iniciadas com exercícios de aquecimento específico, nas quais foram realizadas duas séries de três extensões isométricas submáximas de joelho $\left(90^{\circ}\right.$ de flexão de joelho e quadril), com $3 \mathrm{~s}$ de duração e intervalo de $10 \mathrm{~s}$ e $30 \mathrm{~s}$ entre as repetições e séries, respectivamente. $\mathrm{O}$ protocolo de avaliação neuromuscular foi composto por contrações isométricas voluntária máxima $(\mathrm{CVM})$ de extensão de joelho, e CVMs associadas à estimulação elétrica neuromuscular, por meio da técnica do twitch interpolation (Fig. 3c). 
(a)

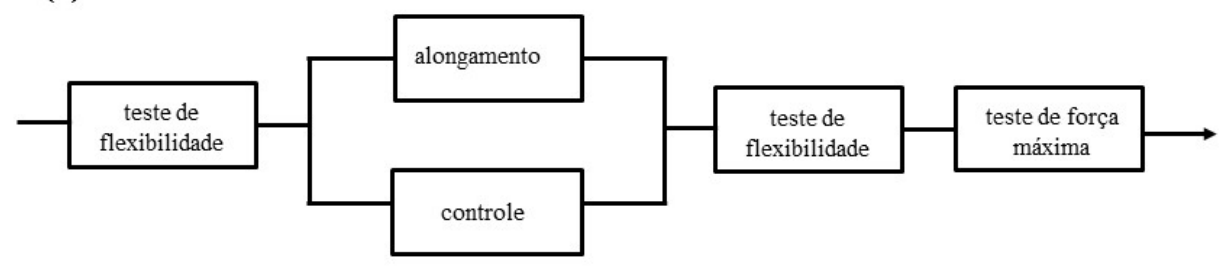

(b)

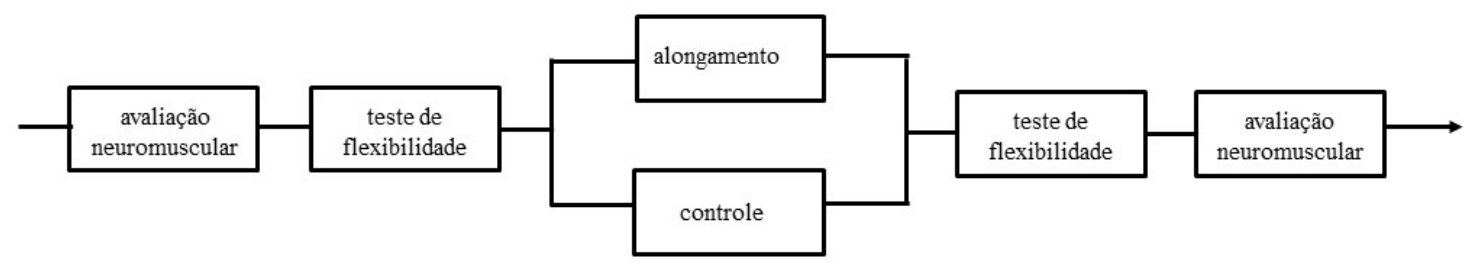

(c) $\square \mathrm{CVM}$ ßE

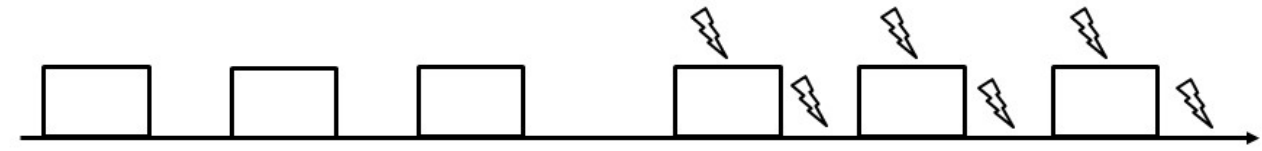

Figura 3. a) Desenho experimental do protocolo 1. b) Desenho experimental do protocolo 2. c) Sequência de eventos durante o protocolo experimental 2. Contração voluntária isométrica máxima (CVM); Estímulo elétrico neuromuscular (EE).

\subsubsection{Participantes}

Participaram do estudo 12 jogadores de futebol treinados (média \pm DP: idade $17,67 \pm 0,87$ anos; estatura $1,76 \pm 0,06 \mathrm{~m}$; massa corporal $67,38 \pm 4,82 \mathrm{~kg}$; \%gordura $6,80 \pm 2,43 \% ; \mathrm{VO}_{2}$ máx 49,76 $\pm 2,12 \mathrm{~mL} . \mathrm{kg}^{-1} \cdot \mathrm{min}^{-1} ; 1 \mathrm{RM}$ relativo 2,18 $\pm 0,25$ u.a.), pertencentes a categoria de base de uma equipe da terceira divisão da liga nacional chinesa. Foram utilizados como critérios de inclusão e exclusão, não possuir lesões neuromusculares e possuir mínimo de um ano de experiência em treinamento de força. O presente estudo foi aprovado por um comitê de ética em pesquisa Institucional $\left(\mathrm{n}^{\mathrm{o}}\right.$ do protocolo: 1050789), sendo realizado de acordo com as normas previstas pela declaração de Helsinki. 


\subsubsection{Sessão de alongamento}

A sessão de alongamento foi desenvolvida com base em quatro exercícios principais, um para cada grupamento muscular (músculos isquitibiais, quadríceps, glúteo máximo e tríceps sural), com pequenas variações em função do método de alongamento empregado (Fig. 2 do estudo 1, e maiores detalhes em BAECHLE e EARLE, 2008):

(1) "toque das pontas dos pés na posição sentada": O participante iniciou sentado, mantendo o tronco na vertical e os joelhos estendidos. Para a execução inclinaram o tronco em direção aos membros inferiores, realizando uma flexão de quadril, segurando ou tentando segurar e puxar, as pontas dos pés ou tornozelos em direção ao tronco.

(2) “alongamento do quadríceps em decúbito lateral": O participante iniciou deitado, em decúbito lateral do esquerdo, com os joelhos estendidos, antebraço esquerdo rente solo e o braço perpendicular ao solo, formando um ângulo de aproximadamente $45^{\circ}$ entre o antebraço e braço. Para a execução seguraram a parte anterior do tornozelo direito com a mão direita, puxando-os em direção aos glúteos, realizando uma flexão do joelho e extensão do quadril.

(3) "flexão de joelho em decúbito dorsal": O participante iniciou deitado, em decúbito dorsal, com os joelhos estendidos. Para a execução flexionaram o joelho e quadril direitos, trazendo a coxa até peito. Colocaram as duas mãos atrás da coxa direita e realizaram a ação de puxar a coxa em direção ao peito.

(4) "alongamento com step": O participante iniciou em pé sobre um step, com os joelhos estendidos, e com a ponta do pé esquerdo sobre a borda e o pé direito plano sobre o step. Para a execução realizaram a ação de descer o calcanhar em direção ao solo, realizando uma dorsiflexão do tornozelo. 
O volume total de sustentação do alongamento foi equalizado entre os métodos, sendo realizado três séries de $30 \mathrm{~s}$ de alongamento com $30 \mathrm{~s}$ de intervalo entre as séries, e um exercício por grupamento muscular (BARROSO et al., 2012). Totalizando $90 \mathrm{~s}$ alongamento por grupamento muscular e $15 \mathrm{~min}$ de tempo total da sessão. A intensidade do alongamento foi pré-estabelecida como o ponto maior desconforto suportável (100\% do point of disconfort [POD]), ou seja, nível 100 u.a. da escala de de percepção de esforço para alongamento desenvolvida por Freitas et al. (2015) (APENNDICE 1).

Para o método AT, os participantes realizaram os exercícios de alongamento de maneira ativa, ou seja, sem auxílio externo, mantendo a posição alongada por $30 \mathrm{~s}$, seguido por $30 \mathrm{~s}$ de intervalo. Da mesma forma, para o método BA os participantes realizaram os exercícios de maneira ativa, porem através de movimentos oscilatórios "bruscos" de alongamento-encurtamento, em uma cadência de 1:1 s por ciclo, durante 1 min (totalizando $30 \mathrm{~s}$ alongamento). A frequência do movimento foi controlada por um metrônomo. Já para o método PA, o mesmo protocolo foi empregado, porém o alongamento foi realizado de maneira passiva por um pesquisador experiente. Foram realizados aumentos progressivos na amplitude de alongamento, com base na percepção subjetiva relatada. Durante o método de FNP, também foi realizado alongamento de maneira passiva, empregando a técnica de "sustentar-relaxar", a qual consistiu de $5 \mathrm{~s}$ de alongamento passivo, seguido de $5 \mathrm{~s}$ de contração isométrica submáxima ( $65 \%$ do máximo; SHEARD \& PAINE, 2010) do músculo alongado, relaxamento do grupo muscular, e mais $20 \mathrm{~s}$ de alongamento passivo. A escala CR-10, adaptada por Foster et al. (2001), foi apresentada a cada atleta imediatamente após as sessões de alongamento para verificação da percepção subjetiva de esforço (PSE). 


\subsubsection{Teste de flexibilidade}

Para a avaliação da amplitude de movimento (ADM) foi utilizado o teste de sentar e alcançar (WELLS; DILLON, 1952). Os participantes iniciaram sentados, tronco na vertical, com as mãos sobrepostas sobre a régua de medida, joelhos extendidos e com a sola dos pés apoiada no caixote de avaliação. Para a execução realizaram três movimentos oscilatórios preparatórios, deslocando-se no quarto movimento as mãos ao longo da régua, levando o tronco à frente até o ponto de maior alcance possível e mantendo a posição por no mínimo $2 \mathrm{~s}$.

\subsubsection{Teste de força máxima}

Para a determinação da força máxima foi realizado o teste de uma repetição máxima (1 RM) para o exercício agachamento completo, seguindo o protocolo descrito abaixo (BAECHLE \& EARLE, 2008):

- 5 a 10 repetições (40\% a $60 \%$ da carga máxima prevista);

- 1 min de intervalo;

- 3 a 5 repetições (60\% a $80 \%$ da carga máxima prevista);

- 2 min de intervalo;

- 2 a 3 repetições (90\% da carga máxima prevista);

- 2 a 4 min de intervalo;

- 1 RM (100\% da carga máxima prevista), onde o avaliado deve ser capaz de realizar, sem auxílio, o movimento completo (fase excêntrica e concêntrica);

Caso a carga para 1 RM não fosse obtida na primeira tentativa, o teste era repetido após 2-4 min de descanso. Foram realizadas no máximo três tentativas por teste, caso contrário, o indivíduo deveria voltar após 48 h para repetir o procedimento. 


\subsubsection{Determinação do limiar de eletroestimulação}

Durante todo o procedimento de determinação do limiar e também de avaliação neuromuscular, os participantes foram posicionados sentados em cadeira específica customizada para a análise, com o quadril e joelhos flexionados em $90^{\circ}$ (BERGQUIST; WIEST; COLLINS, 2012), e firmemente presos ao assento por cintos cruzados na altura do peito, cintura, e também na parte inferior da coxa. O membro dominante do participante foi acoplado ao equipamento na altura do tornozelo, através de uma cinta de velcro, presa a uma haste de metal atrelada a uma célula de carga (MK Controle ${ }^{\circledR}$, CSR200, São Paulo - Brasil).

A determinação do limiar máximo de resposta à eletroestimulação foi realizada por meio da aplicação de estímulos elétricos incrementais consecutivos (incrementos de 5-10 mA) no nervo femoral com o músculo relaxado. Os incrementos ocorreram até o limite voluntário de desconforto do participante, ou até a determinação de uma intensidade na qual, mesmo com incremento, não houve aumento do torque produzido pelo músculo (TRAJANO et al., 2013). Para isto foi utilizado um protótipo de eletroestimulação (Insight ${ }^{\circledR}$, Ribeirão Preto - Brasil), com eletrodos de borracha condutiva $(7 \times 5 \mathrm{~cm})$ posicionados no triângulo femoral (cátodo) e na dobra glútea (ânodo) (BERGQUIST; WIEST; COLLINS, 2012)

\subsubsection{Avaliação Neuromuscular}

No primeiro momento do protocolo experimental foram realizadas três CVMs, com duração de 5 s e 1 min de intervalo entre as tentativas (MILIONI et al., 2016), para obtenção dos valores de força pico (Fpico) e taxa de desenvolvimento de força (TDF) durante a CVM (Fig. 3c). 
Dando sequência ao procedimento experimental foi realizada a técnica do twitch interpolation. Para tanto, foram realizadas novamente mais três CVMs, com $5 \mathrm{~s}$ de duração total e 1 min de intervalo entre elas. Porem durante cada uma das três CVMs, após os 3 s iniciais, foram aplicados estímulos elétricos supramáximos (20\% acima do limiar de eletroestimulação; TRAJANO et al., 2013), na forma de pulso simples de curta duração $(1 \mathrm{~ms})$ e alta voltagem $(400 \mathrm{~V})$ no nervo femoral, na condição de superimposição da CVM (Twitch Superimposed [TS]), e 2 s após o término desta, foram aplicados novos estímulos elétricos no músculo relaxado (Twitch Potentiated [TP]) (TRAJANO et al., 2013), (Fig. 3c). Durante a avaliação do twitch interpolation foram obtidas as varáveis relativas ao sinal de força, amplitude do TS e TP, e percentual de ativação voluntário (\%AV), assim como as variáveis root mean square (RMS) e amplitude máxima do sinal do sinal EMG (M-Wave).

\subsubsection{Coleta e análise dos dados de força}

O sinal da célula de carga foi adquirido em uma frequência de $1.000 \mathrm{~Hz}$ por meio de uma placa de aquisição de sinais analógico/digital (National Instruments ${ }^{\circledR}$, NIUSB 6009, São Paulo - Brasil) e suavizado em filtro Butterworth de quarta ordem e 15 $\mathrm{Hz}$ de frequência de corte (GONÇALVES et. al, 2013) e obtido as variáveis Fpico, TDF, TS, TP e \%AV. A fpico foi obtida em uma janela de $100 \mathrm{~ms}$ no pico de força desenvolvido durante a CVM. A TDF foi determinada como a razão entre o valor da fpico e o tempo para atingir a fpico. A TS e TP foram determinadas como a amplitude pico a pico do sinal de força no momento de estimulação elétrica na condição de superimposição a CVM e com o músculo relaxado, respectivamente (Fig. 5) (MILIONI et al., 2016). Para a determinação do \%AV, foi utilizada a equação proposta por Allen et al. (1995) e adaptada por Strojnik e Komi (1998): \%AV = [1 - (ST x (Força no 
momento da estimulação / Fpico) / PT)] x 100. O tratamento e análise dos dados de força foram conduzidos por meio de rotinas específicas desenvolvidas em ambiente Matlab® (The MathWorks Inc., Natick, USA).

\subsubsection{Coleta e análise dos dados de atividade muscular}

A eletromiografia de superfície (EMG) foi monitorada através do eletromiógrafo EMG System (Delsys ${ }^{\circledR}$, Bagnoli-2, Boston - Estados Unidos), sendo a pele previamente tricotomizada, levemente raspada com lixa fina para abrasão de células mortas e higienizada com álcool 70\% nos locais onde serão fixados os eletrodos $(\mathrm{Ag}-\mathrm{AgCl}, 20$ mm). A disposição desses eletrodos seguiu as diretrizes de Hermens et al. (1999), sendo monitorados os músculos: vasto lateral e reto femoral. A aquisição do sinal EMG foi realizada em $2.000 \mathrm{~Hz}$ com ganho de 1.000 vezes, por meio do software EMGworks $\left(\right.$ Delsys $\left.^{\circledR}\right)$. Em seguida o sinal foi processado em filtro passa-banda, com frequência de corte de 20-500 Hz, e calculado as variáveis RMS e M-Wave do sinal EMG. A RMS foram obtidas em uma janela de corte de $1.000 \mathrm{~ms}$ durante a fpico. A M-Wave foi determinada como a amplitude máxima de pico a pico do sinal EMG durante a TP (Fig. 6)(MILIONI et al., 2016). O tratamento e análise dos dados de EMG foram conduzidos por meio de rotinas específicas desenvolvidas em ambiente Matlab ${ }^{\circledR}$ (The MathWorks Inc., Natick, USA). 

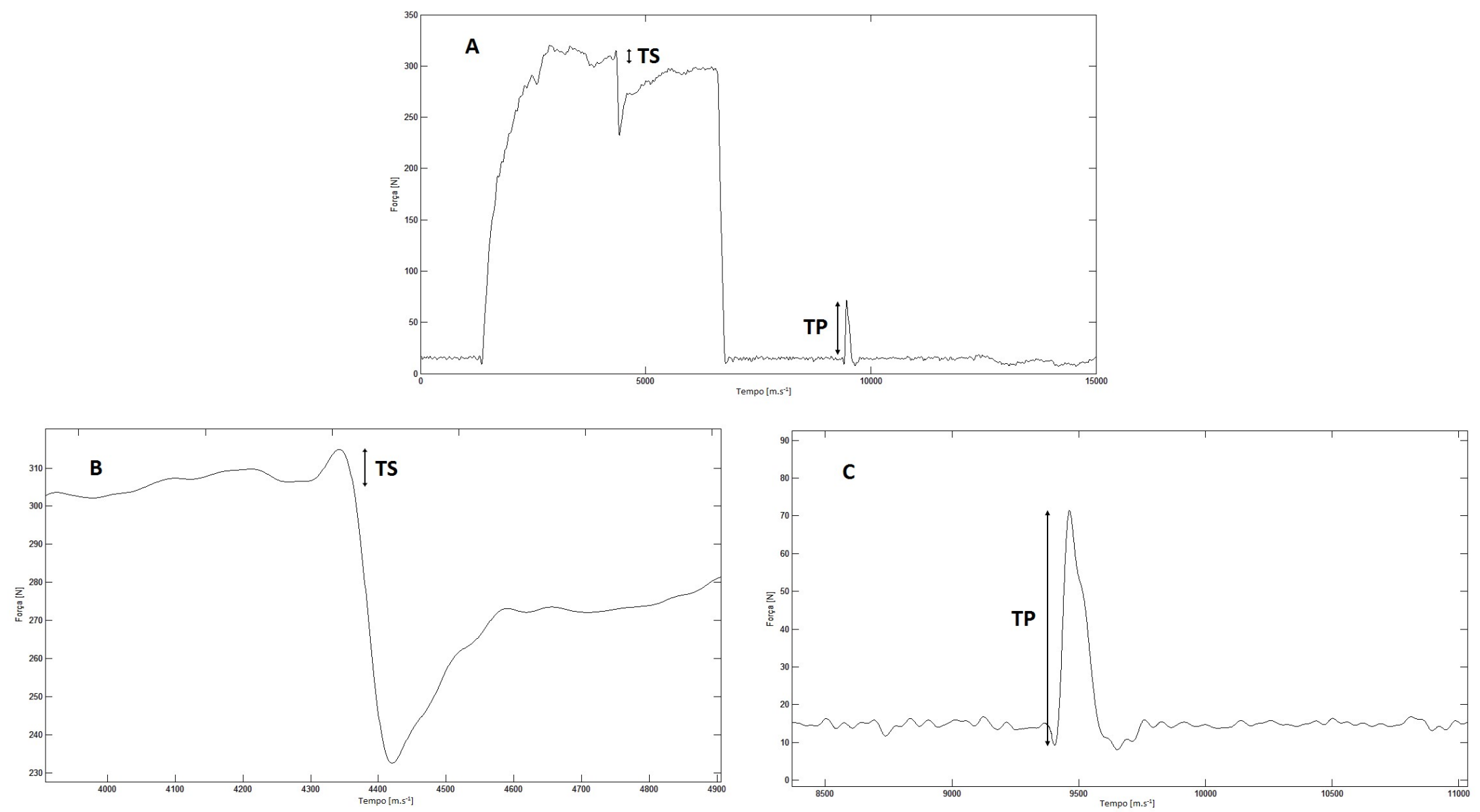

Figura 4. A) Sinal de força durante a avaliação neuromuscular e determinação da twitch superimposed (TS) e twitch potentiated (TP). B) Sinal de força amplificado e determinação da twitch superimposed (TS). C) Sinal de força amplificado e determinação da twitch potentiated (TP). 

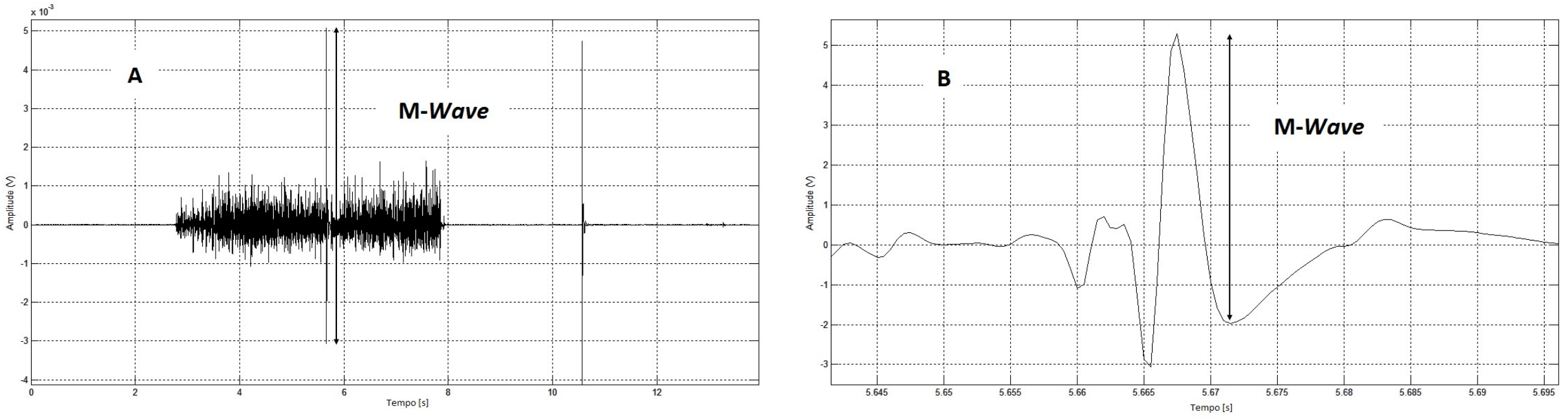

Figura 5. A) Sinal eletromigráfico muscular durante a avaliação neuromuscular e determinação da M-Wave. B) Sinal eletromiográfico amplificado e determinação da M-Wave. 


\subsection{ANÁLISE ESTATÍSTICA}

Inicialmente foi verificada a normalidade dos dados pelo teste de Shapiro Wilk. Confirmada a normalidade, para as comparações entre os momentos (pré e pós) foram empregados o teste $\mathrm{t}$ student para amostras pareadas, e nas comparações entre as condições (AT, BA, PA, FNP e CO) foram empregados ANOVA para medidas repetidas, seguido de post hoc de Bonferroni. O effect size foi analisado pelo Cohen's " $d$ " (COHEN, 1998), e interpretado como: trivial $<0.1 ; 0.1 \geq$ small $\leq 0.20 ; 0.20 \geq$ moderate $\leq 0.50 ; 0.50 \geq$ large $\leq 0.80 ;$ very large $>0.80$ ). A análise de probabilidade de efeito positivo, trivial ou negativo, foi análisada pelo método de Hopkins et al. (2009) e interpretada como: almost certainly not $<1 \%$; very unlikely $1-5 \%$; unlikely $5-25 \%$; possible 25-75\%; likely 75-95\%; very likely 95-99\%; almost certain $>99 \%$. Caso o percentual de chance de ocorrer aumento/positivo ou redução/negativo nas variáveis analisadas forem ambas $>5 \%$, a diferença verdadeira foi interpretada como unclear (HOPKINS et al., 2009). Toda a análise estatística foi realizada pelo software IBM® SPSS ${ }^{\circledR}$ Statistics, versão 20.0 (IBM Corporation ${ }^{\circledR}$ ), e em todos os casos foram considerados o nível de significância de $\mathrm{p}<0.05$. 


\subsection{RESULTADOS}

Aumentos significativas em ADM foram encontrados nas comparações entre os momentos pré e pós nas condições AT $(p=0,00)$, BA $(p=0,00)$, PA $(p=0,00)$ e FNP $(\mathrm{p}=0,01)$ durante o protocolo 1 . Também foram encontradas diferenças significativas no delta de alteração da ADM nas condições AT $(p=0,02)$ e BA $(p=0,01)$ em comparação a condição CO. Ainda para este protocolo, escores superiores de PSE foram reportados após as condições PA e FNP em comparação as condições AT ( $p=0,00$ e 0,00, respectivamente) e BA ( $p=0,04$ e 0,02, respectivamente) (Tab. 8).

Da mesma forma, aumentos significativos em ADM foram encontrados nas comparações entre os momentos pré e pós nas condições AT $(p=0,00)$, BA $(p=0,00)$, PA $(p=0,001)$ e FNP $(p=0,00)$ durante o protocolo 2. Diferenças significativas foram encontradas no delta de alteração da ADM nas condições AT (p=0,002), BA (p = 0,01), PA $(p=0,02)$ e FNP $(p=0,006)$ em comparação a condição CO. Para a PSE escores superiores de PSE foram reportados após as condições PA e FNP em comparação as condições AT ( $p=0,01$ e 0,002 , respectivamente) e BA ( $p=0,01$ e 0,003, respectivamente) (Tab. 8). 
Tabela 8. Efeitos agudos dos métodos de alongamento ativo (AT), balístico (BA), passivo (PA) e facilitação neuromuscular proprioceptiva (FNP) e condição controle (CO) sobre a amplitude de movimento (ADM) e percepção subjetiva de esforço (PSE) para os protocolos 1 e 2.

\begin{tabular}{|c|c|c|c|c|c|c|}
\hline & & $\mathrm{CO}$ & AT & BA & PA & FNP \\
\hline \multicolumn{7}{|l|}{ Protocolo 1} \\
\hline \multirow[t]{7}{*}{$\mathrm{ADM}(\mathrm{cm})$} & Média \pm DP (pré) & $40,17 \pm 5,67$ & $39,89 \pm 6,87$ & $40,56 \pm 5,80$ & $41,00 \pm 5,26$ & $40,00 \pm 6,59$ \\
\hline & Média \pm DP (pós) & $40,67 \pm 5,81$ & $41,83 \pm 7,39^{*}$ & $42,39 \pm 5,52 *$ & $43,06 \pm 5,58^{*}$ & $42,44 \pm 7,64^{*}$ \\
\hline & $\Delta(\%)$ & $1,25 \pm 1,82$ & $4,87 \pm 3,24^{\mathrm{a}}$ & $4,75 \pm 2,52^{\mathrm{a}}$ & $5,01 \pm 3,08$ & $5,94 \pm 4,74$ \\
\hline & $\mathrm{ES}$ & 0,08 & 0,27 & 0,32 & 0,37 & 0,34 \\
\hline & & trivial & moderate & moderate & moderate & moderate \\
\hline & CQ $(\%)$ & $0 / 100 / 0$ & $82 / 18 / 0$ & $96 / 4 / 0$ & $96 / 4 / 0$ & $89 / 11 / 0$ \\
\hline & Média \pm DP & $\begin{array}{c}\text { almost certain trivial } \\
-\end{array}$ & $\begin{array}{c}\text { likely }+ \\
5,22 \pm 1,85\end{array}$ & $\begin{array}{c}\text { very likely }+ \\
7,00 \pm 1,73\end{array}$ & $\begin{array}{l}\text { very likely }+ \\
8,66 \pm 1,32^{\mathrm{b}, \mathrm{c}}\end{array}$ & $\begin{array}{c}\text { likely }+ \\
9,00 \pm 1,00^{\mathrm{b}, \mathrm{c}}\end{array}$ \\
\hline \multicolumn{7}{|l|}{ Protocolo 2} \\
\hline \multirow[t]{7}{*}{$\mathrm{ADM}(\mathrm{cm})$} & Média \pm DP (pré) & $41,42 \pm 4,64$ & $40,58 \pm 5,93$ & $40,71 \pm 5,49$ & $40,29 \pm 5,65$ & $39,75 \pm 6,01$ \\
\hline & Média \pm DP (pós) & $41,75 \pm 4,55$ & $42,29 \pm 6,29^{*}$ & $42,54 \pm 5,11^{*}$ & $42,50 \pm 5,59 *$ & $42,21 \pm 5,59^{*}$ \\
\hline & $\Delta(\%)$ & $0,85 \pm 1,32$ & $4,19 \pm 2,25^{\mathrm{a}}$ & $4,73 \pm 3,44^{\mathrm{a}}$ & $5,67 \pm 4,76^{\mathrm{a}}$ & $6,51 \pm 4,05^{\mathrm{a}}$ \\
\hline & ES & 0,07 & 0,28 & 0,34 & 0,39 & 0,42 \\
\hline & & trivial & moderate & moderate & moderate & moderate \\
\hline & CQ $(\%)$ & $0 / 100 / 0$ & $94 / 6 / 0$ & $96 / 4 / 0$ & $97 / 3 / 0$ & $100 / 0 / 0$ \\
\hline & Média \pm DP & $\begin{array}{c}\text { almost certain trivial } \\
-\end{array}$ & $\begin{array}{c}\text { likely }+ \\
5,42 \pm 1,68\end{array}$ & $\begin{array}{c}\text { very likely }+ \\
6,17 \pm 1,85\end{array}$ & $\begin{array}{l}\text { very likely }+ \\
8,50 \pm 1,31^{\mathrm{b}, \mathrm{c}}\end{array}$ & $\begin{array}{l}\text { almost certain }+ \\
8,83 \pm 0,94^{\mathrm{b}, \mathrm{c}}\end{array}$ \\
\hline
\end{tabular}

“*” diferença significativa na comparação com o momento pré sessão de alongamento (p < 0.05); "a" diferença significativa na comparação com a condição CO $(\mathrm{p}<0.05)$. "b" diferença significativa na comparação com a condição AT $(\mathrm{p}<0.05)$; "c" diferença significativa na comparação com a condição BA $(\mathrm{p}<0.05)$.

Nota: Os valores de effect size (ES), delta de alteração $(\Delta)$, e de chances quantitativas (CQ) foram obtidos a partir da média e desvio padrão da ADM na comparação entre os momentos pré e pós sessão de alongamento. Os valores de QC estão expressos como o percentual de chance de efeito positivo/trivial/negativo, respectivamente. 
Não foram encontradass diferenças siginificativas na carga máxima levantada no teste de 1 RM no exercício de agachamento na comparação entre os momentos e condições CO, AT, PA e FNP (Tab. 9). Também não foram encontradas diferenças significativas na Fpico e TDF desenvolvida durante a CVM no exercício de extensão de joelho (Tab. 9). Da mesma forma, não foram encontradas diferenças significativas nas variáveis amplitude da TS e TP e \%AV durante a realização do twitch interpolation (Tab. 9). 
Tabela 9. Efeitos agudos dos métodos de alongamento ativo (AT), balístico (BA), passivo (PA) e facilitação neuromuscular proprioceptiva (FNP) e condição controle (CO) sobre a performance no teste de uma repetição máxima (1 RM) no agachamento, e sobre a força pico (Fpico) e taxa de desenvolvimento de força (TDF) na contração voluntária isométrica máxima de extensão de joelho.

\begin{tabular}{|c|c|c|c|c|c|c|}
\hline & & CO & AT & $\mathbf{B A}$ & $\mathbf{P A}$ & FNP \\
\hline \multirow[t]{7}{*}{$1 \mathrm{RM}(\mathrm{kg})$} & Média \pm DP (pré) & - & - & - & - & - \\
\hline & Média \pm DP (pós) & $146,33 \pm 17,82$ & $146,67 \pm 20,69$ & $147,56 \pm 11,13$ & $144,44 \pm 19,69$ & $146,67 \pm 16,55$ \\
\hline & $\Delta(\%)$ & - & $0,69 \pm 12,12$ & $1,52 \pm 8,24$ & $-1,10 \pm 9,31$ & $0,69 \pm 8,88$ \\
\hline & ES & - & 0,01 & 0,08 & 0,10 & 0,01 \\
\hline & & - & trivial & trivial & small & trivial \\
\hline & CQ (\%) & - & $27 / 49 / 24$ & $26 / 63 / 11$ & $10 / 58 / 32$ & $22 / 60 / 18$ \\
\hline & & - & unclear & unclear & unclear & unclear \\
\hline \multirow[t]{7}{*}{ Fpico $(\mathrm{N})$} & Média \pm DP (pré) & $533,85 \pm 171,67$ & $560,52 \pm 180,49$ & $521,63 \pm 199,37$ & $501,52 \pm 165,44$ & $519,71 \pm 141,20$ \\
\hline & Média \pm DP (pós) & $536,50 \pm 178,27$ & $545,42 \pm 170,92$ & $538,42 \pm 192,67$ & $530,96 \pm 157,88$ & $510,05 \pm 175,82$ \\
\hline & $\Delta(\%)$ & $1,39 \pm 13,38$ & $-1,77$ & $6,57 \pm 24,33$ & $9,06 \pm 23,34$ & $-2,05$ \\
\hline & ES & 0,01 & 0,08 & 0,08 & 0,18 & 0,06 \\
\hline & & trivial & trivial & trivial & small & trivial \\
\hline & CQ $(\%)$ & $3 / 96 / 1$ & $0 / 91 / 8$ & $15 / 83 / 2$ & $40 / 59 / 1$ & $5 / 75 / 19$ \\
\hline & & very likely trivial & likely trivial & likely trivial & possibly + & unclear \\
\hline \multirow[t]{7}{*}{$\operatorname{TDF}\left(\mathrm{N} \cdot \mathrm{s}^{-1}\right)$} & Média \pm DP (pré) & $239,52 \pm 85,08$ & $204,39 \pm 80,17$ & $175,17 \pm 62,43$ & $178,66 \pm 52,07$ & $196,33 \pm 55,46$ \\
\hline & Média \pm DP (pós) & $230,95 \pm 93,03$ & $225,42 \pm 119,69$ & $187,38 \pm 89,82$ & $214,17 \pm 77,81$ & $169,51 \pm 64,85$ \\
\hline & $\Delta(\%)$ & $3,04 \pm 38,08$ & $12,43 \pm 53,23$ & $9,08 \pm 38,65$ & $24,50 \pm 41,44$ & $-19,61 \pm 35,37$ \\
\hline & ES & 0,09 & 0,20 & 0,15 & 0,53 & 0,44 \\
\hline & & trivial & small & small & large & moderate \\
\hline & CQ (\%) & $18 / 45 / 37$ & $71 / 18 / 12$ & $48 / 37 / 15$ & $89 / 9 / 1$ & $2 / 21 / 77$ \\
\hline & & unclear & unclear & unclear & likely + & likely - \\
\hline
\end{tabular}

Nota: No caso do teste de 1 RM os valores de effect size (ES), delta de alteração $(\Delta)$ e chances quantitativas (CQ) foram obtidos a partir da média e desvio padrão nas condições envolvendo alongamento (AT, BA, PA e FNP) em comparação à condição CO. Já para a Fpico e TDF estes valores foram obtidos a partir da média e desvio padrão nas comparações entre os momentos pré e pós para condição (CO, AT, BA, PA e FNP). Os valores de CQ estão expressos como o percentual de chance de efeito positivo/trivial/negativo, respectivamente. 
Tabela 10. Efeitos agudos dos métodos de alongamento ativo (AT), balístico (BA), passivo (PA) e facilitação neuromuscular proprioceptiva (FNP) e condição controle (CO) sobre as variáveis twitch superimposed (TS), twitch potentiated (TP) e percentual de ativação voluntária (\%AV) do twitch interpolation.

\begin{tabular}{ccccccc}
\hline & CO & AT & BA & PA & FNP \\
\hline TS (N) & Média \pm DP (pré) & $41,76 \pm 17,57$ & $39,67 \pm 13,87$ & $46,05 \pm 17,46$ & $40,31 \pm 16,91$ & $39,55 \pm 17,57$ \\
& Média \pm DP (pós) & $35,42 \pm 12,91$ & $40,27 \pm 12,50$ & $43,49 \pm 13,31$ & $42,10 \pm 14,97$ & $42,90 \pm 14,35$ \\
& $\Delta(\%)$ & $-8,71 \pm 29,98$ & $6,30 \pm 28,43$ & $-0,42 \pm 27,98$ & $93,44 \pm 255,27$ & $23,51 \pm 17,57$ \\
& ES & 0,41 & 0,04 & 0,16 & 0,11 & 0,20 \\
& moderate & trivial & small & small & small \\
& CQ (\%) & $0 / 21 / 78$ & $25 / 59 / 16$ & $8 / 52 / 39$ & $40 / 36 / 24$ & $46 / 49 / 5$ \\
TP (N) & likely - & unclear & unclear & unclear & unclear \\
& Média \pm DP (pré) & $166,175 \pm 3,32$ & $185,64 \pm 42,64$ & $181,70 \pm 52,27$ & $169,96 \pm 50,92$ & $194,0034,40$ \\
& Média \pm DP (pós) & $168,65 \pm 49,34$ & $186,38 \pm 41,79$ & $178,27 \pm 55,29$ & $173,26 \pm 40,91$ & $186,38 \pm 35,64$ \\
& $\Delta(\%)$ & $3,16 \pm 17,67$ & $1,21 \pm 8,24$ & $-2,10 \pm 13,92$ & $9,04 \pm 34,64$ & $-3,71 \pm 8,78$ \\
& ES & 0,04 & 0,01 & 0,06 & 0,07 & 0,21 \\
& trivial & trivial & trivial & trivial & moderate \\
& CQ (\%) & $13 / 82 / 5$ & $2 / 97 / 1$ & $1 / 90 / 9$ & $23 / 68 / 9$ & $1 / 48 / 52$ \\
& Média \pm DP (pré) & $76,95 \pm 7,36$ & $79,65 \pm 6,98$ & $76,37 \pm 6,67$ & $78,55 \pm 7,05$ & $81,04 \pm 8,37$ \\
& Média \pm DP (pós) & $79,96 \pm 7,42$ & $79,68 \pm 7,31$ & $76,74 \pm 4,76$ & $75,79 \pm 12,67$ & $78,06 \pm 8,47$ \\
& $\Delta$ (\%) & $4,37 \pm 10,20$ & $0,26 \pm 7,66$ & $1,12 \pm 10,25$ & $-2,26 \pm 19,73$ & $-3,19 \pm 9,09$ \\
ES & 0,40 & 0,004 & 0,06 & 0,26 & 0,35 \\
& moderate & trivial & trivial & moderate & moderate \\
& CQ (\%) & $75 / 22 / 2$ & $20 / 62 / 19$ & $30 / 50 / 20$ & $20 / 20 / 60$ & $3 / 27 / 70$ \\
& likely + & unclear & unclear & unclear & possibly - \\
\hline
\end{tabular}

Nota: Os valores de effect size (ES), delta de alteração $(\Delta)$ e chances quantitativas (CQ) foram obtidos a partir da média e desvio padrão nas comparações entre os momentos pré e pós para cada condição (CO, AT, BA, PA e FNP). Os valores de CQ estão expressos como o percentual de chance de efeito positivo/trivial/negativo, respectivamente. 
Não foram encontradas alterações significativas nas variáveis RMS, M-Wave e razão RMS/M-Wave dos músculos vasto lateral e reto femoral entre os momentos e condições envolvendo alongamento AT, BA, PA e FNP (Tab. 11 e Tab. 12). Reduções significativas foram encontradas na amplitude da M-Wave do sinal EMG do músculo reto femoral na condição $\mathrm{CO}$ na comparação entre os momentos pré e pós (p $=0,01)($ Tab. 12). 
Tabela 11. Efeitos agudos dos métodos de alongamento ativo (AT), balístico (BA), passivo (PA) e facilitação neuromuscular proprioceptiva (FNP) e condição controle (CO) sobre a root mean square (RMS), M-Wave e razão do root mean square e M-Wave (RMS/M-Wave) do sinal eletromiográfico do músculo vasto lateral.

\begin{tabular}{|c|c|c|c|c|c|c|}
\hline 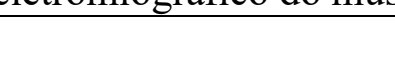 & & $\mathrm{CO}$ & AT & $\mathbf{B A}$ & PA & FNP \\
\hline \multirow[t]{7}{*}{$\mathrm{RMS}_{\mathrm{VL}}(\mu \mathrm{V})$} & Média \pm DP (pré) & $128,02 \pm 55,40$ & $156,95 \pm 66,63$ & $121,38 \pm 51,94$ & $160,89 \pm 98,78$ & $143,41 \pm 68,87$ \\
\hline & Média \pm DP (pós) & $168,84 \pm 83,91$ & $150,88 \pm 55,44$ & $146,00 \pm 99,00$ & $154,66 \pm 80,91$ & $130,06 \pm 37,39$ \\
\hline & $\Delta(\%)$ & $36,66 \pm 49,88$ & $4,26 \pm 37,43$ & $22,01 \pm 62,62$ & $6,13 \pm 53,55$ & $4,93 \pm 42,77$ \\
\hline & ES & 0,57 & 0,09 & 0,31 & 0,06 & 0,24 \\
\hline & & large & trivial & moderate & trivial & moderate \\
\hline & CQ (\%) & $91 / 8 / 1$ & $11 / 58 / 31$ & $71 / 21 / 7$ & $9 / 69 / 22$ & $6 / 48 / 47$ \\
\hline & & likely + & unclear & unclear & unclear & unclear \\
\hline \multirow[t]{7}{*}{$\mathrm{M}-$ Wave $_{\mathrm{VL}}(\mu \mathrm{V})$} & Média \pm DP (pré) & $1081,90 \pm 513,71$ & $1276,95 \pm 900,67$ & $1715,08 \pm 1047,45$ & $1510,08 \pm 934,63$ & $1286,47 \pm 806,85$ \\
\hline & Média \pm DP (pós) & $1142,64 \pm 515,04$ & $1204,25 \pm 821,91$ & $1490,42 \pm 921,80$ & $1500,48 \pm 983,66$ & $1365,37 \pm 804,96$ \\
\hline & $\Delta(\%)$ & $22,78 \pm 67,40$ & $30,05 \pm 96,26$ & $-4,02 \pm 53,81$ & $33,78 \pm 138,90$ & $25,89 \pm 68,12$ \\
\hline & ES & 0,11 & 0,08 & 0,22 & 0,01 & 0,09 \\
\hline & & small & trivial & moderate & trivial & trivial \\
\hline & CQ (\%) & $64 / 26 / 10$ & $4 / 43 / 52$ & $81 / 13 / 6$ & $11 / 35 / 54$ & $64 / 19 / 18$ \\
\hline & & unclear & unclear & possibly - & unclear & unclear \\
\hline \multirow[t]{7}{*}{ RMS/M-Wave ${ }_{\mathrm{VL}}$ (u.a.) } & Média \pm DP (pré) & $0,17 \pm 0,11$ & $0,23 \pm 0,26$ & $0,10 \pm 0,07$ & $0,19 \pm 0,17$ & $0,15 \pm 0,09$ \\
\hline & Média \pm DP (pós) & $0,21 \pm 0,13$ & $0,17 \pm 0,10$ & $0,15 \pm 0,18$ & $0,15 \pm 0,11$ & $0,20 \pm 0,21$ \\
\hline & $\Delta(\%)$ & $76,86 \pm 163,77$ & $37,33 \pm 139,85$ & $59,99 \pm 88,36$ & $26,70 \pm 127,54$ & $94,02 \pm 301,00$ \\
\hline & ES & 0,33 & 0,30 & 0,36 & 0,27 & 0,30 \\
\hline & & moderate & moderate & moderate & moderate & moderate \\
\hline & CQ $(\%)$ & $64 / 26 / 10$ & $4 / 43 / 52$ & $81 / 13 / 6$ & $11 / 35 / 54$ & $64 / 19 / 18$ \\
\hline & & unclear & possibly - & unclear & unclear & unclear \\
\hline
\end{tabular}

Nota: Os valores de effect size (ES), delta de alteração $(\Delta)$ e chances quantitativas (CQ) foram obtidos a partir da média e desvio padrão nas comparações entre os momentos pré e pós para cada condição (CO, AT, BA, PA e FNP). Os valores de CQ estão expressos como o percentual de chance de efeito positivo/trivial/negativo, respectivamente. 
Tabela 12. Efeitos agudos dos métodos de alongamento ativo (AT), balístico (BA), passivo (PA) e facilitação neuromuscular proprioceptiva (FNP) e condição controle (CO) sobre a root mean square (RMS), M-Wave e razão do root mean square e M-Wave (RMS/M-Wave) do sinal eletromiografico do músculo reto femoral.

\begin{tabular}{|c|c|c|c|c|c|c|}
\hline & & $\mathrm{CO}$ & AT & $\mathbf{B A}$ & PA & FNP \\
\hline \multirow[t]{7}{*}{$\mathrm{RMS}_{\mathrm{RF}}(\mu \mathrm{V})$} & Média \pm DP (pré) & $121,50 \pm 50,71$ & $128,62 \pm 60,82$ & $132,42 \pm 62,26$ & $104,41 \pm 43,76$ & $106,05 \pm 52,17$ \\
\hline & Média \pm DP (pós) & $129,63 \pm 59,96$ & $123,70 \pm 56,13$ & $142,78 \pm 141,19$ & $110,42 \pm 31,08$ & $89,11 \pm 25,06$ \\
\hline & $\Delta(\%)$ & $14,48 \pm 56,31$ & $2,47 \pm 31,14$ & $14,72 \pm 78,69$ & $19,43 \pm 42,23$ & $1,21 \pm 57,88$ \\
\hline & ES & 0,14 & 0,08 & 0,09 & 0,15 & 0,41 \\
\hline & & small & trivial & trivial & small & moderate \\
\hline & CQ (\%) & $42 / 50 / 9$ & $5 / 74 / 21$ & $47 / 25 / 28$ & $40 / 46 / 14$ & $2 / 30 / 68$ \\
\hline & & unclear & unlikely - & unclear & unclear & possibly - \\
\hline \multirow[t]{7}{*}{$\mathrm{M}-$ Wave $_{\mathrm{RF}}(\mu \mathrm{V})$} & Média \pm DP (pré) & $3907,86 \pm 1601,60$ & $4661,44 \pm 1176,46$ & $3054,55 \pm 1637,94$ & $4098,70 \pm 1881,40$ & $3991,99 \pm 1614,79$ \\
\hline & Média \pm DP (pós) & $3299,86 \pm 1811,42 *$ & $4535,32 \pm 1137,24$ & $3498,35 \pm 1486,34$ & $3948,51 \pm 1737,92$ & $3518,11 \pm 1578,19$ \\
\hline & $\Delta(\%)$ & $-18,48 \pm 25,96$ & $-2,23 \pm 6,24$ & $37,68 \pm 95,77$ & $17,99 \pm 83,53$ & $-11,02 \pm 23,91$ \\
\hline & ES & 0,35 & 0,10 & 0,28 & 0,08 & 0,29 \\
\hline & & moderate & small & moderate & trivial & moderate \\
\hline & CQ (\%) & $0 / 13 / 87$ & $0 / 94 / 6$ & $60 / 38 / 2$ & $4 / 76 / 20$ & $0 / 30 / 69$ \\
\hline & & likely - & likely trivial & possibly + & most likely - & most likely - \\
\hline \multirow[t]{7}{*}{ RMS/M-Wave $\mathrm{RF}$ (u.a.) } & Média \pm DP (pré) & $0,03 \pm 0,02$ & $0,02 \pm 0,01$ & $0,07 \pm 0,07$ & $0,06 \pm 0,12$ & $0,03 \pm 0,02$ \\
\hline & Média \pm DP (pós) & $0,05 \pm 0,04$ & $0,02 \pm 0,009$ & $0,05 \pm 0,05$ & $0,06 \pm 0,08$ & $0,04 \pm 0,06$ \\
\hline & $\Delta(\%)$ & $64,85 \pm 99,76$ & $5,17 \pm 31,01$ & $-1,19 \pm 71,87$ & $56,48 \pm 181,08$ & $49,13 \pm 137,73$ \\
\hline & ES & 0,63 & 0,09 & 0,32 & 0,03 & 0,22 \\
\hline & & large & trivial & moderate & trivial & moderate \\
\hline & CQ (\%) & $94 / 4 / 2$ & $5 / 69 / 26$ & $4 / 31 / 65$ & $21 / 51 / 28$ & $79 / 11 / 9$ \\
\hline & & likely + & unclear & possibly - & unclear & unclear \\
\hline
\end{tabular}

\footnotetext{
“*”diferença significativa na comparação com o momento pré $(\mathrm{p}<0.05)$.
}

Nota: Os valores de effect size (ES), delta de alteração $(\Delta)$ e chances quantitativas (CQ) foram obtidos a partir da média e desvio padrão nas comparações entre os momentos pré e pós para cada condição (CO, AT, BA, PA e FNP). Os valores de CQ estão expressos como o percentual de chance de efeito positivo/trivial/negativo, respectivamente. 


\subsection{DISCUSSÃO}

O objetivo do presente estudo foi comparar os efeitos agudos dos métodos de alongamento AT, BA, PA e FNP sobre parâmetros associados a força e a EMG em testes de 1 RM no agachamento e CVM na extensão de joelho. Nesse sentido os principais achados foram as inalterações dos parâmetros associados a força e EMG entre os métodos de alongamento em atletas treinados.

Em contradição, a literatura demonstra reduções na força máxima após sessões de alongamento AT, PA e FNP (MILLER et al., 2016; TRAJANO et al., 2014; MIYAHARA et al., 2013; SIERRA et al., 2013; TRAJANO et al. 2013; BARROSO et al., 2012; OLIVEIRA et al., 2012; WINCHESTER; NELSON; KOKKONEN, 2011; PABLO et al., 2010; BACURAU et al., 2009; HERDA et al., 2009; SIATRAS et al., 2008; BRIDE; NIMPHIUS, 2007; OGURA et al., 2007; POWER et al., 2004; BEHM; BUTTON; BUTT, 2001). Porem, a literatura tem apontado que as variáveis volume e intensidade do alongamento, e o nível de treinamento podem afetar as respostas (AVLONITI et al., 2015; KAY; BLAZEVITH, 2012; YOUNG; ELIAS; POWER, 2006). Aparentemente, sessões de alongamento com tempos de sustentação menores ou iguais a 30 s, tendem a não afetar, por outro lado, sessões com tempos maiores ou iguais a $60 \mathrm{~s}$, promovem efeitos negativos na performance da força máxima de membros inferiores (KAY; BLAZEVITH, 2012; OGURA et al., 2007). Além disso, Young, Elias e Power (2006) demonstraram que as reduções na performance física ocorrem a partir de 2 min de volume total de alongamento por grupamento muscular (4 séries x $30 \mathrm{~s}$ ), na intensidade de $100 \%$ do POD. Enquanto que quando o volume é mantido e a intensidade reduzida (4 séries x 30 s a 90\% do POD) não há alteração da performance (YOUNG; ELIAS; POWER, 2006). Em relação ao nível de treinamento, enquanto indivíduos moderadamente treinados parecem até mesmo se beneficiar de sessões de 
alongamento AT de curta duração (1 série x 20 s), indivíduos altamente treinados não apresentam alteração da performance física (AVLONITI et al., 2015).

Dessa forma, apesar dos maiores escores de PSE após as sessões de alongamento envolvendo os métodos PA e FNP apontarem para uma maior intensidade (Tab. 8), é provavel que o volume de total de alongamento por grupamento muscular ( 3 séries $\mathrm{x} 30$ s) tenha sido insuficiente para promover alterações negativas na performance da força máxima. Além disso, os valores de 1 RM relativo à massa corporal dos jovens jogadores de futebol avaliados $(2,18 \pm 0,25$ u.a.) estão muito próximos aos de jogadores profissionais de futebol (2,20 $\pm 0,30$ u.a.) (WISLOFF et al., 2002). Portanto, é possível especular também que nível de treinamento dos jogadores do presente estudo possa ter interferido nas respostas do alongamento na performance, evitando possíveis reduções na força máxima.

Em relação aos dados da avaliação neuromuscular, não foram encontrados alterações significativas nos dados de força e também na EMG dos músculos do quadríceps. Em contradição, a literatura tem apontado reduções nas variáveis Fpico, TDF, \%AV do sinal de força e RMS do sinal EMG durante a CVM (TRAJANO et al., 2013; PABLO et al., 2010; HERDA et al., 2009; CRAEMER et al., 2005; BEHM et al., 2001; FOWLES; SALE; MACDOUGALL, 2000). Apontando para uma resposta de fadiga após sessões de alongamento PA. No entanto, a maioria dos estudos supracitados empregam tempos de sustentação de alongamento (e.g., $30 \mathrm{~s}-300 \mathrm{~s}$ ) e sessões de alongamento muito extensas (e.g., $20 \mathrm{~min}$ - 33 min). Além disso, estes estudos avaliaram sujeitos recreacionistas e não-atletas (TRAJANO et al., 2013; PABLO et al., 2010; HERDA et al., 2009; CRAEMER et al., 2005; BEHM et al., 2001; FOWLES; SALE; MACDOUGALL, 2000), enquanto no presente estudo foram avaliados jogadores de futebol treinados. Portanto, conforme já apontado, é possível que o volume 
relativamente baixo de alongamento e o nível de treinamento dos participantes tenham interferido nas respostas evitando efeitos deletérios do alongamento na força máxima e em parâmetros neuromusculares.

Por outro lado, apesar da não significância estatística, foram encontrados moderados valores de ES e CQ para redução nas variáveis TDF (ES=0,44; $\mathrm{CQ}=2 / 21 / 77), \mathrm{TP}(\mathrm{ES}=0,21 ; \mathrm{CQ}=1 / 48 / 52), \% \mathrm{AV}(\mathrm{ES}=0,35 ; \mathrm{CQ}=3 / 27 / 70)$, e $\mathrm{RMS}$ $(\mathrm{ES}=0,41 ; \mathrm{CQ}=2 / 30 / 68)$ e $\mathrm{M}-$ Wave $(\mathrm{ES}=0,29 ; \mathrm{CQ}=0 / 30 / 69)$ do músculo reto femoral, sugerindo uma possível fadiga após a sessão de FNP (Tab. 9; Tab. 10; Tab. 12). Segundo Gandevia (2001), uma uma redução da TP indica que o impulso elétrico não esta se propagando de maneira eficiente a nível periférico para produzir o mesmo nível de força antes da fadiga instaurada. Um redução da RMS é um indicativo de redução da atividade elétrica de determinado grupamento muscular, podendo ser causado tanto por uma redução da excitação do neurônio motor (fator neural) quanto por uma falha na propagação do estimulo elétrico a nível muscular (fator periférico) (GANDEVIA, 2001). No entanto, quando analisado a M-Wave, como esta variável é resultado da estimulação elétrica acima do que pode ser produzido voluntariamente (i.e., estímulo supramáximo), uma redução desta variável pode ser interpretado como uma baixa no potencial de recrutamento das fibras musculares sendo este um índice associado à fadiga de caráter periférico (AAGAARD et al., 2002; GANDEVIA, 2001).

Dessa forma, redução na TDF acompanhada de reduções da TP, \%AV, e RMS e M-Wave do sinal EMG, favorecem a interpretação de fadiga após a sessão de FNP causada predominantemente por fatores periféricos. Além disso, estes dados apontam para uma possível resposta diferenciada entre os testes de 1 RM no agachamento e CVM na extensão de joelho. Durante a execução do agachamento diversos músculos auxiliares são solicitados, em comparação ao exercício de extensão de joelho (BRIDE; 
NIMPHIUS, 2007). Logo, é possível que outros músculos não alongados possam ter compensado a redução de força dos músculos alongados, mantendo nível de produção de força total. No entanto, as comparações das respostas destes exercícios ao alongamento, e da mesma forma os mecanismos neurofisiológicos associados à fadiga, necessitam ser melhor investigados.

\subsection{CONCLUSÃO}

Com base nos resultados encontrados em nosso estudo, os métodos AT, BA, PA e FNP não promovem efeitos negativos na performance da força máxima nos testes de 1 RM no agachamento e na CVM de extensão de joelho em atletas treinados. No entanto, apesar da não significância estatística, os resultados sugerem reduções na TDF, TP, \%AV e RMS e M-Wave do músculo reto femoral, após a sessão de FNP. Indicando uma possível fadiga causada por fatores periféricos, e possibilidade de resposta diferenciada entre os exercícios de agachamento e extensão de joelho ao alongamento.

\subsection{REFERÊNCIAS}

\subsubsection{Revisão da literatura}

ALEMDAROGLU, U.; KÖKLÜ, Y.; KOZ, M. The acute effect of different stretching methods on sprint performance in taekwondo practitioners. The Journal of sports medicine and physical fitness, 2016.

ALIKHAJEH; RAHIM; FAZELI; FAZELI. The effect of different warm-up stretch protocols on a 20-meter sprint in trained soccer players. Procedia Soc Behav Sci, v.30, p. 1588-1592, 2011.

ANDERSON, B.; BURKE, E. R. Scientific, medical, and practical aspects of stretching. Clinics in Sports Medicine, v. 10, n. 1, p. 63, 1991. 
AVlONITI, A.; CHATZINIKOLAOU, A.; FATOUROS, I. G.; AVlONITI, C.; PROTOPAPA, M.; DRAGANIDIS, D.; STAMPOULIS, T.; LEONTSINI, D.; MAVROPALIAS, G.; GOUNELAS, G.; KAMBAS, A. The Acute Effects of Static Stretching on Speed and Agility Performance Depend on Stretch Duration and Conditioning Level. J Strength Cond Res. Epub ahead of print.[2014 Jun 17].

BACURAU, R. F. P.; MONTEIRO, G. A.; UGRINOWITSCH, C.; TRICOLI, V.; CABRAL, L. F.; AOKI, M. S. Acute effect of a ballistic and a static stretching exercise bout on flexibility and maximal strength. The Journal of Strength \& Conditioning Research, v. 23, n. 1, p. 304-308, 2009.

BAECHLE, T. R.; EARLE, R. W. National Strength \& Conditioning Association (US). Essentials of strength training and conditioning. Champaign, IL: Human Kinetics, p. 395-396, 2008.

BARBANTI, V. Treinamento esportivo: as capacidades motoras dos esportistas. 2010 .

BARROSO, R.; TRICOLI, V.; GIL, S.; UGRINOWITSCH, C.; ROSCHEL, H. Maximal strength, number of repetitions, and total volume are differently affected by static-, ballistic-, and proprioceptive neuromuscular facilitation stretching. The Journal of Strength \& Conditioning Research, v. 26, n. 9, p. 2432-2437, 2012.

BEHM, D. G.; BUTTON, D. C.; BUTT, J. C. Factors affecting force loss with prolonged stretching. Canadian Journal of Applied Physiology, v. 26, n. 3, p. 262$272,2001$.

BRADLEY, P. S.; OLSEN, P. D.; PORTAS, M. D. The effect of static, ballistic, and proprioceptive neuromuscular facilitation stretching on vertical jump performance. $\mathbf{J}$ Strength Cond Res, v. 21, n. 1, p. 223-226, 2007.

CARVALHO, F. L.; CARVALHO, M. C.; SIMÃO, R.; GOMES, T. M.; COSTA, P. B.; NETO, L. B.; DANTAS, E. H. Acute effects of a warm-up including active, passive, and dynamic stretching on vertical jump performance. The Journal of Strength \& Conditioning Research, v. 26, n. 9, p. 2447-2452, 2012. 
CHAOUACHI, A.; CASTAGNA, C.; CHTARA, M.; BRUGHELLI, M.; TURKI, O.; GALY, O.; BEHM, D. G. Effect of warm-ups involving static or dynamic stretching on agility, sprinting, and jumping performance in trained individuals. The Journal of Strength \& Conditioning Research, v. 24, n. 8, p. 2001-2011, 2010.

COSTA, P. B., RYAN, E. D., HERDA, T. J., WAlter, A. A., HOGE, K. M., \& CRAMER, J. T. Acute effects of passive stretching on the electromechanical delay and evoked twitch properties. European journal of applied physiology, v. 108, n. 2, p. $301,2010$.

CRAMER, J. T.; BECK, T. W.; HOUSH, T. J.; MASSEY, L. L.; MAREK, S. M.; DANGLEMEIER, S.; PURKAYASTHA, S.; CULBERTSON, J. Y.; FITZ, K. A.; EGAN, A. D. Acute effects of static stretching on characteristics of the isokinetic angle - torque relationship, surface electromyography, and mechanomyography. J Sports Sci, v. 25 , n. 6 , p. 687-698, 2007.

CRAMER, J. T.; HOUSH, T. J.; WEIR, J. P.; JOHNSON, G. O.; COBURN, J. W.; BECK, T. W. The acute effects of static stretching on peak torque, mean power output, electromyography, and mechanomyography. Eur J Appl Physiol, v. 93, n. 5-6, p. 530$539,2005$.

DALLAS, G.; SMIRNIOTOU, A.; TSIGANOS, G.; TSOPANI, D.; DI CAGNO, A.; TSOLAKIS, C. Acute effect of different stretching methods on flexibility and jumping performance in competitive artistic gymnasts. The Journal of sports medicine and physical fitness, v. 54, n. 6, p. 683-690, 2014.

FLETCHER, I. M.; JONES, B. The effect of different warm-up stretch protocols on 20 meter sprint performance in trained rugby union players. The Journal of Strength \& Conditioning Research, v. 18, n. 4, p. 885-888, 2004.

FOWLES, J. R.; SALE, D. G.; MACDOUGALL, J. D. Reduced strength after passive stretch of the human plantarflexors. J Appl Physiol, v. 89, n. 3, p. 1179-1188, 2000.

GELEN, E. Acute effects of different warm-up methods on sprint, slalom dribbling, and penalty kick performance in soccer players. The Journal of Strength \& Conditioning Research, v. 24, n. 4, p. 950-956, 2010. 
KISNER, C.; COLBY, L. A. Stretching. Therapeutic exercise: foundations and techniques. Philadelphia: FA Davis Company, p. 121-53, 2002.

LITTLE, T.; WILLIAMS, A. G. Effects of differential stretching protocols during warm-ups on high-speed motor capacities in professional soccer players. J Strength Cond Res, v. 20, n. 1, p. 203-207, 2006.

MANOEL, M. E.; HARRIS-LOVE, M. O.; DANOFF, J. V.; MILLER, T. A. Acute effects of static, dynamic, and proprioceptive neuromuscular facilitation stretching on muscle power in women. J Strength Cond Res, v. 22, n. 5, p. 1528-1534, 2008.

MCARDLE, W. D.; KATCH, F. I.; KATCH, V. L. Fisiologia do exercício: nutrição, energia e desempenho humano. $7^{\mathrm{a}}$ ed. Rio Janeiro: Guanabara Koogan, 2011.

MCBRIDE, J. M.; DEANE, R.; NIMPHIUS, S. Effect of stretching on agonistantagonist muscle activity and muscle force output during single and multiple joint isometric contractions. Scandinavian journal of medicine $\&$ science in sports, v. 17, n. 1, p. 54-60, 2007.

MILLER, J. D.; HERDA, T. J.; TREVINO, M. A.; MOSIER, E. M. The effects of passive stretching plus vibration on strength and activation of the plantar flexors. Applied Physiology, Nutrition, and Metabolism, v. 41, n. 9, p. 917-923, 2016.

MIYAHARA, Y.; NAITO, H.; OGURA, Y.; KATAMOTO, S.; AOKI, J. Effects of proprioceptive neuromuscular facilitation stretching and static stretching on maximal voluntary contraction. The Journal of Strength \& Conditioning Research, v. 27, n. 1, p. 195-201, 2013.

OGURA, Y.; MIYAHARA, Y.; NAITO, H.; KATAMOTO, S.; AOKI, J. Duration of static stretching influences muscle force production in hamstring muscles. The Journal of Strength \& Conditioning Research, v. 21, n. 3, p. 788-792, 2007.

OLIVEIRA, A. L. M.; GRECO, C. C.; MOLINA, R.; DENADAI, B. S. The rate of force development obtained at early contraction phase is not influenced by active static stretching. The Journal of Strength \& Conditioning Research, v. 26, n. 8, p. 21742179, 2012. 
PLACE, N.; BLUM, Y.; ARMAND, S.; MAFFIULETTI, N. A.; BEHM, D. G. Effects of a short proprioceptive neuromuscular facilitation stretching bout on quadriceps neuromuscular function, flexibility, and vertical jump performance. The Journal of Strength \& Conditioning Research, v. 27, n. 2, p. 463-470, 2013.

POWER, K.; BEHM, D.; CAHILL; CARROLL, M.; YOUNG, W. An acute bout of static stretching: effects on force and jumping performance. Medicine and science in sports and exercise, v. 36, p. 1389-1396, 2004.

REIS, E. D. F. S.; PEREIRA, G. B.; SOUSA, N. M. F.; TIBANA, R. A.; SILVA, M. F.; ARAUJO, M.; PRESTES, J. Acute effects of proprioceptive neuromuscular facilitation and static stretching on maximal voluntary contraction and muscle electromyographical activity in indoor soccer players. Clinical physiology and functional imaging, v. 33, n. 6, p. 418-422, 2013.

RYAN, E. D.; BECK, T. W.; HERDA, T. J.; HULL, H. R.; HARTMAN, M. J.; STOUT, J. R.; CRAMER, J. T. Do practical durations of stretching alter muscle strength? A dose-response study. Med Sci Sports Exerc, v. 40, n. 8, p. 1529-1537, $2008 \mathrm{a}$.

SERRA, A. J.; SILVA JR, J. A.; MARCOLONGO, A. A.; MANCHINI, M. T.; OLIVEIRA, J. V.; SANTOS, L. F.; BOCALINI, D. S. Experience in resistance training does not prevent reduction in muscle strength evoked by passive static stretching. The Journal of Strength \& Conditioning Research, v. 27, n. 8, p. 2304-2308, 2013.

SIATRAS, T. A.; MITTAS, V. P.; MAMELETZI, D. N.; VAMVAKOUDIS, E. A. The duration of the inhibitory effects with static stretching on quadriceps peak torque production. The Journal of Strength \& Conditioning Research, v. 22, n. 1, p. 40-46, 2008.

STAFILIDIS, S.; TILP, M. Effects of short duration static stretching on jump performance, maximum voluntary contraction, and various mechanical and morphological parameters of the muscle-tendon unit of the lower extremities. European journal of applied physiology, v. 115, n. 3, p. 607-617, 2015. 
STEWART, M.; ADAMS, R.; ALONSO, A.; VAN KOESVELD, B.; CAMPBELL, S. Warm-up or stretch as preparation for sprint performance? Journal of Science and Medicine in Sport, v. 10, n. 6, p. 403-410, 2007.

TRAJANO, G. S.; KAZUNORI N.; BLAZEVICH. Intermittent stretch reduces force and central drive more than continuous stretch. Medicine and science in sports and exercise, v. 46, n. 5, p. 902-910, 2013.

TRAJANO, G. S.; NOSAKA, K.; BLAZEVICH, A. J. Intermittent stretch reduces force and central drive more than continuous stretch. Medicine and science in sports and exercise, v. 46, n. 5, p. 902-910, 2013.

VASCONCELlOS, F.; DE SALLES, P.; JUNIOR, A.; DE MELLO, D.; DANTAS, E. The vertical jump height of soccer players after static overstretching. Human Movement, v. 13, n. 1, p. 4-7, 2012.

WEINECK, J. Biologia do Esporte. Tradução de Luciano Prado. rev. e amp. 2005.

WILSON, GREG J.; MURPHY, ARON J.; PRYOR, JOHN F. Musculotendinous stiffness: its relationship to eccentric, isometric, and concentric performance. Journal of applied physiology, v. 76, n. 6, p. 2714-2719, 1994.

\subsubsection{Estudo 1}

ALEMDAROGLU, U.; KOKLU, Y.; KOZ, M. The acute effect of different stretching methods on sprint performance in taekwondo practitioners. The Journal of Sports Medicine and Physical Fitness, Jul 212016.

ARTEAGA, R. et al. Reliability of jumping performance in active men and women under different stretch loading conditions. The Journal of Sports Medicine and Physical Fitness, v. 40, n. 1, p. 26-34, Mar 2000.

AVLONITI, A. et al. The Acute Effects of Static Stretching on Speed and Agility Performance Depend on Stretch Duration and Conditioning Level. The Journal of Strength \& Conditioning Research, v. 30, n. 10, p. 2767-73, Oct 2016. 
BACURAU, R. F. et al. Acute effect of a ballistic and a static stretching exercise bout on flexibility and maximal strength. The Journal of Strength \& Conditioning Research, v. 23, n. 1, p. 304-8, Jan 2009.

BAECHLE, T. R.; EARLE, R. W. National Strength \& Conditioning Association (US). Essentials of strength training and conditioning. Champaign, IL: Human Kinetics, p. 395-396, 2008.

BARROSO, R. et al. Maximal strength, number of repetitions, and total volume are differently affected by static-, ballistic-, and proprioceptive neuromuscular facilitation stretching. The Journal of Strength \& Conditioning Research, v. 26, n. 9, p. 2432-7, Sep 2012.

BEEDLE, B. B.; MANN, C. L. A comparison of two warm-ups on joint range of motion. The Journal of Strength \& Conditioning Research, v. 21, n. 3, p. 776-9, Aug 2007.

BEHM, D. G. et al. Acute effects of muscle stretching on physical performance, range of motion, and injury incidence in healthy active individuals: a systematic review. Appl Physiol Nutr Metab, v. 41, n. 1, p. 1-11, Jan 2016.

BEHM, D. G.; CHAOUACHI, A. A review of the acute effects of static and dynamic stretching on performance. Eur J Appl Physiol, v. 111, n. 11, p. 2633-51, Nov 2011.

BOSCO, C. et al. A dynamometer for evaluation of dynamic muscle work. Eur J Appl Physiol Occup Physiol, v. 70, n. 5, p. 379-86, 1995.

BRADLEY, P. S.; OLSEN, P. D.; PORTAS, M. D. The effect of static, ballistic, and proprioceptive neuromuscular facilitation stretching on vertical jump performance. The Journal of Strength \& Conditioning Research, v. 21, n. 1, p. 223-6, Feb 2007.

COHEN, J. Statistical power analysis for the behavioral sciences Lawrence Earlbaum Associates. Hillsdale, NJ, p. 20-26, 1988.

CRAMER, J. T. et al. Acute effects of static stretching on characteristics of the isokinetic angle - torque relationship, surface electromyography, and mechanomyography. J Sports Sci, v. 25, n. 6, p. 687-98, Apr 2007. 
CRAMER, J. T. et al. The acute effects of static stretching on peak torque, mean power output, electromyography, and mechanomyography. Eur J Appl Physiol, v. 93, n. 5-6, p. 530-9, Mar 2005.

DALLAS, G. et al. Acute effect of different stretching methods on flexibility and jumping performance in competitive artistic gymnasts. The Journal of Sports Medicine and Physical Fitness, v. 54, n. 6, p. 683-90, Dec 2014.

FOSTER, C. et al. A new approach to monitoring exercise training. The Journal of Strength \& Conditioning Research, v. 15, n. 1, p. 109-115, 2001.

FOWLES, J. R.; SALE, D. G.; MACDOUGALL, J. D. Reduced strength after passive stretch of the human plantarflexors. J Appl Physiol (1985), v. 89, n. 3, p. 1179-88, Sep 2000 .

FREITAS, S. R. et al. A New Tool to Assess the Perception of Stretching Intensity. The Journal of Strength \& Conditioning Research, v. 29, n. 9, p. 2666-78, Sep 2015.

GELEN, E. Acute effects of different warm-up methods on sprint, slalom dribbling, and penalty kick performance in soccer players. The Journal of Strength \& Conditioning Research, v. 24, n. 4, p. 950-6, Apr 2010.

HERDA, T. J. et al. The effects of dynamic stretching on the passive properties of the muscle-tendon unit. J Sports Sci, v. 31, n. 5, p. 479-87, 2013.

HINDLE, K. B. et al. Proprioceptive Neuromuscular Facilitation (PNF): Its Mechanisms and Effects on Range of Motion and Muscular Function. J Hum Kinet, v. 31, p. 105-13, Mar 2012.

HOPKINS, W. G. et al. Progressive statistics for studies in sports medicine and exercise science. Med Sci Sports Exerc, v. 41, n. 1, p. 3-13, Jan 2009.

JAGGERS, J. R. et al. The acute effects of dynamic and ballistic stretching on vertical jump height, force, and power. The Journal of Strength \& Conditioning Research, v. 22, n. 6, p. 1844-9, Nov 2008. 
KIRMIZIGIL, B.; OZCALDIRAN, B.; COLAKOGLU, M. Effects of three different stretching techniques on vertical jumping performance. The Journal of Strength \& Conditioning Research, v. 28, n. 5, p. 1263-71, May 2014.

LITTLE, T.; WILLIAMS, A. G. Effects of differential stretching protocols during warm-ups on high-speed motor capacities in professional soccer players. The Journal of Strength \& Conditioning Research, v. 20, n. 1, p. 203-7, Feb 2006.

MADDIGAN, M. E.; PEACH, A. A.; BEHM, D. G. A comparison of assisted and unassisted proprioceptive neuromuscular facilitation techniques and static stretching. The Journal of Strength \& Conditioning Research, v. 26, n. 5, p. 1238-44, May 2012.

MAGNUSSON, S. P. et al. Mechanical and physical responses to stretching with and without preisometric contraction in human skeletal muscle. Arch Phys Med Rehabil, v. 77, n. 4, p. 373-8, Apr 1996.

MAGNUSSON, S. P. et al. A mechanism for altered flexibility in human skeletal muscle. J Physiol, v. 497 ( Pt 1), p. 291-8, Nov 1996.

MANOEL, M. E. et al. Acute effects of static, dynamic, and proprioceptive neuromuscular facilitation stretching on muscle power in women. The Journal of Strength \& Conditioning Research, v. 22, n. 5, p. 1528-34, Sep 2008.

MITCHELL, U. H. et al. Neurophysiological reflex mechanisms' lack of contribution to the success of PNF stretches. J Sport Rehabil, v. 18, n. 3, p. 343-57, Aug 2009.

MORSE, C. I. et al. The acute effect of stretching on the passive stiffness of the human gastrocnemius muscle tendon unit. J Physiol, v. 586, n. 1, p. 97-106, Jan 012008.

NEEDHAM, R. A.; MORSE, C. I.; DEGENS, H. The acute effect of different warm-up protocols on anaerobic performance in elite youth soccer players. The Journal of Strength \& Conditioning Research, v. 23, n. 9, p. 2614-20, Dec 2009.

O'HORA, J. et al. Efficacy of static stretching and proprioceptive neuromuscular facilitation stretch on hamstrings length after a single session. The Journal of Strength \& Conditioning Research, v. 25, n. 6, p. 1586-91, Jun 2011. 
OZMEN, T. et al. The effect of kinesio taping versus stretching techniques on muscle soreness, and flexibility during recovery from nordic hamstring exercise. Journal of Bodywork and Movement Therapies, v. 21, n. 1, p. 41-47, Jan 2017.

PERRIER, E. T.; PAVOL, M. J.; HOFFMAN, M. A. The acute effects of a warm-up including static or dynamic stretching on countermovement jump height, reaction time, and flexibility. The Journal of Strength \& Conditioning Research, v. 25, n. 7, p. 1925-31, Jul 2011.

RYAN, E. D. et al. The time course of musculotendinous stiffness responses following different durations of passive stretching. J Orthop Sports Phys Ther, v. 38, n. 10, p. 632-9, Oct 2008.

SAYERS, S. P. et al. Cross-validation of three jump power equations. Med Sci Sports Exerc, v. 31, n. 4, p. 572-7, Apr 1999.

SHEARD, P. W.; PAINE, T. J. Optimal contraction intensity during proprioceptive neuromuscular facilitation for maximal increase of range of motion. The Journal of Strength \& Conditioning Research, v. 24, n. 2, p. 416-21, Feb 2010.

SMIRNIOTOU, A. et al. Strength-power parameters as predictors of sprinting performance. The Journal of Sports Medicine and Physical Fitness, v. 48, n. 4, p. 447-54, Dec 2008.

SPORT, F. Canadian Standardized Test Of Fitness (Cstf) Operations Manual: Minister Of State Ottawa 1986.

TAYLOR, K. L. et al. Negative effect of static stretching restored when combined with a sport specific warm-up component. J Sci Med Sport, v. 12, n. 6, p. 657-61, Nov 2009.

WELLS, K. F.; DILLON, E. K. The sit and reach - a test of back and leg flexibility. Research Quarterly. American Association for Health, Physical Education and Recreation, v. 23, n. 1, p. 115-118, 1952. ISSN 1067-1188. 
YOUNG, W.; ELIAS, G.; POWER, J. Effects of static stretching volume and intensity on plantar flexor explosive force production and range of motion. The Journal of Sports Medicine and Physical Fitness, v. 46, n. 3, p. 403-11, Sep 2006.

\subsubsection{Estudo 2}

AAGAARD, P.; SIMONSEN, E. B.; ANDERSEN, J. L.; MAGNUSSON, P.; DYHREPOULSEN, P. Neural adaptation to resistance training: changes in evoked V-wave and H-reflex responses. Journal of Applied Physiology, v. 92, n. 6, p. 2309-2318, 2002.

ALLEN, G. M.; GANDEVIA, S. C.; MCKENZIE, D. K. Reliability of measurements of muscle strength and voluntary activation using twitch interpolation. Muscle Nerve, v. 18, n. 6, p. 593-600, 1995.

AVLONITI, A.; CHATZINIKOLAOU, A.; FATOUROS, I. G.; AVLONITI, C.; PROTOPAPA, M.; DRAGANIDIS, D.; STAMPOULIS, T.; LEONTSINI, D.; MAVROPALIAS, G.; GOUNELAS, G.; KAMBAS, A. The Acute Effects of Static Stretching on Speed and Agility Performance Depend on Stretch Duration and Conditioning Level. J Strength Cond Res. Epub ahead of print.[2014 Jun 17].

BACURAU, R. F. P.; MONTEIRO, G. A.; UGRINOWITSCH, C.; TRICOLI, V.; CABRAL, L. F.; AOKI, M. S. Acute effect of a ballistic and a static stretching exercise bout on flexibility and maximal strength. The Journal of Strength \& Conditioning Research, v. 23, n. 1, p. 304-308, 2009.

BAECHLE, T. R.; EARLE, R. W. Essentials of Strength Training and Conditioning. 3ed. Champaign: Human Kinetics, 2008

BARROSO, R.; TRICOLI, V.; SANTOS GIL, S. D.; UGRINOWITSCH, C.; ROSCHEL, H. Maximal strength, number of repetitions, and total volume are differently affected by static-, ballistic-, and proprioceptive neuromuscular facilitation stretching. J Strength Cond Res, v. 26, n. 9, p. 2432-2437, 2012.

BEHM, D. G.; KIBELE, A. Effects of differing intensities of static stretching on jump performance. Eur J Appl Physiol, v. 101, n. 5, p. 587-594, 2007. 
BEHM, D. G.; BUTTON, D. C.; BUTT, J. C. Factors affecting force loss with prolonged stretching. Canadian Journal of Applied Physiology, v. 26, n. 3, p. 262$272,2001$.

BERGQUIST, A. J.; WIEST, M. J.; COLLINS, D. F. Motor unit recruitment when neuromuscular electrical stimulation is applied over a nerve trunk compared with a muscle belly: quadriceps femoris. J Appl Physiol, v. 113, n. 1, p. 78-89, 2012.

BRADLEY, P. S.; OLSEN, P. D.; PORTAS, M. D. The effect of static, ballistic, and proprioceptive neuromuscular facilitation stretching on vertical jump performance. $\mathbf{J}$ Strength Cond Res, v. 21, n. 1, p. 223-226, 2007.

COSTA, P. B.; RYAN, E. D.; HERDA, T. J.; WALTER, A. A.; HOGE, K. M.; CRAMER, J. T. Acute effects of passive stretching on the electromechanical delay and evoked twitch properties. Eur J Appl Physiol, v. 108, n. 2, p. 301-310, 2010.

CRAMER, J. T.; BECK, T. W.; HOUSH, T. J.; MASSEY, L. L.; MAREK, S. M.; DANGLEMEIER, S.; PURKAYASTHA, S.; CULBERTSON, J. Y.; FITZ, K. A.; EGAN, A. D. Acute effects of static stretching on characteristics of the isokinetic angle - torque relationship, surface electromyography, and mechanomyography. J Sports Sci, v. 25 , n. 6, p. 687-698, 2007.

CRAMER, J. T.; HOUSH, T. J.; WEIR, J. P.; JOHNSON, G. O.; COBURN, J. W.; BECK, T. W. The acute effects of static stretching on peak torque, mean power output, electromyography, and mechanomyography. Eur J Appl Physiol, v. 93, n. 5-6, p. 530$539,2005$.

OLIVEIRA, A. L. M.; GRECO, C. C.; MOLINA, R.; DENADAI, B. S. The rate of force development obtained at early contraction phase is not influenced by active static stretching. The Journal of Strength \& Conditioning Research, v. 26, n. 8, p. 2174$2179,2012$.

DUCHATEAU, J. Bed rest induces neural and contractile adaptations in triceps surae. Med Sci Sports Exerc, v. 27, n. 12, p. 1581-1589, 1995. 
FOWLES, J. R.; SALE, D. G.; MACDOUGALL, J. D. Reduced strength after passive stretch of the human plantarflexors. J Appl Physiol (1985), v. 89, n. 3, p. 1179-1188, 2000 .

FREITAS, S. R.; VILARINHO, D.; VAZ, J. R.; BRUNO, P. M.; COSTA, P. B.; MILHOMENS, P. Responses to static stretching are dependent on stretch intensity and duration. Clin Physiol Funct Imaging. Epub ahead of print.[2014 Aug 27].

GANDEVIA, S. C. Spinal and supraspinal factors in human muscle fatigue. Physiol Rev, v. 81, n. 4, p. 1725-1789, 2001.

GIRARD, O.; BISHOP, D. J.; RACINAIS, S. Neuromuscular adjustments of the quadriceps muscle after repeated cycling sprints. PLoS One, v. 8, n. 5, p. e61793, 2013.

GONCALVES, R.; GURJAO, A. L.; JAMBASSI FILHO, J. C.; FARINATTI, P. D. E. T.; GOBBI, L. T.; GOBBI, S. The acute effects of static stretching on peak force, peak rate of force development and muscle activity during single- and multiple-joint actions in older women. J Sports Sci, v. 31, n. 7, p. 690-698, 2013.

HERMENS, H. J.; FRERIKS, B.; MERLETTI, R.; STEGEMAN, D.; BLOK, J.; RAU, G.; DISSELHORST-KLUG, C.; HÄGG, G. European recommendations for surface electromyography. Roessingh Research and Development, v. 8, n. 2, p. 13-54, 1999.

KAY, A.D.; BLAZEVICH, A.J. Effect of acute static stretch on maximal muscle performance: a systematic review. Med Sci Sports Exerc, v. 44, n. 1, p. 154-164, 2012.

MCBRIDE, J. M.; DEANE, R.; NIMPHIUS, S. Effect of stretching on agonistantagonist muscle activity and muscle force output during single and multiple joint isometric contractions. Scandinavian journal of medicine $\&$ science in sports, v. 17, n. 1, p. 54-60, 2007.

MILIONI, F., VIEIRA, L.H., BARBIERI, R.A., ZAGATTO, A.M., NORDSBORG, N.B., BARBIERI, F.A., DOS-SANTOS, J.W., SANTIAGO, P.R., PAPOTI M. Futsal Match-Related Fatigue Affects Running Performance and Neuromuscular Parameters but Not Finishing Kick Speed or Accuracy. Front Physiol, v. 7, p. 518, 2016. ISSN 1664-042X (Linking). 
MILlER, J. D.; HERDA, T. J.; TREVINO, M. A.; MOSIER, E. M. The effects of passive stretching plus vibration on strength and activation of the plantar flexors. Applied Physiology, Nutrition, and Metabolism, v. 41, n. 9, p. 917-923, 2016.

MIYAHARA, Y.; NAITO, H.; OGURA, Y.; KATAMOTO, S.; AOKI, J. Effects of proprioceptive neuromuscular facilitation stretching and static stretching on maximal voluntary contraction. The Journal of Strength \& Conditioning Research, v. 27, n. 1, p. 195-201, 2013.

OGURA, Y.; MIYAHARA, Y.; NAITO, H.; KATAMOTO, S.; AOKI, J. Duration of static stretching influences muscle force production in hamstring muscles. The Journal of Strength \& Conditioning Research, v. 21, n. 3, p. 788-792, 2007.

Power, K., Behm, D., Cahill, Carroll, M., Young, W. An acute bout of static stretching: effects on force and jumping performance. Medicine and science in sports and exercise, v. 36, p. 1389-1396, 2004.

REIS, E. D. F. S.; PEREIRA, G. B.; SOUSA, N. M. F.; TIBANA, R. A.; SILVA, M. F.; ARAUJO, M.; PRESTES, J. Acute effects of proprioceptive neuromuscular facilitation and static stretching on maximal voluntary contraction and muscle electromyographical activity in indoor soccer players. Clinical physiology and functional imaging, v. 33, n. 6, p. 418-422, 2013.

RYAN, E. D.; BECK, T. W.; HERDA, T. J.; HULL, H. R.; HARTMAN, M. J.; STOUT, J. R.; CRAMER, J. T. Do practical durations of stretching alter muscle strength? A dose-response study. Med Sci Sports Exerc, v. 40, n. 8, p. 1529-1537, 2008a.

RYAN, E. D.; BECK, T. W.; HERDA, T. J.; HULL, H. R.; HARTMAN, M. J.; COSTA, P. B.; DEFREITAS, J. M.; STOUT, J. R.; CRAMER, J. T. The time course of musculotendinous stiffness responses following different durations of passive stretching. J Orthop Sports Phys Ther, v. 38, n. 10, p. 632-639, 2008 b.

SERRA, A. J.; SIlVA JR, J. A.; MARCOLONGO, A. A.; MANCHINI, M. T.; OLIVEIRA, J. V.; SANTOS, L. F.; BOCALINI, D. S. Experience in resistance training does not prevent reduction in muscle strength evoked by passive static stretching. The Journal of Strength \& Conditioning Research, v. 27, n. 8, p. 2304-2308, 2013. 
SIATRAS, T. A.; MITTAS, V. P.; MAMELETZI, D. N.; VAMVAKOUDIS, E. A. The duration of the inhibitory effects with static stretching on quadriceps peak torque production. The Journal of Strength \& Conditioning Research, v. 22, n. 1, p. 40-46, 2008 .

STAFILIDIS, S.; TILP, M. Effects of short duration static stretching on jump performance, maximum voluntary contraction, and various mechanical and morphological parameters of the muscle-tendon unit of the lower extremities. Eur $\mathbf{J}$ Appl Physiol, v. 115, n. 3, p. 607-17, Mar 2015.

STROJNIK, V.; KOMI, P. V. Neuromuscular fatigue after maximal stretch-shortening cycle exercise. J Appl Physiol, v. 84, n. 1, p. 344-350, 1998.

TRAJANO, G. S.; NOSAKA, K.; L, B. S.; BLAZEVICH, A. J. Intermittent stretch reduces force and central drive more than continuous stretch. Med Sci Sports Exerc, v. 46, n. 5, p. 902-910, 2014.

TRAJANO, G. S.; SEITZ, L.; NOSAKA, K.; BLAZEVICH, A. J. Contribution of central vs. peripheral factors to the force loss induced by passive stretch of the human plantar flexors. J Appl Physiol, v. 115, n. 2, p. 212-218, 2013.

WISlØFF, U., CAStagnA, C., HElgerud, J., JONES, R., HOFF, J. Strong correlation of maximal squat strength with sprint performance and vertical jump height in elite soccer players. British Journal of Sports Medicine, v. 38, n. 3, p. 285-288, 2004.

YOUNG, W.; ELIAS, G.; POWER, J. Effects of static stretching volume and intensity on plantar flexor explosive force production and range of motion. The Journal of Sports Medicine and Physical Fitness, v. 46, n. 3, p. 403-11, Sep 2006. 
ANEXOS 
COMPROVANTE DE APROVAÇÃO DO TERMO DE CONSENTIMENTO LIVRE E ESCLARECIDO 


\section{USP ESCOLA DE EDUCAÇÃO FÍSICA E ESPORTE DE RIBEIRÃO PRETO}

\section{PARECER CONSUBSTANCIADO DO CEP}

\section{DADOS DO PROJETO DE PESQUISA}

Título da Pesquisa: Efeito agudo de diferentes métodos de alongamento sobre o desempenho da força máxima e potência de membros inferiores

Pesquisador: Enrico Fuini Puggina

Área Temática:

Versão: 4

CAAE: 39060614.5 .0000 .5659

Instituição Proponente: UNIVERSIDADE DE SAO PAULO

Patrocinador Principal: Financiamento Próprio

\section{DADOS DO PARECER}

Número do Parecer: 1.050 .789

Data da Relatoria: 06/05/2015

Apresentação do Projeto:

Vide parecer anterior.

Objetivo da Pesquisa:

Vide parecer anterior.

Avaliação dos Riscos e Benefícios:

Vide parecer anterior.

Comentários e Considerações sobre a Pesquisa:

Vide parecer anterior.

Considerações sobre os Termos de apresentação obrigatória:

Vide parecer anterior.

Conclusões ou Pendências e Lista de Inadequações:

Não há pendências.

Situação do Parecer:

Aprovado

Necessita Apreciação da CONEP:

Não 


\section{USP \\ $=$ \\ ESCOLA DE EDUCAÇÃO FÍSICA E ESPORTE DE RIBEIRÃO PRETO}

Continuação do Parecer: 1.050 .789

\section{Considerações Finais a critério do CEP:}

O projeto encontra-se APROVADO para execução. Pedimos atenção aos seguintes itens:

1) De acordo com a Resolução CNS n. 466/2012, o pesquisador deverá apresentar relatórios semestrais (parciais e final, em função da duração da pesquisa);

2) Eventuais emendas (modificações) ao protocolo devem ser apresentadas, com justificativa, ao CEP de forma clara e sucinta, identificando a parte do protocolo a ser modificada. Neste caso, o pesquisador deve aguardar nova aprovação do CEP para realizar os procedimentos de acordo com as mudanças solicitadas;

3) Sobre o TCLE: caso o termo tenha DUAS páginas ou mais, lembramos que no momento da sua assinatura, tanto o participante da pesquisa (ou seu representante legal) quanto o pesquisador responsável deverão RUBRICAR todas as folhas, colocando as assinaturas na última página;

4) Caso haja instituição(ões) coparticipante(s) no projeto, atender a solicitação da carta $n .^{\circ}$ 0212/CONEP/CNS, de 21 de outubro de 2010.

RIBEIRAO PRETO, 06 de Maio de 2015

Assinado por:

Carlos Roberto Bueno Júnior

(Coordenador)

Endereço: Avenida Bandeirantes, 3900

Bairro: VILA MONTE ALEGRE

UF: SP Município: RIBEIRAO PRETO

Telefone: (16)3315-0494

CEP: $14.040-907$

E-mail: cep90@usp.br 
APÊNDICE 1 
Escala de intensidade de alongamento (FREITAS et al., 2015)

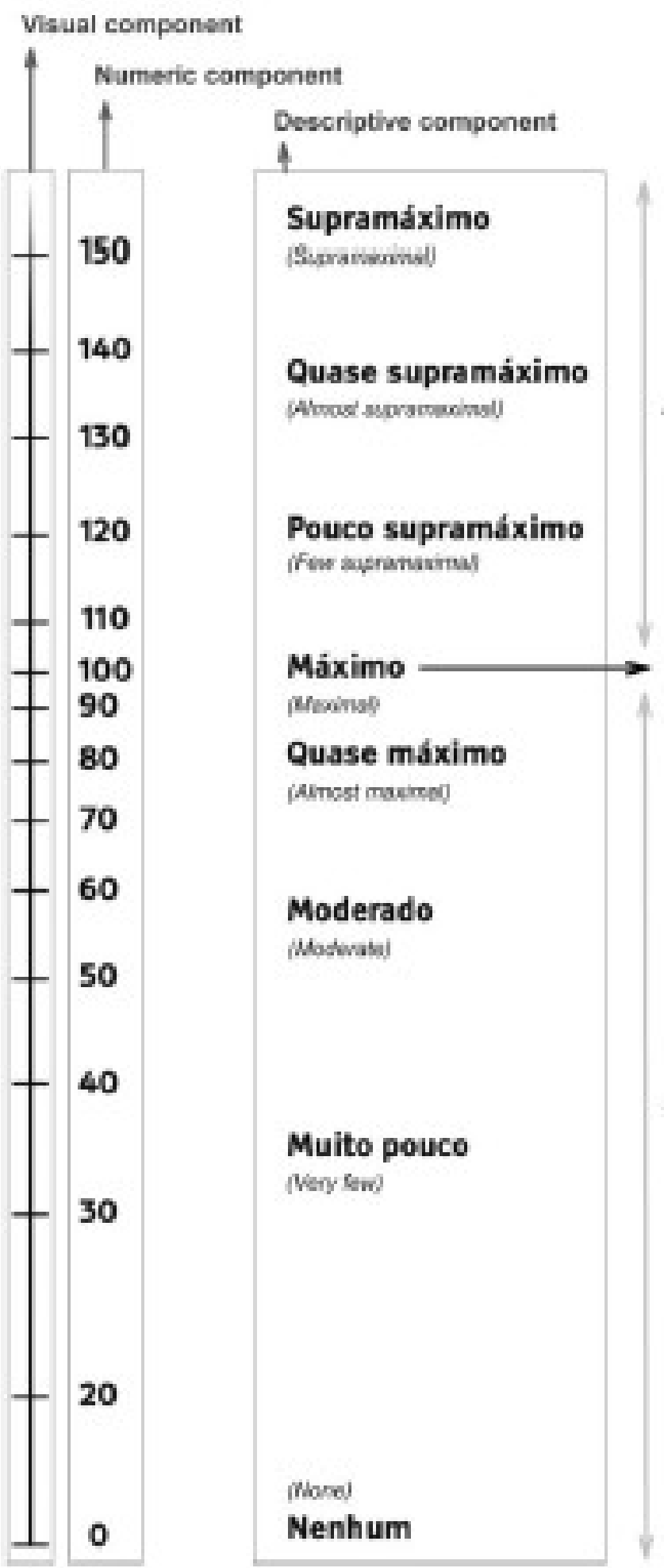

\begin{abstract}
Maximal range of motion whout pain
\end{abstract}

Submaxhual intensily nange 